\title{
EFEITOS DA ESTIMULAÇÃO ELÉTRICA NEUROMUSCULAR SOBRE O GASTO ENERGÉTICO DE LESADOS MEDULARES
}

MARCELA DE OLIVEIRA SENE

Dissertação apresentada ao Programa de Pós Graduação Bioengenharia Interunidades - Escola de Engenharia de São Carlos; Instituto de Química de São Carlos; Faculdade de Medicina de Ribeirão Preto, da Universidade de São Paulo, como parte dos requisitos para a obtenção do Título de Mestre em Bioengenharia.

ORIENTADOR: Prof. Dr. Alberto Cliquet Jr

São Carlos 
Aos meus pais e irmãos pelo apoio. Meus avós, presentes e ausentes. $E$ ao meu noivo Erick pela compreensão e dedicação. 


\section{AGRADECIMENTOS}

Aos amigos Labciberianos: Renata, Fransérgio, Daniel, Benigno, Rogério, Idalírio, Andréia, Fernanda, Alessandra, Farelo, Beatriz, Samuel, Cíntia, Mauro, Vanderlei, Ana Elisa e Paula, pela ajuda e animação.

Aos amigos da Federal: Carlos Alexandre, Cacá, Nádia, Danielle, Fabiana, Marla, Ricardo, João Paulo, Paulão, Fernanda, Neuli e Cris, por tudo que passei com vocês.

Todos os meus amigos que me ajudaram direta ou indiretamente na realização deste trabalho.

A Ana Dâmaso pelos ensinamentos e amizade.

Ao meu orientador.
A CAPES
e
FAPESP pelo
apoio
financeiro. 


\section{SUMÁRIO}

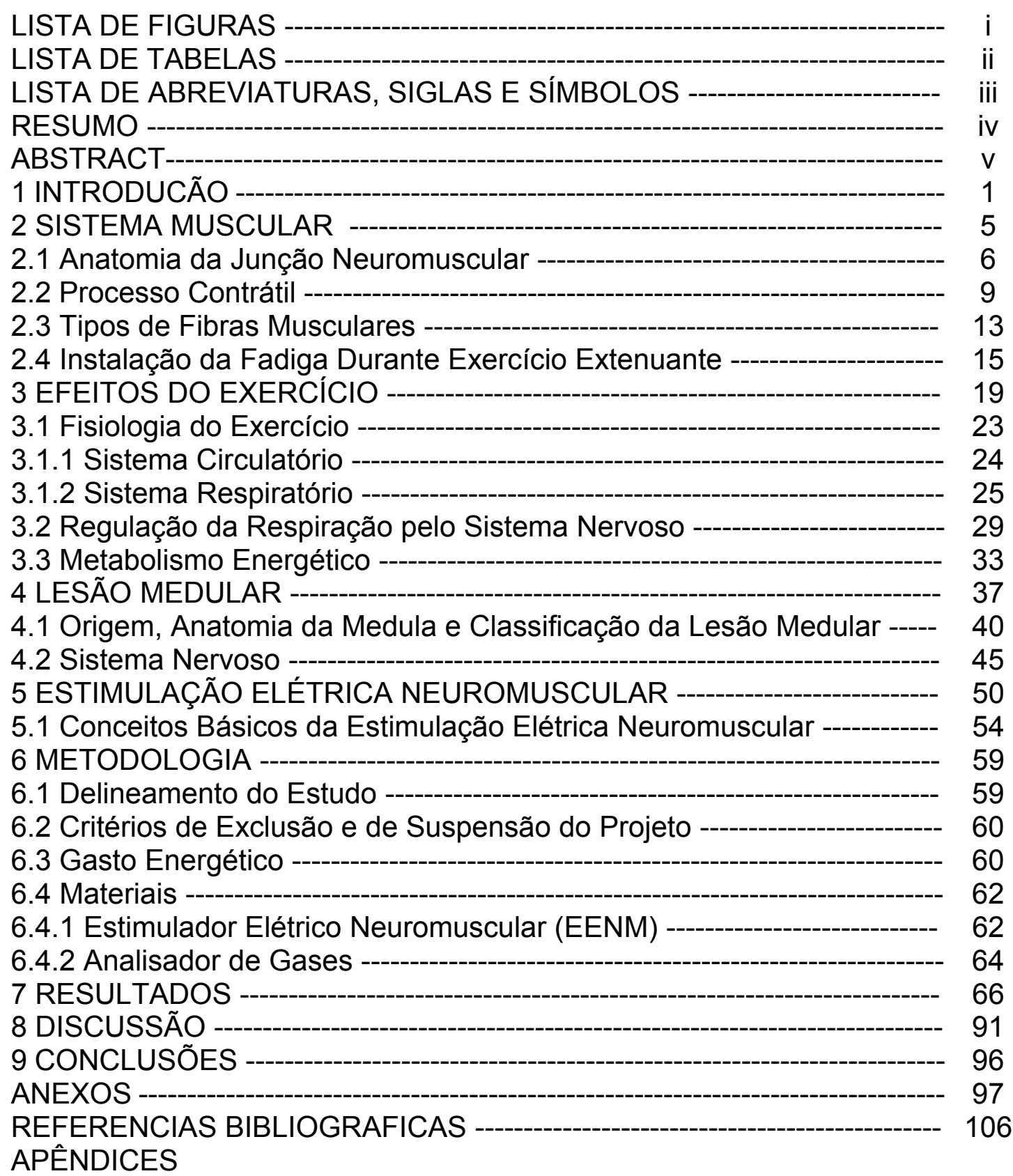




\section{LISTA DE FIGURAS}

Figura 01 - (A) Visão Microscópica da Junção Neuromuscular e Eventos que precedem a contração muscular. (B) Processo Contrátil. --------------Figura 02 - Esquema Representativo da Teoria dos Filamentos Deslizantes ou Cremalheira. (A) Músculo Relaxado; (B) Músculo Contraído

Figura 03 - Modelo proposto por JAKEMAN (1998) para explicar a Teoria da Fadiga.

Figura 04 - Esquema Representativo da Inter-relação dos Sistemas -----Figura 05 - Esquema Representativo dos Quimiorreceptores Periféricos

Figura 06 - Esquema Representativo da Área Quimiosensitiva. ------------

Figura 07 - Esquema Representativo do Centro Respiratório.

Figura 08 - Relação entre a Ventilação Total e o Consumo de Oxigênio.

Figura 09 - Relação entre a Ventilação Alveolar e a $\mathrm{PCO}_{2}$ Arterial --------

Figura 10 - Estatísticas Norte-Americanas sobre algumas características dos pacientes lesados medulares (aproximadamente válidos para o Brasil). A) Porcentagem de pacientes agrupados por idade na ocasião da lesão; B) Porcentagem de pacientes agrupados por sexo; C) Porcentagem de pacientes agrupados por atividade esportiva.

Figura 11 - Visão Microscópica da Medula Espinhal.

Figura 12 - Coluna vertebral A) Coluna cervical (Lordose cervical); B) Coluna torácica (Cifose torácica); C) Coluna lombar (Lordose lombar). 1) Corpo vertebral; 2) Disco intervetebral; 3) Raiz nervosa.

Figura 13 - Desenho esquemático mostrando de onde derivam os nervos que partem da medula e que regulam o sistema simpático e parassimpático

Figura 14 - Curva da Duração pela Amplitude do estímulo para um Nervo e para um Músculo Denervado.

Figura 15 - Fluxos de Correntes entre eletrodos positivos e negativos. --

Figura 16 - Aparelho para Estimulação Elétrica Neuromuscular (2 canais).

Figura 17 - Analisador de gases Vmax, modelo 29c da marca SensorMedics.

Figura 18 - Materiais do Vmax.

Figura 19 - Consumo de Oxigênio $\left(\mathrm{VO}_{2}\right)$ do Voluntário I -------------------- 71

Figura 20 - Produção de Dióxido de Carbono $\left(\mathrm{VCO}_{2}\right)$ do Voluntário I ---- 72

Figura 21 - Gasto Energético do Voluntário I --------------------------------- 72

Figura 22 - Consumo de Oxigênio $\left(\mathrm{VO}_{2}\right)$ do Voluntário II ------------------ 73

Figura 23 - Produção de Dióxido de Carbono $\left(\mathrm{VCO}_{2}\right)$ do Voluntário II---- 73

Figura 24 - Gasto Energético do Voluntário II ---------------------------- 74

Figura 25 - Consumo de Oxigênio $\left(\mathrm{VO}_{2}\right)$ do Voluntário III ------------------ 75

Figura 26 - Produção de Dióxido de Carbono $\left(\mathrm{VCO}_{2}\right)$ do Voluntário III--- 75

Figura 27 - Gasto Energético do Voluntário III ------------------------------- 76

Figura 28 - Consumo de Oxigênio $\left(\mathrm{VO}_{2}\right)$ do Voluntário IV ----------------- 76

Figura 29 - Produção de Dióxido de Carbono $\left(\mathrm{VCO}_{2}\right)$ do Voluntário IV-- 77

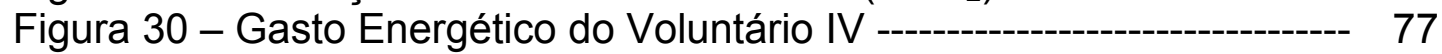


Figura 31 - Consumo de Oxigênio $\left(\mathrm{VO}_{2}\right)$ do Voluntário $\mathrm{V}$-------------- 78 Figura 32 - Produção de Dióxido de Carbono $\left(\mathrm{VCO}_{2}\right)$ do Voluntário $\mathrm{V}$--- 78 Figura 33 - Gasto Energético do Voluntário $V$---_ós Figura 34 - Consumo de Oxigênio $\left(\mathrm{VO}_{2}\right)$ do Voluntário Padrão ---------- 79 Figura 35 - Produção de Dióxido de Carbono $\left(\mathrm{VCO}_{2}\right)$ do Voluntário 80 Padrão-

Figura 36 - Gasto Energético do Voluntário Padrão 80

Figura 37 - Comportamento do Consumo de Oxigênio $\left(\mathrm{VO}_{2}\right)$------------- 83

Figura 38 - Visão Microscópica do Músculo Esquelético ------------------- 100

Figura 39 - Visão Microscópica do Músculo Esquelético --_-_-_-_-_-_-- 101

Figura 40 - Representação Esquemática de uma molécula de miosina -- 103 Figura 41 - Modelo de localização das subunidades TNC, TNI e TNT na molécula de troponina 


\section{LISTA DE TABELAS}

Tabela 01 - Diferenças anatômicas e farmacológicas entre o sistema simpático e parassimpático 48

Tabela 02 - Descrição dos Voluntários 66

Tabela 03 - Variáveis Observadas durante a Marcha -------------------------- 66

Tabela 04 - Variáveis observadas durante o período de Repouso (10 $\min$ )

Tabela 05 - Variáveis observadas durante o período de Exercício -------- 38

Tabela 06 - Variáveis observadas durante o período de Recuperação (10 min)

Tabela 07 - Energia Consumida (J/Kgs)

69

Tabela 08 - Comparação entre estudos - Energia Consumida (J/kgs) ---- 70

Tabela 09 - Gasto Energético (J/Kgm) 71 


\section{LISTA DE ABREVIATURAS E SÍMBOLOS}

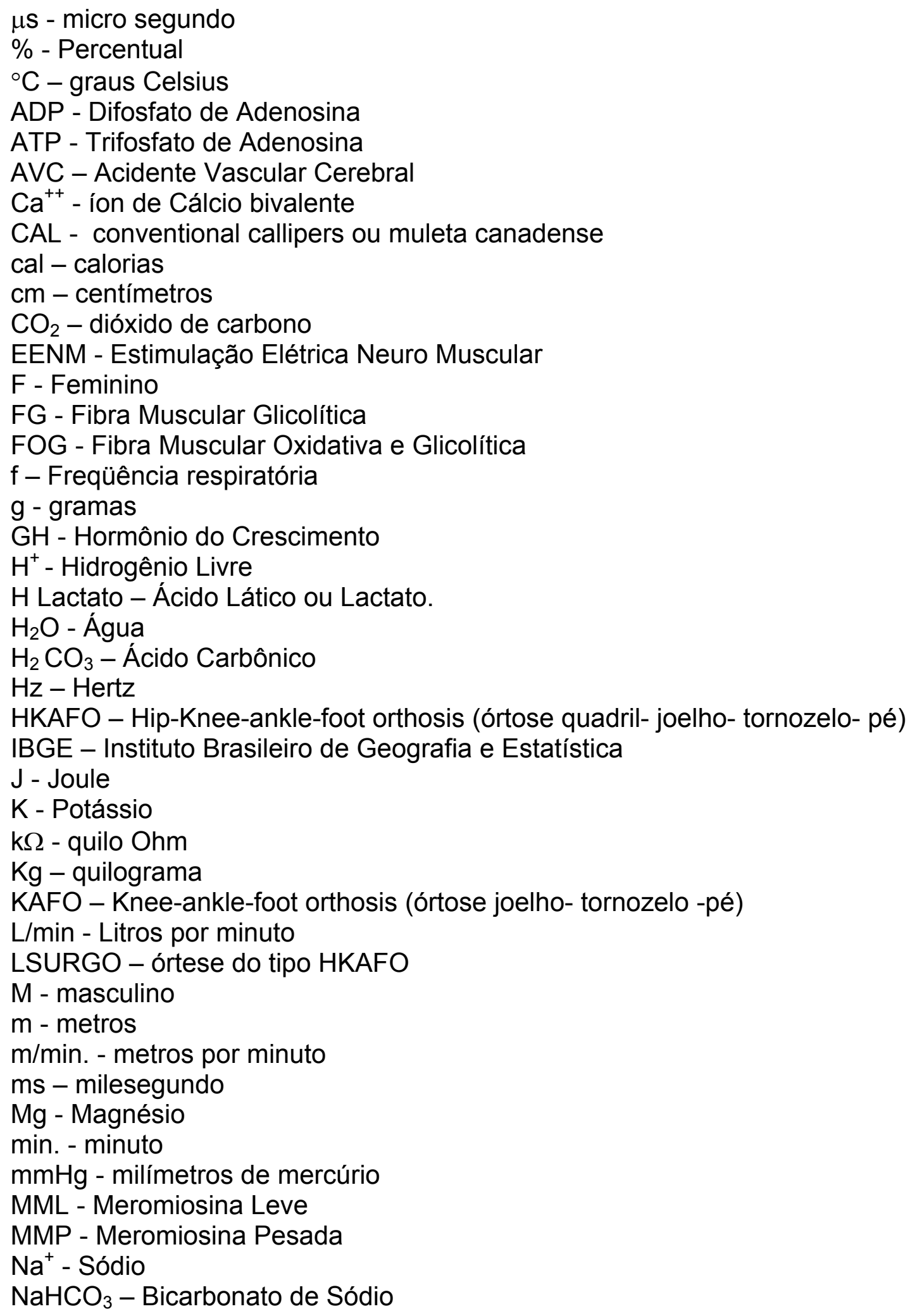


NaLactato - Lactato de Sódio

$\mathrm{pH}$ - percentual de Hidrogênio

$\mathrm{O}_{2}$ - Oxigênio

$\mathrm{Pi}$ - Fósforo inorgânico

$\mathrm{PO}_{2}$ - Pressão parcial de oxigênio

$\mathrm{PCO}_{2}-$ Pressão parcial de dióxido de carbono

RGO - órtese do tipo Parawalker

$S$ - segundo

SNC - Sistema Nervoso Central

SNP -

Sistema Nervoso Periférico

SO - Fibra Muscular Oxidativa Lenta

TNC - Sítio de Ligação da Troponina com o Cálcio

TNI - Subunidade Inibidora da TNC

Túbulo T - Túbulo Transverso

TNT - Sítio de Ligação da Troponina com a Tropomiosina

UNICAMP - Universidade Estadual de Campinas

$\mathrm{V}-\mathrm{Volt}$

Ve - Ventilação

$\mathrm{Vt}$ - volume corrente médio expirado

Vel. - Velocidade 


\section{RESUMO}

SENE, M.O. Efeitos da Estimulação Elétrica Neuromuscular (EENM) sobre o Gasto Energético de Lesados Medulares. São Carlos, 2003.p.106, Dissertação - Programa de Pós Graduação Interunidades Bioengenharia EESC/IQSC/FMRP, Universidade de São Paulo.

Lesões na medula espinhal atingem um grande número de pessoas, devido a traumas, doenças congênitas ou adquiridas. Para estes tipos de lesões não há cura e os indivíduos lesados medulares dependem de tratamento através de fisioterapia ou órteses que auxiliem na recuperação de possíveis funções perdidas. A Estimulação Elétrica Neuromuscular (EENM) tem sido pesquisada com essa proposta: reabilitar pessoas portadoras de lesão medular ou disfunções do aparelho locomotor. Muitos estudos já foram desenvolvidos na área de estimulação elétrica neuromuscular, avaliando a marcha, o ato de levantar-se ou outros movimentos. Um ponto em comum entre estes estudos é a preocupação com os efeitos fisiológicos da EENM, como por exemplo o gasto energético. Diante disto, o objetivo deste projeto foi avaliar os efeitos da EENM sobre o gasto energético de lesados medulares. Foi observado o consumo de oxigênio durante o repouso, a marcha e a recuperação. A avaliação proposta foi realizada por método indireto e as análises estatísticas foram realizada $s$ através do teste ANOVA ONE WAY. Os resultados sugerem os voluntários tiveram recuperação fisiológica. Entretanto novas pesquisas são necessárias, com outras variáveis sendo avaliadas.

Palavras-chave: estimulação elétrica neuromuscular, consumo de oxigênio, lesão medular 


\begin{abstract}
SENE, M.O. Effects of the Neuromuscular Electrical Stimulation (NMES) on the Cost Energy of Spinal Cord Injured Patients. São Carlos, 2003. p.106 Dissertação - Programa de Pós Graduação Interunidades Bioengenharia EESC/IQSC/FMRP, Universidade de São Paulo.

Lesions in the spinal cord affect a great number of individuals, either due to traumas or to congenital or acquired diseases. Such lesions are incurable, and the injured patients depend on physiotherapy or orthosis to aid in the recovery of lost functions. The Neuromuscular Electrical Stimulation (NMES) has been researched with this purpose: rehabilitating spinal cord injured patients, or those with motor system dysfunction. Several studies have already been developed in the field of neuromuscular electrical stimulation, assessing gait, the act of getting up or other everyday movements. All these studies bear something in common: the concern with the physiologic effects of NMES, such as the energy consumption. Hence, the objective of this project was to evaluate the effects of NMES on the energy cost of spinal injured patients. The consumption of oxygen was assessed during rest, gait and the recovery period. The proposed evaluation was made through indirect method, and the statistical analyses through the ANOVA ONE WAY test. The results to suggest that the volunteers had phisyological recovery. However, news reserchs there are needs, with others variable to be estimated.
\end{abstract}

Keywords: Neuromuscular Electrical Stimulation, consumption of oxygen, spinal cord injury. 


\section{CAPÍTULO 1}

\section{INTRODUCÃO}

Grupos multidisciplinares vêm sendo formados com o intuito de otimizar e humanizar a reabilitação ou tratamento de pessoas. No caso dos obesos, por exemplo, eles podem ser atendidos por um grupo formado por fisioterapeutas, educadores físicos, nutricionistas, endocrinologistas e psicólogos. Para cada caso existe um grupo de profissionais diferente. Especificamente para lesados medulares, o grupo de profissionais formado será muito amplo, variando de acordo com a técnica usada.

Muitos estudos tem sido realizados buscando desenvolver equipamentos capazes de promover melhorias fisiológicas para os pacientes, como é o caso da estimulação elétrica neuromuscular (EENM), que visa a reabilitação de lesados medulares (MALEZIC, 1995; KRALJ, 1980; MATSUNAGA, 1999). 
Esta técnica vem sendo amplamente estudada nesta última década em muitos laboratórios com o intuito de promover a habilidade de andar para pessoas paraplégicas com lesões do nível cefálico ao nível torácico 12, que são as mais observadas (MARSOLAIS, 1987; NENE, 1990).

A EENM gera um estímulo nos motoneurônios do membro lesionado, promovendo desta forma um movimento reflexo, com o qual o indivíduo pode realizar um ato motor específico. No caso de paraplégicos, esta técnica é utilizada nos membros inferiores, possibilitando a marcha, como já foi dito anteriormente.

Entretanto, alguns problemas vêm sendo observados no decorrer da utilização desta técnica, como a fadiga muscular precoce, o estresse cardiovascular, o elevado gasto energético, entre outros.

No que se refere ao gasto energético, este aspecto tem sido estudado através do consumo de oxigênio, demonstrando que o gasto energético em lesados medulares depende principalmente do nível da lesão e do nível de atividade física do paciente (CLIQUET, 1989; LIN, 1993).

O comportamento do metabolismo energético nos lesados medulares é o aspecto que mais preocupa visto que, um aumento da energia gasta pode ter 
sérias implicações indiretas principalmente no sistema cardiovascular e direta no balanço energético.

Todavia, a fadiga muscular precoce não deve ser esquecida pois é um dos motivos que pode influenciar o desempenho do lesado medular durante a EENM, seja realizando a marcha ou apenas o treinamento dinâmico sentado.

Muitos autores têm ressaltado que o exercício pode ser um elemento importante para a reabilitação de pessoas com lesão medular (LANGBEIN, 1995; BROMLEY, 1997) reforçando assim a necessidade do uso da EENM como ferramenta para a execução de uma atividade física.

A aplicação desses conhecimentos torna-se importante visto que, há um grande número de lesados medulares, que não tem condições físicas, fisiológicas e/ou funcionais para praticar determinados tipos de exercício. Dessa forma, conhecer a técnica, a fisiologia da lesão medular e a fisiologia do exercício são preceitos fundamentais para reabilitar lesados medulares através da EENM.

Diante da necessidade dos lesados medulares se beneficiarem dos efeitos fisiológicos específicos e gerais do exercício, faz-se necessário avaliar os possíveis efeitos promovidos pelo exercício induzido através de EENM, no seu metabolismo energético e na sua composição corporal. 
O objetivo deste estudo foi avaliar os efeitos marcha induzida por EENM sobre o gasto energético de lesados medulares, através de dados obtidos por métodos diretos e não invasivos. Esses métodos consistem em testes onde o consumo de oxigênio foi medido durante o repouso, o exercício de marcha induzida por EENM e a recuperação do esforço.

Todavia, para compreender os efeitos da EENM deve-se conhecer os fatores que estão envolvidos nesta atividade, a saber: Sistema Muscular, Exercício, Lesão Medular e EENM. Deste modo, tem-se uma explicação básica desses sistemas a seguir. 


\section{CAPÍTULO 2}

\section{SISTEMA MUSCULAR}

O Sistema Muscular está envolvido com as diferentes funções que o organismo realiza. Dentre essas funções tem-se: o bombeamento do sangue pelo coração, os movimentos peristálticos do intestino, expressões faciais, movimentação do corpo ou parte dele, entre outras (McARDLE, 1993,1994).

Devido às diferenças morfofuncionais o sistema muscular é dividido em: músculo cardíaco, músculo liso e músculo estriado esquelético, sendo que este último corresponde a $40 \%$ do nosso corpo. Para este estudo é necessário o conhecimento da anatomia e fisiologia do músculo esquelético, que está descrita no Anexo B (YOUNG, 1982; BERGMAN, 1989; McARDLE, 1994; MACHADO, 2000). 


\subsection{Anatomia da Junção Neuromuscular}

O Sistema Nervoso Central (SNC) é o responsável pelo controle dos músculos esqueléticos. Ele regula a força muscular, variando as freqüências dos impulsos transmitidos por neurônios motores individuais. O complexo é constituído por um único nervo com seus múltiplos terminais e fibras musculares associadas são denominadas unidade motora (ASTRAND 1987; BERGMAN, 1989; McARDLE, 1994; MACHADO, 2000).

Os músculos esqueléticos são inervados por grandes fibras nervosas mielinizadas, que tem origem nos motoneurônios dos cornos anteriores da medula espinhal. A terminação nervosa forma com a fibra muscular uma junção neuromuscular ou placa terminal. Sendo que esta ocupa apenas uma pequena fração do total da superfície muscular, normalmente próximo ao centro da fibra (ASTRAND, 1987; BERGMAN, 1989; McARDLE, 1994; MACHADO, 2000).

As fibras nervosas se ramificam na extremidade para formar um complexo de terminações que se invagina na fibra muscular. A placa motora é isolada dos líquidos circulantes por uma camada de células de schwann. A membrana da fibra muscular também sofre invaginação, denominada sulco sináptico. O espaço entre o terminal sináptico e a membrana é chamado fenda sináptica. 
Esta fenda é preenchida por um líquido amorfo, que é rico em fibras colágenas, proteoglicanos, enzimas derivadas e células pré e pós sinápticas.

No sulco sináptico existe a formação de pregas que compõem as fendas sinápticas secundárias, com isso a superfície de contato entre o neurotransmissor (acetilcolina) e a membrana da fibra muscular é maior.

No terminal pré-sináptico existem vesículas que armazenam acetilcolina, que liberam seu conteúdo através do mecanismo de exocitose, controlado eletricamente pelo potencial de ação. Existe também um grande número de mitocôndrias, que fornecem energia para a síntese do neurotransmissor. 0 neurotransmissor da placa terminal é a acetilcolina.

Quando o potencial de ação chega no terminal pré-sináptico, a acetilcolina é liberada na forma de pacotes multimoleculares, chamados de quanta. Externamente a membrana do terminal, tem-se a enzima acetilcolinesterase que tem a capacidade de hidrolisar a acetilcolina em colina e ácido acético.

O potencial de ação se propaga por toda a terminação nervosa pré-sináptica, ocorrendo então a abertura dos canais de cálcio. Por difusão, o cálcio passa para o interior dos terminais pré-sinápticos, atraindo as vesículas de acetilcolina para a membrana neural. As vesículas atravessam a membrana sendo hidrolisadas pela enzima acetilcolinesterase, podendo ficar espalhada ou 
combinar-se com uma proteína específica na superfície externa da membrana plasmática da placa motora. A macroscopia e a seqüência completa dos eventos que precedem a contração muscular podem ser visualizados na Figura $01(A)$

A combinação da acetilcolina com a proteína receptora produz uma alteração de conformação. Essa alteração irá desencadear um aumento momentâneo da condutância (na membrana pós) de $\mathrm{Na}$ e $\mathrm{K}$, que carregam cargas positivas. Estas correntes iônicas resultam na despolarização da placa motora, gerando um potencial de placa, que leva a um aumento no potencial de ação da membrana muscular (ASTRAND1987; BERGMAN, 1989; McARDLE, 1994; MACHADO, 2000).

Se a placa terminal é seguidamente excitada por um período de tempo, a capacidade de despolarização em resposta ao estímulo é gradualmente perdida, apenas quando o estímulo cessa é que a resposta volta aos valores basais. Este evento é chamado de dessensibilização do receptor e protege a fibra muscular de ativações excessivas. 


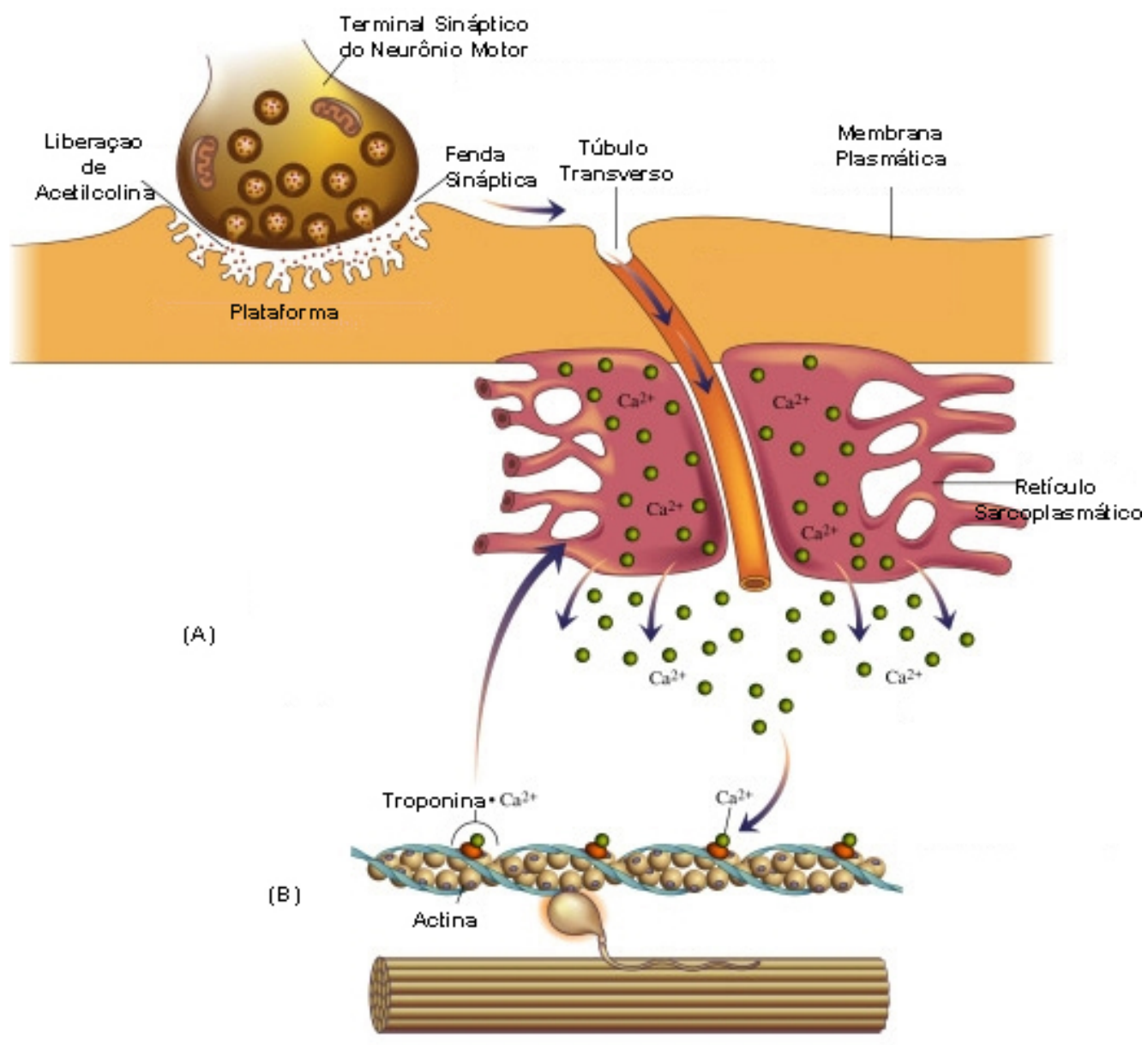

Figura 01 - (A) Visão Microscópica da Junção Neuromuscular e Eventos que precedem a contração muscular. (B) Processo Contrátil. Adaptado (MATTHEWS, 2000).

\subsection{Processo Contrátil}

A teoria mais aceita que explica a contração muscular é a dos filamentos deslizantes ou cremalheira (Figura 02). Nesta teoria, o potencial de ação propaga-se pela placa motora e o estímulo é transmitido pelo túbulo transverso (túbulo T), que o leva para a cerne da fibra muscular atingindo o retículo 
sarcoplasmático, ocorrendo uma despolarização da membrana aumentando dessa forma a permeabilidade dos íons de cálcio na membrana do retículo sarcoplasmático (ASTRAND, 1987; McARDLE, 1994,1996; WILMORE, 1994).
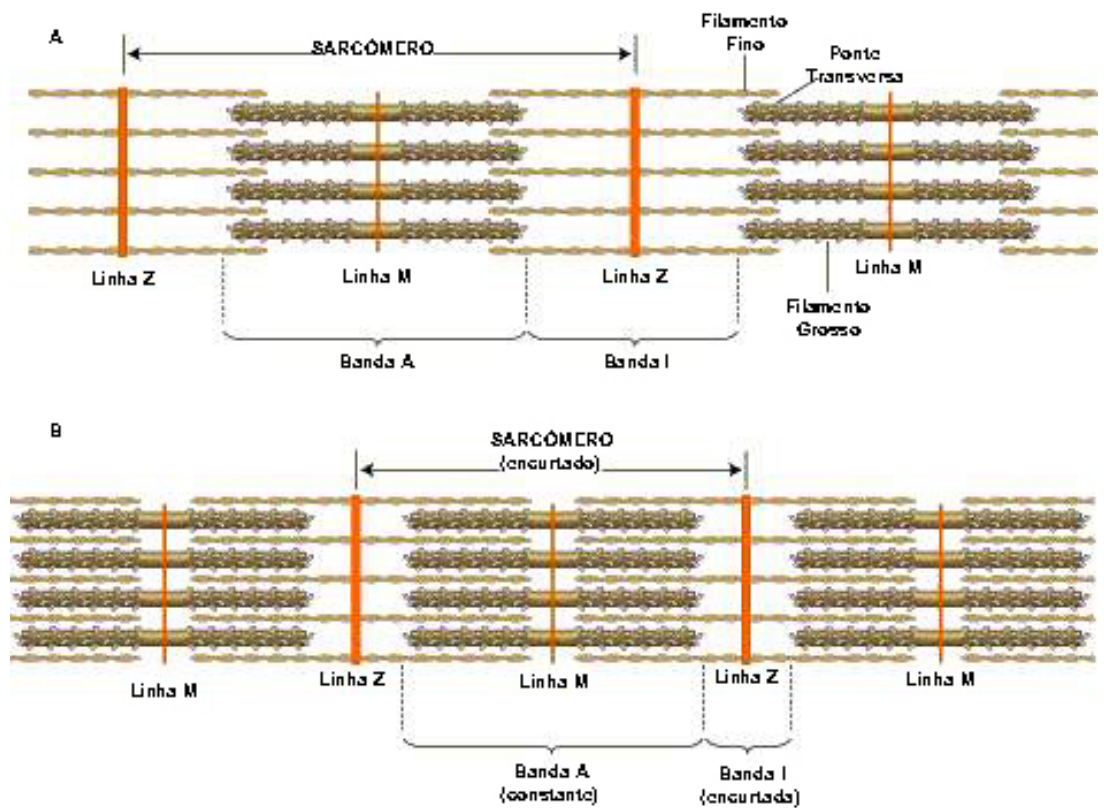

Figura 02 - Esquema Representativo da Teoria dos Filamentos Deslizantes ou Cremalheira. (A) Músculo Relaxado; (B) Músculo Contraído. Adaptado (MATTHEWS, 2000).

O cálcio passa rapidamente para o mioplasma, por difusão e atração de cargas elétricas vai para os miofilamentos. Como o cálcio é um íon bivalente positivo, ao passar para o mioplasma se liga rapidamente às moléculas de troponina, mais precisamente à subunidade TNC. 
Esta ligação ocasiona mudanças na estrutura da troponina devido as cargas elétricas adicionadas a molécula, levando a tropomiosina para as regiões interiores dos sulcos do filamento de actina, liberando o sítio de ligação da meromiosina pesada com a actina.

Com essa liberação, ocorre a ligação das pontes transversas da subunidade S1 da meromiosina pesada com o filamento de actina. A hipótese é que essa ligação acontece devido a uma molécula de ATP existente na cabeça da meromiosina pesada. Essa molécula é carregada negativamente e estas cargas elétricas provocam a flexão em dobradiça dos filamentos de miosina (Figura 01B).

Alguns autores supõem que essa flexão ocorre somente na dobradiça entre os filamentos de S1 e S2. E outros acreditam que a flexão ocorra na meromiosina leve e meromiosina pesada.

Esta flexão de aproximadamente $45^{\circ}$, arrasta os filamentos finos por entre os grossos e também posiciona a molécula de ATP próximo à região de atividade da enzima ATPásica actomiosina, provocando a hidrólise do ATP em ADP e fosfato inorgânico (Pi).

A quebra do ATP modifica o conjunto de cargas elétricas levando a cabeça da meromiosina pesada de volta a posição de origem, este processo é chamado 
de re-engatilhamento. O ADP + Pi é ressintetizado pela creatina fosfato ao ser substituída por outra molécula de ATP. Isso leva novamente a ligação da meromiosina pesada com o sítio ativo e assim sucessivamente, os filamentos de actina e miosina vão sobrepondo-se, diminuindo o comprimento do sarcômero.

Enquanto existir níveis altos de cálcio no sarcoplasma e ATP suficiente no momento do retorno do cálcio ao retículo sarcoplasmático haverá contração, caso contrário, ela cessa. No relaxamento muscular o potencial de ação deixa de chegar, não ocorrendo a liberação de cálcio.

Em relação ao gasto energético para se realizar a contração muscular, o fluxo de cálcio da tropomiosina para a cisterna do retículo sarcoplasmático requer para cada dois íons de cálcio transportado a hidrólise de um ATP, por ser contra um gradiente de concentração. Desta forma, um terço da energia despendida pelo músculo é utilizada na bomba de cálcio e dois terços no processo de re-engatilhamento. O processo de relaxamento do sarcômero é passivo. 


\subsection{Tipos de Fibras Musculares}

O músculo esquelético não é um grupo homogêneo de fibras com propriedades metabólicas e funcionais semelhantes. São as diferenças entre elas que nos permitem graduar a força e modular o movimento.

As primeiras pesquisas observaram o músculo esquelético a olho nu, verificando que existia dois tipos básicos de fibras, as quais foram denominadas vermelhas e brancas. As diferenças fisiológicas entre esses tipos de fibras foram estudadas no decorrer dos anos e sugeriu que as vermelhas eram de contração lenta e as brancas de contração rápida (ASTRAND, 1987; McARDLE, 1994; McARDLE, 1996; WILMORE, 1994; KRALJ, 1989).

Na década de 60 foi observado o conteúdo e a disposição das organelas, principalmente das mitocôndrias. Em 1970, as fibras musculares foram classificadas em tipos: I, de contração lenta; IIA e IIB de contração rápida (BROOKE \& KAISER, 1970).

Após essa classificação, foram analisados diversos músculos esqueléticos para quantificar a concentração de glicogênio, a velocidade de contração e a atividade das enzimas oxidativas e glicolíticas, classificando as fibras em: FG; 
FOG e SO (ASTRAND, 1987; McARDLE, 1994,1996; WILMORE, 1994; KRALJ, 1989).

As fibras FG (ou tipo IIB) são de contração rápida, predominantemente glicolíticas (anaeróbias), possuem alta concentração de glicogênio, lactato desidrogenase, pequena capacidade aeróbia e baixas concentrações de citocromos e mioglobina. A musculação, por exemplo, é realizada por esse tipo de fibra.

Também de contração rápida, as fibras FOG (ou tipo IIA) são consideradas intermediárias ou mistas, pois possuem tanto a alta capacidade glicolítica e concentração de lactato desidrogenase, que possibilitam o metabolismo anaeróbio quanto a grande concentração de citrocromo e mioglobina que estão relacionadas ao metabolismo aeróbio. Atividades como caminhadas leves, ginásticas localizadas, capoeira, etc.

Já as fibras SO (ou tipo I) são de contração lenta, possuem baixas concentrações de glicogênio e lactato desidrogenase e grande concentração de citrocromo e mioglobina, tendo características predominantemente aeróbias. Caminhada moderada, entre outras são exemplos de atividades realizadas por essas fibras. 
As diferenças metabólicas entre as fibras têm grande importância na aplicação de treinamentos ou reabilitação, pois dependendo do objetivo a ser alcançado deve-se primeiramente adaptá-las à requisição energética imposta pelo exercício, caso contrário poderá haver fadiga precoce (ASTRAND, 1987; McARDLE, 1994; KATCH \& McARDLE, 1996; WILMORE, 1994).

Entretanto, a contração do músculo esquelético é apenas um dos aspectos que se deve estudar para compreender tanto a EENM quanto os efeitos do exercício induzidos por ela. Conhecer a fisiologia do exercício antes e após lesão medular também deve ser abordado, pois existem diferenças entre essas duas situações.

\subsection{Instalação da Fadiga Durante Exercício Extenuante}

Como citado anteriormente, em lesados medulares, devido à alta requisição energética a fadiga muscular pode instalar-se precocemente. Conhecer o processo de fadiga é importante, por ser um dos fatores que interferem no desempenho físico.

A fadiga compreende alterações no estado fisiológico, psicológico ou ambos, que prejudicam ou incapacitam a realização de uma atividade de esforço e ou cotidiana. Estas alterações podem ser neuromusculares ou energéticas. 
A fadiga neuromuscular resulta de muitos fatores, cada um dos quais está relacionado a demandas específicas do exercício que a produz. Esses fatores podem interagir de tal maneira que acabam afetando tanto a contração quanto à excitação, ou ambas. As contrações dos músculos voluntários possuem quatro componentes principais: sistema nervoso central; sistema nervoso periférico; junção neuromuscular; função das fibras musculares (McARDLE, 1992).

Pode ocorrer fadiga, se a cadeia de eventos do processo contrátil for interrompida entre o sistema nervoso central e a fibra muscular, seja qual for à razão. Alguns trabalhos científicos estudam a fadiga como um evento fisiológico periférico; enquanto outros como um evento fisiológico central. Existem ainda, pesquisas que tratam da fadiga como uma associação entre os mecanismos centrais e periféricos.

A fadiga periférica está relacionada com o acúmulo de metabólitos, principalmente o lactato e desequilíbrio na concentração dos íons cálcio $\left(\mathrm{Ca}^{++}\right)$, nas fibras musculares. Quando há um acúmulo de lactato (derivado do piruvato), o $\mathrm{pH}$ da fibra muscular se altera para valores mais ácidos do que o normal impedindo que a contração prossiga. Por outro lado, para que a contração muscular ocorra, é imprescindível a presença do $\mathrm{Ca}^{++}$, e um desequilíbrio na concentração desse íon pode ocorrer devido à alteração da 
permeabilidade da membrana celular, depleção durante o exercício e ou deficiência da ingestão diária (McARDLE, 1992).

A fadiga central pode ser caracterizada tanto pela depleção dos substratos energéticos necessários para manter o esforço, principalmente a glicose, quanto por uma diminuição na função dos neurotransmissores (SYNDER, 1998; JAKEMAN, 1998). Na verdade, a queda nos níveis de glicogênio muscular pode levar ao prejuízo na função dos neurotransmissores.

Durante um exercício prolongado, uma queda nos níveis de glicose levam à uma ativação do metabolismo dos aminoácidos, gerando um aumento da concentração plasmática do triptofano, principal precursor da serotonina, causando uma maior ação serotonérgica no Sistema Nervoso Central gerando diminuição na ação dos neurotransmissores e como conseqüência a diminuição do limiar à fadiga (JAKEMAN,1998). Dessa forma, pode-se concluir que a fadiga central e a periférica estão intimamente relacionadas e que a sua divisão ocorre, apenas, para efeitos didáticos (Figura 03). 


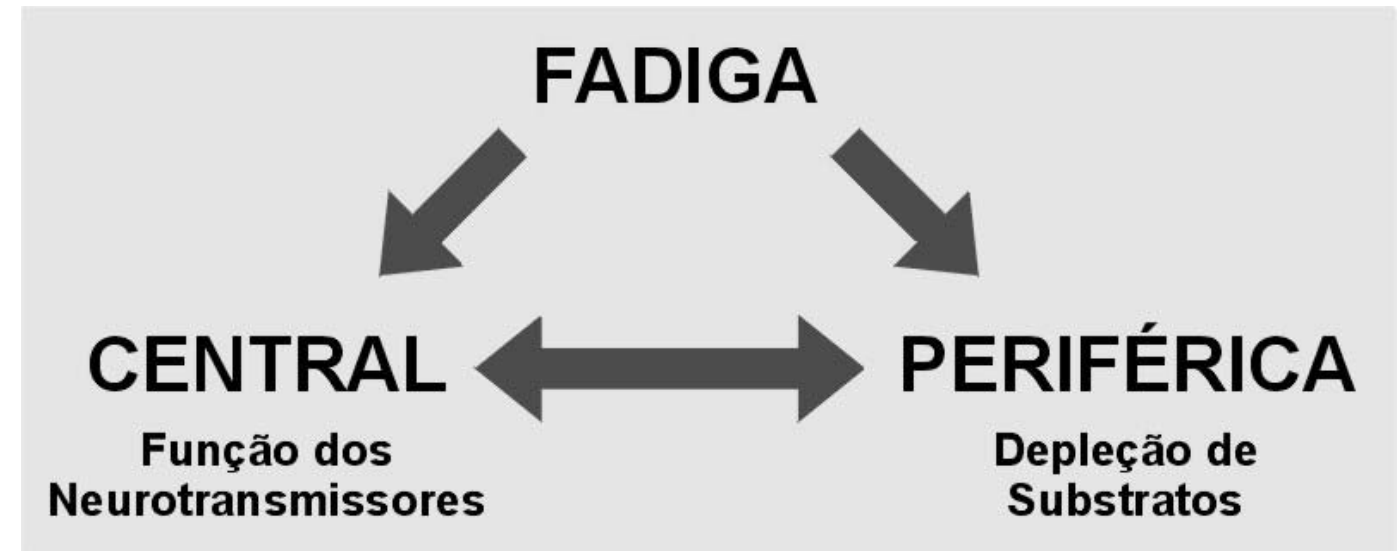

Figura 03 - Modelo proposto por JAKEMAN (1998) para explicar a Teoria da Fadiga.

Se o exercício induzido pela EENM for de alta intensidade para o indivíduo, a hipótese mais provável é que a fadiga muscular seja periférica, pelo excesso de íons $\mathrm{H}^{+}$. Esse parâmetro pode ser verificado através da lactacidemia (concentração de lactato sangüíneo) ou pela $\mathrm{VCO}_{2}$. 


\section{CAPÍTULO 3}

\section{EFEITOS DO EXERCÍCIO}

Atualmente a prática regular de atividades físicas vem sendo considerada um importante fator para o equilíbrio do balanço energético, tendo seus efeitos amplamente estudados nas diversas áreas do conhecimento. Podendo avaliar o metabolismo energético desde os períodos do desenvolvimento humano (infância, adolescência, senescência) até casos específicos, como por exemplo, o ciclo reprodutivo, dislipidemias e deficiências motoras. Neste último caso incluem-se os lesados medulares.

Estes estudos observaram os efeitos do exercício no metabolismo energético de maneiras distintas, entretanto visaram obter resultados que pudessem ser amplamente utilizados na promoção de melhorias na qualidade de vida das pessoas (KHANNA, 1998; CLIQUET, 1989; HARVEY, 1998). 
A prática regular de exercício proporciona algumas adaptações gerais ao indivíduo, como o aumento da Reserva Funcional, a redução na incidência de doenças crônico-degenerativas e também a manutenção da densidade óssea (McARDLE, 1992, 1993; GUYTON, 1992a).

Além destas, a atividade física promove também numerosas adaptações fisiológicas específicas em cada um dos diferentes sistemas (GUYTON, 1992a).

No Sistema Nervoso promove a maturação das vias nervosas, a memorização do ato motor e adaptações ao estresse físico. No Sistema Renal, tem-se o aumento na eficiência de excreção de ácidos (controle do $\mathrm{pH}$ ) e aumento da biosíntese da eritropoitina (elevando a produção de eritrócitos).

No Sistema Muscular pode ser observado hipertrofia e hiperplasia das fibras musculares e o aumento nos seguintes parâmetros fisiológicos: estoque de glicogênio, ATP e fosfocreatina; concentração de ATPase; número e tamanho das mitocôndrias; concentração das enzimas glicolíticas e oxidativas e fosfofrutoquinase; concentração de miogloblina; força muscular e oxidação de glicogênio e ácidos graxos livres.

Além disso, tem-se a redução da fadiga muscular e promoção de modificações nos tipos de fibras musculares. Essas adaptações no sistema muscular são de grande valia principalmente para os portadores de lesão medular, uma vez que 
esses indivíduos devido ao seu estilo de vida, que na maioria dos casos é sedentário, sofrem perda e atrofia da massa magra, principalmente abaixo do nível da lesão e também fadiga muscular precoce (FAGHIRI, 1992; SPUNGEN, 1993).

No Sistema Cardiovascular a manutenção da Freqüência Cardíaca Máxima, e a sua redução ao longo treinamento e do tempo; aumento da vascularização cardíaca e periférica (angiogênese) e discreta redução da Pressão Arterial (para hipertensos).

No Sistema Pulmonar observa-se o aumento no Fluxo Máximo Respiratório; na Ventilação Máxima e Voluntária Máxima; na extração do oxigênio alvéolocapilar e capilar- tecidual e na eficiência do Sistema Ácido-Base.

E no Sistema Endócrino e Metabólico pode-se observar aumento: da sensibilidade à insulina e da tolerância à glicose; da liberação do Hormônio GH durante o exercício; da eficiência na mobilização dos triglicerídeos dos adipócitos; e redução na liberação do cortisol durante o estresse do exercício; nos níveis de colesterol e triglicerídeos circulantes, e aumento na deposição de glicogênio muscular (McARDLE, 1992,1993).

Em contraposição, tem-se que períodos de inatividade física e excessiva ingestão alimentar, decorrente do estilo de vida atual estão relacionados com o 
rápido aumento na quantidade de gordura (BRAY, 1990), que podem levar ao desenvolvimento de doenças degenerativas, como por exemplo: cardiopatias, diabetes, osteoporose, dislipidemias, obesidade, entre outras.

De acordo com DÂMASO (1996), é importante estudar alterações específicas no metabolismo lipídico, como por exemplo, a forma e quantidade da deposição de gordura, uma vez que a obesidade é resultante principalmente de alterações dessa via metabólica (GEERLING et al., 1994).

No caso dos lesados medulares, as lesões têm ocorrido principalmente devido a acidentes, mas também podem ser de origem patológica, alterando significativamente o estilo de vida dessas pessoas, pois estas acabam tendo uma vida parcial ou totalmente sedentária.

A prática de atividade física por essa população especial deve ser estudada, pois para cada nível de lesão podem ocorrer alterações fisiológicas distintas no organismo. A partir de parâmetros diretos e indiretos pode-se avaliar qual exercício é melhor e a intensidade que ele deve ser executado, para que os efeitos do exercício sejam alcançados. Para tal, conhecer a fisiologia do exercício é importante. 


\subsection{Fisiologia do Exercício}

Durante a realização de uma atividade física qualquer, diferentes parâmetros fisiológicos estão envolvidos para que este trabalho não cause estresse ao organismo.

Para que o exercício possa ser realizado, tem-se envolvidos três sistemas básicos: Circulatório, Respiratório e de Captação de Oxigênio. Cada um deles tem uma função específica e afeta o desempenho físico de maneiras distintas.

Estes Sistemas estão interligados como se fossem engrenagens, todavia têm limites fisiológicos diferentes, portanto, se um deles estiver acima do seu limite, o desempenho será menor (Figura 04).

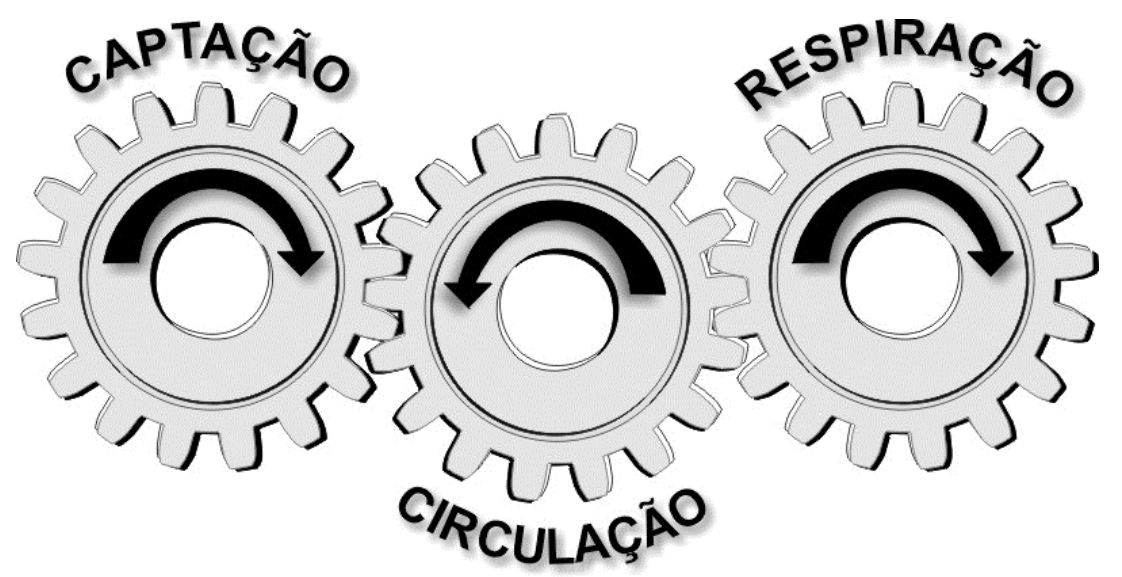

Figura 04 - Esquema Representativo da Inter-relação dos Sistemas. 
A fisiologia do Sistema Muscular pode ser vista no Capítulo 2, restando descrever os Sistemas Circulatório e Respiratório. Este último tem importância para este trabalho, uma vez que as avaliações propostas são provenientes desse sistema.

\subsubsection{Sistema Circulatório}

O Sistema Circulatório atende a quatro funções importantes durante a atividade física: fornecimento de sangue aos músculos que estão sendo ativados, onde o oxigênio é trocado por uma quantidade quase igual de dióxido de carbono; retorno do sangue aos pulmões, onde os gases resultantes do metabolismo dos tecidos são trocados pelo do meio ambiente; liberação de calor, subproduto do metabolismo celular e distribuição da glicose e lipídios para os tecidos, para que sirvam de combustível para a manutenção do exercício (KATCH \& McARDLE, 1996).

Caso o Sistema Circulatório não suporte a intensidade do exercício, os substratos energéticos não chegarão aos tecidos, bem como o oxigênio, podendo iniciar um trabalho anaeróbio precocemente. 


\subsubsection{Sistema Respiratório}

O objetivo da respiração consiste na garantia da troca de oxigênio e dióxido de carbono entre o sangue e o ar atmosférico. Desta forma, esses gases participam diretamente da regulação da respiração. A ventilação também participa diretamente na regulação do equilíbrio Ácido-Base, que controla o pH sangüíneo, associado aos sistemas tampões (de ação rápida) e ao sistema renal (de ação lenta).

Das variáveis envolvidas na respiração, pode-se destacar as seguintes:

Ventilação Pulmonar (Ve), é dada por:

$V e=f \times V_{t}$

Onde:

$f=$ freqüência respiratória

$\mathrm{V}_{\mathrm{t}}=$ volume corrente médio expirado.

Em repouso a ventilação é de aproximadamente 6 L/min, durante atividades físicas pode aumentar até 150 L/min (ASTRAND, 1987).

$\mathrm{PCO}_{2}$ e $\mathrm{PO}_{2}$, que são as pressões parciais do dióxido de carbono e do oxigênio, estão diretamente relacionadas com o equilíbrio Ácido-Base do sangue. Quando a $\mathrm{PCO}_{2}$ diminui os quimiorreceptores centrais geram uma hipoventilação e quando seus valores aumentam, haverá uma hiperventilação. 
Para níveis de $\mathrm{PO}_{2}$ abaixo de $20 \mathrm{mmHg}$ haverá hipoventilação. Este sistema dura minutos, mas o ajuste é mais preciso, trazendo o $\mathrm{pH}$ mais próximo da normalidade. A hiperventilação tem como objetivo aumentar a eliminação de $\mathrm{CO}_{2}$, já a hipoventilação tem como objetivo aumentar a concentração de $\mathrm{CO}_{2}$ no sangue.

$\mathrm{VO}_{2}$, é o volume de oxigênio captado pelo organismo durante um ciclo respiratório. A partir desse valor pode ser calculado o gasto energético de qualquer atividade física.

$\mathrm{VCO}_{2}$, que é o volume de $\mathrm{CO}_{2}$ expirado, está relacionado com o consumo de oxigênio nos processos aeróbios (Ciclo de Krebs), como um produto final desse processo bioquímico. Durante o repouso, o comportamento dessa variável é similar com a da $\mathrm{VO}_{2}$, mas com o aumento do esforço durante o exercício essa variável passará a crescer gradualmente ou exponencialmente (no caso de exercício de cargas crescentes) correspondendo ao Limiar de Anaerobiose ou ao Consumo Máximo de Oxigênio do indivíduo.

Durante a realização de um exercício há um aumento retilíneo da ventilação, sendo que em exercícios pesados esse aumento acentua-se.

O volume respiratório é regulado através de um mecanismo de retroalimentação negativa, determinado principalmente pela produção de $\mathrm{CO}_{2}$. 
Durante um trabalho anaeróbio a concentração de $\mathrm{H}^{+}$do sangue aumentará, o que representa um estímulo adicional para a respiração. Bem como a produção de $\mathrm{CO}_{2}$ metabólico, produto final do tamponamento do Ácido Lático pelo Bicarbonato $\left(\mathrm{H}\right.$. Lactato $+\mathrm{NaHCO}_{3} \rightarrow \mathrm{Na}$ Lactato $+\mathrm{H}_{2} \mathrm{CO}_{3}\left[\mathrm{H}_{2} \mathrm{O}+\mathrm{CO}_{2^{-}}\right.$ metabólico]).

Exercícios intensos, os quimiorreceptores periféricos existentes nos corpos carotídeos e aórticos também estimulam a respiração, possivelmente porque uma maior atividade simpática reduzirá o fluxo sangüíneo para as áreas quimiorreceptoras produzindo uma queda na $\mathrm{PO}_{2}$ local, apesar desta variável apresentar valores quase normais no sangue arterial. Os quimiorreceptores não são muito sensíveis ao $\mathrm{O}_{2}$, mas muito ao $\mathrm{CO}_{2}$ (Figura 05). Existe também uma área quimiosensitiva central, que regula a inspiração (Figura 06). 


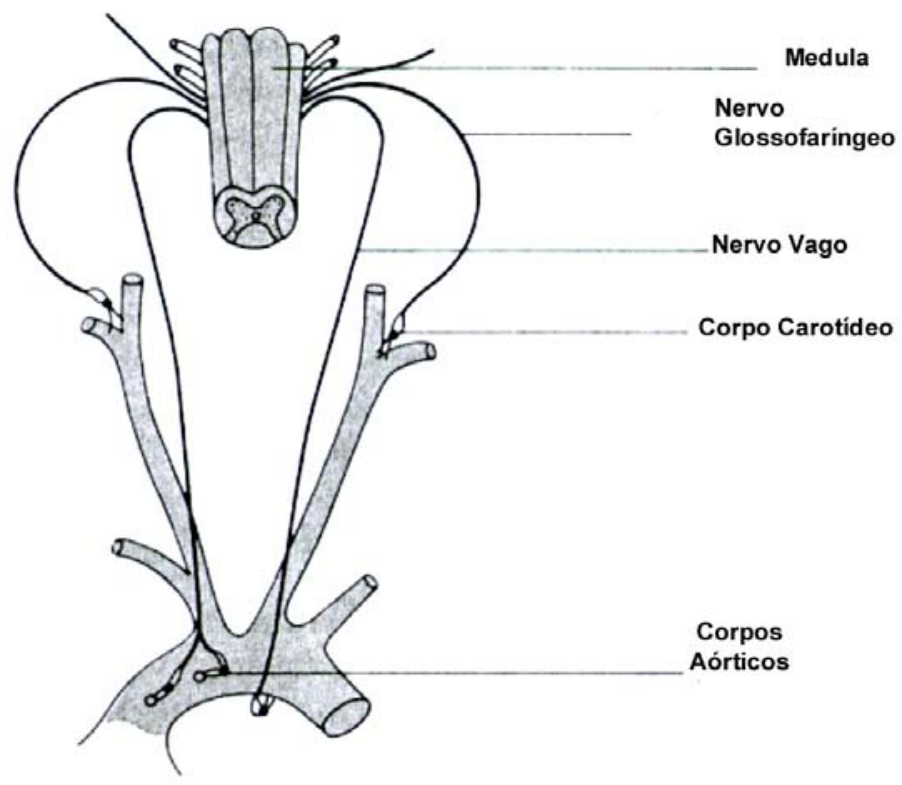

Figura 05 - Esquema Representativo dos Quimiorreceptores Periféricos (GUYTON, 1992b).

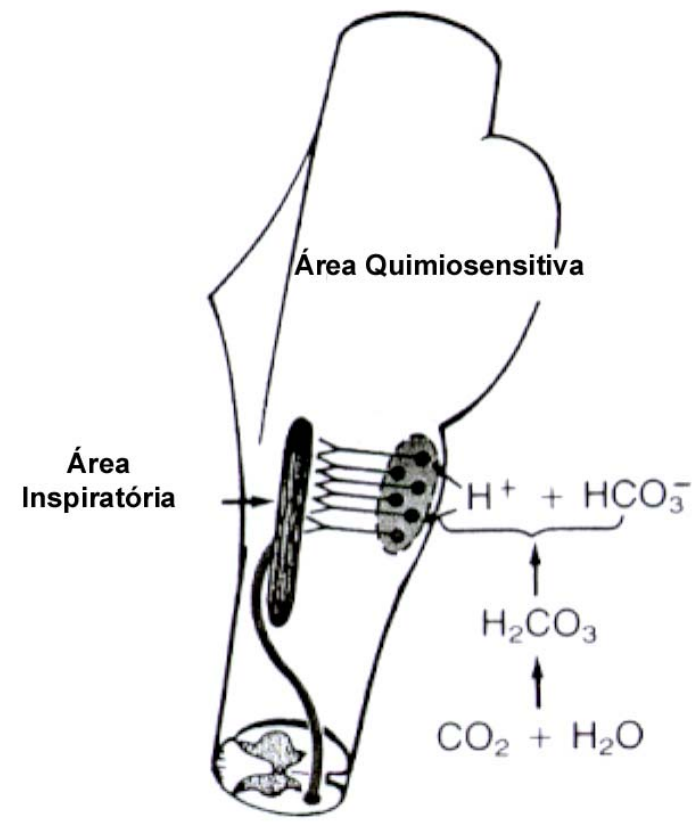

Figura 06 - Esquema Representativo da Área Quimiosensitiva (GUYTON, 1992b). 
Quando o organismo não consegue restabelecer o equilíbrio Ácido-Base, há interrupção do exercício, por excesso de íons $\mathrm{H}^{+}$, que irão competir com o $\mathrm{Ca}^{++}$ no sítio de ligação da troponina, mais precisamente à subunidade TNC, dificultando o processo de contração muscular, podendo interromper o exercício, como descrito no item 2.4 .

\subsection{Regulação da Respiração pelo Sistema Nervoso}

O Sistema Nervoso ajusta a taxa da ventilação alveolar aproximadamente igual à demanda do corpo, dessa forma a $\mathrm{PO}_{2}$ e a $\mathrm{PCO}_{2}$ também alteram durante exercícios extenuantes e qualquer outro tipo de estresse respiratório (GUYTON,1992b).

Essa regulação é executada pelo Centro Respiratório, formado por um conjunto de neurônios localizados nos dois lados da medula oblonga, ponte e bulbo (Figura 07). Esse conjunto de neurônios por sua vez, é dividido em três partes, cada uma delas com uma função específica no controle da respiração.

$\mathrm{Na}$ parte dorsal da medula tem-se o grupo respiratório dorsal, que é responsável principalmente pela inspiração. O Centro Pneumotáxico, tem a função primária de limitar a duração da inspiração, mas também pode fazer a taxa respiratória aumentar. 
O último é o grupo respiratório ventral que tem como função o controle da inspiração e da expiração. Entretanto, durante a respiração normal, este grupo é inativo. Quando a ventilação pulmonar aumenta mais do que o normal, sinais respiratórios advindos do grupo dorsal irão sobrecarregar o grupo ventral, tendo como conseqüência uma contribuição para melhorar a respiração (GUYTON,1992b).

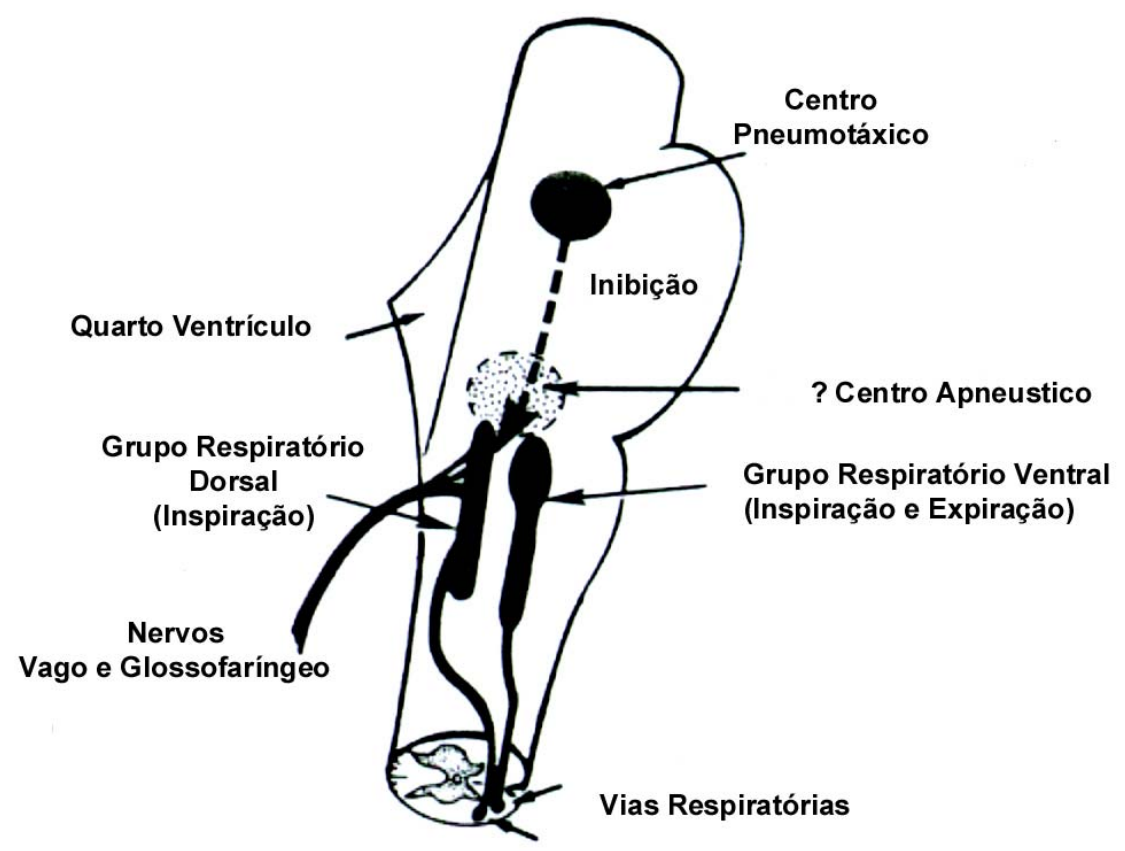

Figura 07 - Esquema Representativo do Centro Respiratório (GUYTON, 1992b).

Durante um exercício, o consumo de oxigênio e a produção de dióxido de carbono pode aumentar cerca de 20 vezes. A ventilação alveolar total também 
aumenta de acordo com a requisição do metabolismo, mas a $\mathrm{PO}_{2}$ e a $\mathrm{PCO}_{2}$ não sofrem alterações tão grandes, pois são mantidas pelo sistema de tamponamento (Figura 08) (GUYTON,1992b). Pode ser observado na Figura 09 a relação entre a $\mathrm{PO}_{2}$ e a ventilação alveolar durante o repouso e o exercício (GUYTON,1992b).

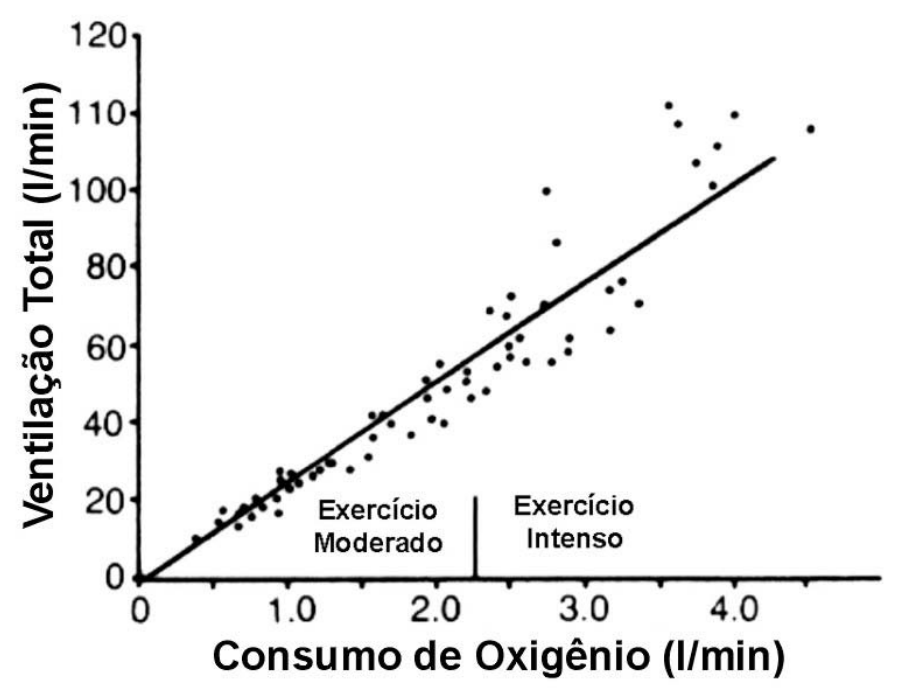

Figura 08 - Relação entre a Ventilação Total e o Consumo de Oxigênio (GUYTON, 1992b). 
32

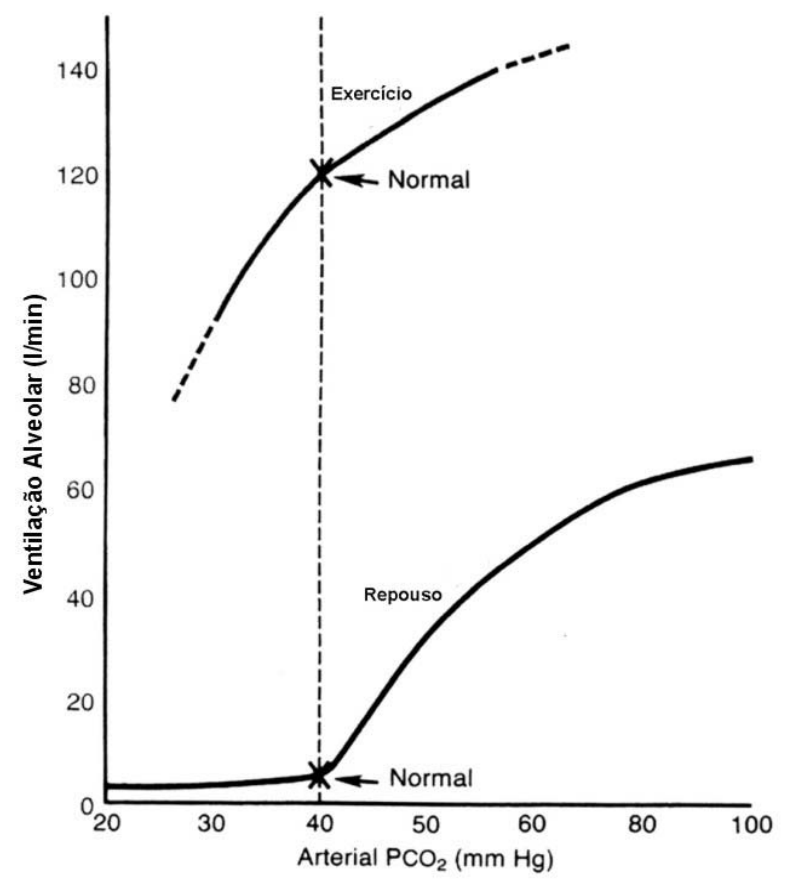

Figura 09 - Relação entre a Ventilação Alveolar e a $\mathrm{PCO}_{2}$ Arterial (GUYTON, 1992b). 


\subsection{Metabolismo Energético}

Os lesados medulares geralmente não alteram significativamente o seu hábito alimentar após a lesão, mantendo ou possivelmente aumentando a sua ingestão alimentar em detrimento ao seu balanço energético.

Para avaliar melhor as implicações desse desequilíbrio energético, tem-se que primeiramente compreender o metabolismo energético. Esse metabolismo pode ser considerado de importância primária para a vida, pois ele é responsável pelos processos de anabolismo e catabolismo, isto é, pela síntese e quebra dos substratos energéticos. Esses substratos são os responsáveis pelo suporte de todos os sistemas, mantendo as suas funções vitais.

Entretanto, esse metabolismo sofre influências da taxa metabólica de repouso, do efeito termogênico do alimento consumido e da energia gasta durante a atividade física e recuperação. Esses parâmetros são considerados como as componentes do gasto energético.

A Taxa Metabólica de Repouso compreende o metabolismo basal, isto é, o metabolismo do sono e o metabolismo ao despertar. Essa componente é responsável pelo suporte da vida, desde a parte fisiológica até a bioquímica, e corresponde de 50 a 75\% do gasto energético diário. 
O efeito térmico dos nutrientes corresponde aproximadamente $10 \%$ do gasto energético diário e possui duas componentes. A primeira é a termogênese obrigatória, que consiste na energia gasta nos processos de absorção e assimilação dos nutrientes, e a segunda componente é a termogênese facultativa. Esse aumento no metabolismo ocasionado pela ingestão de alimentos está relacionado com a ativação do sistema nervoso simpático e seu efeito estimulante sobre o mesmo.

Já a energia gasta durante a prática de atividade física e recuperação corresponde de 15 à $30 \%$ do gasto energético diário, compreende as atividades cotidianas, de trabalho e os exercícios de desporto e lazer. Esta é uma componente muito importante para o equilíbrio do balanço energético, isto é, do que é consumido (ingerido) com o que é gasto.

Caso haja um desequilíbrio energético positivo, tem-se uma ingestão de alimentos maior que o gasto; e se for um desequilíbrio negativo a ingestão será menor que o gasto energético. No primeiro caso, observam-se efeitos anabólicos, principalmente em relação ao metabolismo lipídico, além de aumento nas concentrações plasmáticas de colesterol, lipídios totais, glicose, entre outros. Essas alterações podem levar a obesidade e doenças degenerativas como arterosclerose e diabetes. 
No segundo caso, tem-se o catabolismo. Os principais efeitos que podem ser observados são perda de massa muscular e massa gorda, podendo levar à desnutrição. Deve-se ressaltar também, que algumas doenças podem alterar a taxa metabólica basal, diminuindo ou aumentando o gasto energético, provocando também um desequilíbrio no balanço energético que deve ser compensado de acordo com a alteração.

Em suma, o equilíbrio no balanço energético tem grande importância na manutenção da vida, visto que qualquer alteração pode ocasionar efeitos deletérios ao organismo, principalmente no que se refere à composição corporal. Desta forma, é muito importante saber qual o valor da energia gasta em determinados tipos de exercício e suas implicações no balanço energético.

No caso de lesados medulares é necessária uma avaliação mais detalhada dos efeitos diretos do aumento do gasto energético que é geralmente observado durante um protocolo de marcha, induzida por EENM, para que a reabilitação através desta seja alcançada sem danos ao paciente.

As mudanças na composição corporal associada à lesão medular podem gerar várias conseqüências metabólicas, similares as que são observadas em indivíduos obesos, como desordens no metabolismo dos carboidratos, dos lipídios e do potássio (SPUNGEN, 1993; OLLE, 1993). 
Essa similaridade gera preocupações, uma vez que a obesidade é conhecida desde de 1985 como uma doença multifatorial (BLACKBURN \& KANDERS, 1994), isto é, possui inúmeros fatores de riscos mórbidos e aumenta a ocorrência de doenças crônico-degenerativas como problemas cardiovasculares (REYBROUK, 1987), endócrinos (BJORNTORP, 1987, 1990), alterações posturais, bioquímicas e comportamentais (DÂMASO, 1995).

A similaridade com a obesidade associada a inatividade física possivelmente potencializa o risco para os lesados medulares desenvolverem doenças crônico-degenerativas. Ressaltando assim, a importância de assegurar os possíveis efeitos benéficos da utilização da EENM, induzindo a marcha, para que esta técnica possa ser efetivamente utilizada como forma de intervenção à essas adaptações deletérias.

Dentre esses possíveis efeitos benéficos do uso da EENM, temos as alterações na taxa metabólica basal e diária, a manutenção, ganho da massa muscular, as alterações na distribuição e quantidade de gordura corporal depositada, a redução da fadiga muscular e do gasto energético, em decorrência do treinamento físico com a EENM (BARSTOW, 1996).

Todos esses efeitos gerariam ao lesado medular uma melhoria na qualidade e na expectativa de vida possibilitando uma melhor adequação do mesmo à sociedade. 


\section{CAPÍTULO 4}

\section{LESÃO MEDULAR}

A medula espinhal pode ser considerada de fundamental importância para vários sistemas biológicos por controlar ou ser mediadora de diferentes funções fisiológicas de um indivíduo.

Essas funções estão relacionadas ao fato da medula ser a principal via do Sistema Nervoso, e este por sua vez associado ao Sistema Endócrino é responsável pela maior parte das funções de controle do corpo (GUYTON, 1992b).

Pode-se dizer que o Sistema Nervoso controla as atividades rápidas do corpo como: contrações musculares, eventos viscerais e até mesmo a velocidade de secreção de algumas glândulas endócrinas. Por outro lado, o Sistema Endócrino regula principalmente as funções metabólicas (GUYTON, 1992b). 
As funções medulares que se destacam são a motora e a sensorial, por estarem presentes em várias atividades conscientes dos indivíduos, por exemplo, atividades em que o indivíduo controla um determinado movimento ou segura um objeto.

O comprometimento dessas funções, ou seja, uma lesão medular, faz com que as sensações e os movimentos voluntários sejam impossíveis de serem percebidos ou executados, e por sua vez, os movimentos involuntários ou espásticos passam a ser exagerado (STEFANOVSKA, 1986).

As principais causas das lesões medulares observadas em dois hospitais da Rede SARAH (Salvador e Brasília), no período de 01 de fevereiro de 1999 a 31 de janeiro de 2000 , foram acidentes de trânsito $(38,3 \%)$ e agressão por arma de fogo $(34,2 \%)$ (REDE SARAH, 2001).

Dados epidemiológicos demonstraram que os números de lesões medulares são expressivos. No Brasil, na faixa etária dos 18 aos 29 anos tem alta incidência de paraplegia, sendo maior para o sexo masculino $(61,33 \%)$ do que para o feminino $(38,67 \%)$. O senso comum nos leva a crer que estes valores estão relacionados, principalmente, a acidentes automobilísticos (IBGE, 1991).

No Estados Unidos (Figura 10), pode ser observado valores similares para a faixa etária da lesão (de 16 a 29 anos - 61,1\% de incidência) entretanto não 
está classificado em paraplegia e tetraplegia, como no caso dos dados brasileiros. Mesmo assim, o sexo masculino (82\%) tem incidência maior quando comparado com o feminino (18\%).

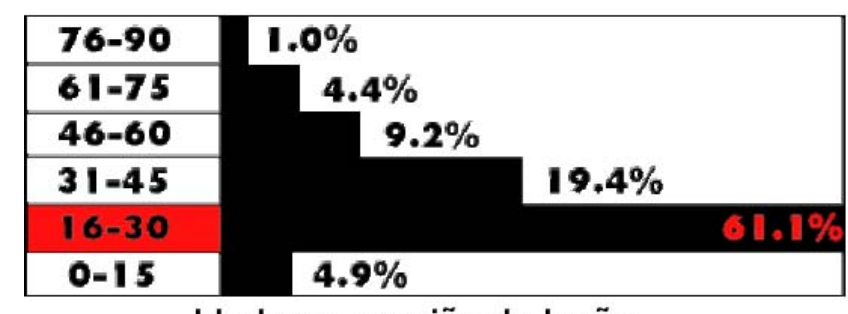

Idade na ocasião da lesão

A

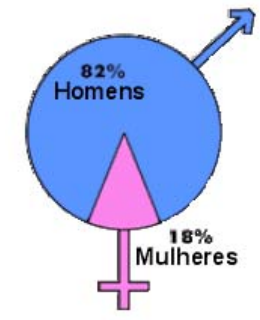

B

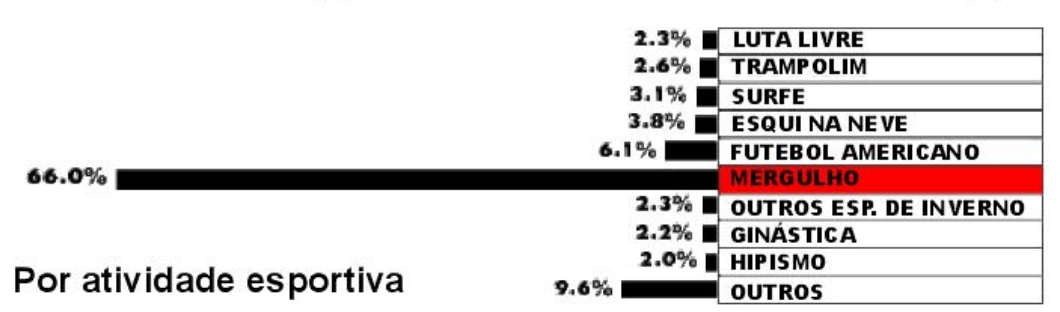

C

Figuras 10 - Estatísticas norte-americanas sobre algumas características dos pacientes lesados medulares (dados similares comparados com os do Brasil). A) Porcentagem de pacientes agrupados por idade na ocasião da lesão; B) Porcentagem de pacientes agrupados por sexo; C) Porcentagem de pacientes agrupados por atividade esportiva. (Adaptado de YOUNG, 1982)

Esses dados reforçam a importância de um trabalho de reabilitação para essa população, com a finalidade de melhorar a qualidade de vida desses indivíduos e possivelmente reintegrá-los a sociedade. 


\subsection{Origem, Anatomia da Medula e Classificação da Lesão}

\section{Medular.}

A medula é uma massa alongada, cilindróide, de tecido nervoso situada dentro do canal vertebral, sem ocupá-lo complemente e ligeiramente achatada ânteroposteriormente. Tem calibre não uniforme por possuir duas dilatações, as intumescências cervical e lombar, de onde partem o maior número de nervos através dos plexos braquial e lombossacral, para inervar os membros superiores e inferiores, respectivamente (MACHADO, 2000).

Seu comprimento médio é de $42 \mathrm{~cm}$ na mulher adulta e de $45 \mathrm{~cm}$ no homem adulto. Sua massa total corresponde a apenas $2 \%$ do Sistema Nervoso Central humano, contudo inerva áreas motoras e sensoriais de todo o corpo, exceto as áreas inervadas pelos nervos cranianos.

A medula espinhal recebe impulsos sensoriais de receptores e envia impulsos motores a efetuadores tanto somáticos quanto viscerais. Ela pode atuar em reflexos dependente ou independentemente do encéfalo. Este órgão é a parte mais simples do Sistema Nervoso Central tanto ontogenético (embriológico), quanto filogeneticamente (evolutivamente). Daí o fato de a maioria das conexões encefálicas com o Sistema Nervoso Periférico ocorrer via medula (MACHADO, 2000). 
A medula origina-se da parte caudal do tubo neural e é relativamente pouco diferenciada em relação ao encéfalo. A diferenciação ocorre na medida que o tubo se desenvolve, com o surgimento de uma depressão longitudinal na superfície interna das paredes laterais da medula e na parte caudal do encéfalo.

Esta depressão é o sulco limitante que delimita dois grupos celulares: a placa alar (dorsal), que é constituída predominantemente de células sensitivas, e a placa basal (ventral) com células motoras. No desenvolvimento, a placa alar vai formar o corno posterior da substância cinzenta da medula, e a placar basal, o corno anterior (MACHADO,1979).

Outro fator importante é o crescimento diferenciado da coluna vertebral e da medula, onde a primeira cresce mais rapidamente. Dessa forma os pares de nervos que partem da medula deixam de passar diretamente pelo seu forâme, fazendo com que os últimos nervos percorram maior distância para sair. Com isso há formação de duas estruturas importantes: a cauda eqüina e a cisterna lombar de onde se retira o líquor sem risco de lesão. Na Figura 11 temos a visão macroscópica da medula de um adulto. 


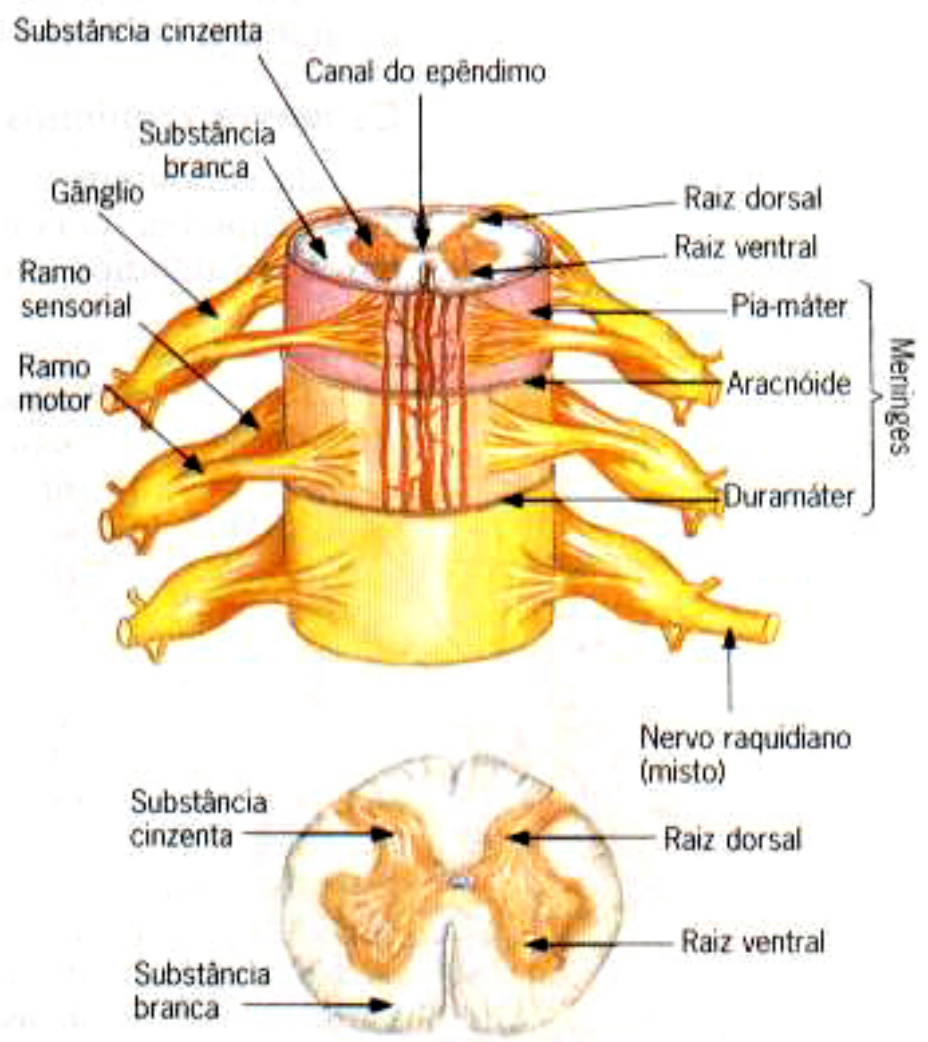

Figura 11 - Visão Microscópica da Medula Espinhal (MACHADO,2000).

A coluna vertebral é dividida anatomicamente em: coluna cervical (pescoço), coluna torácica (tórax), coluna lombar (cintura), sacro e cóccix - o sacro se articula com a bacia de cada lado e o cóccix é formado por quatro pequenos ossos sem nenhuma função definida (Figura 12). 


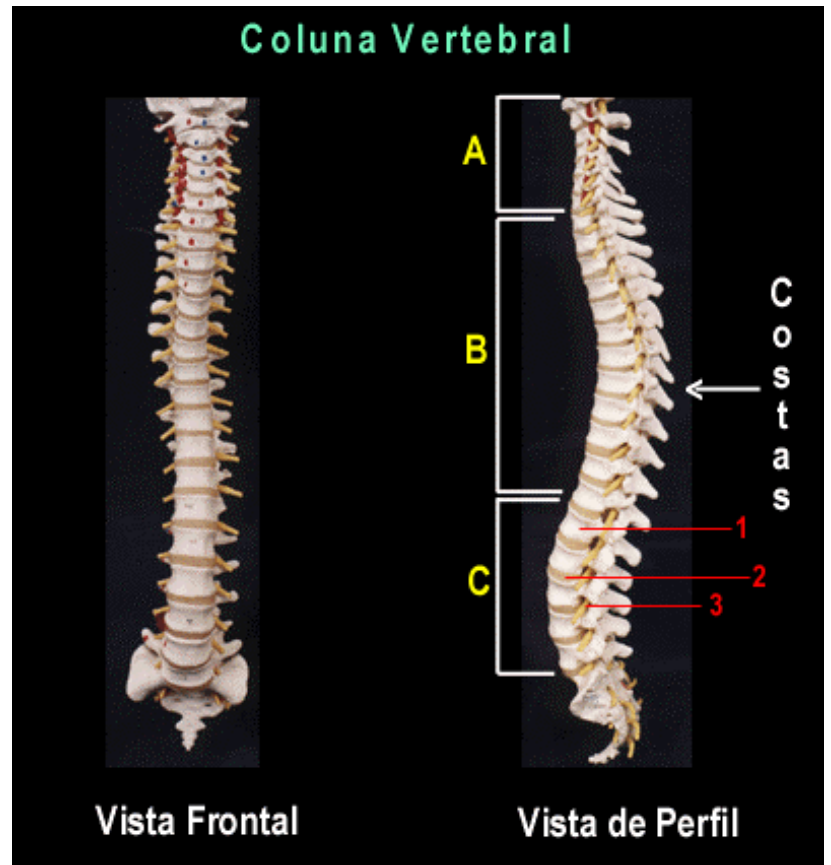

Figura 12 - Coluna vertebral (FERRARETTO, 2000) (A) Coluna cervical (Lordose cervical); B) Coluna torácica (Cifose torácica); C) Coluna lombar (Lordose lombar). 1) Corpo vertebral; 2) Disco intervetebral; 3) Raiz nervosa.

A região cervical é composta de sete vértebras numeradas de $\mathrm{C} 1$ a $\mathrm{C} 7$, e inicia com a vértebra que se localiza na base do crânio, conhecida também como Atlas. Uma lesão nesta região resulta em uma tetraplegia, ou seja, uma paralisia dos membros superiores e inferiores.

A região torácica vem logo a seguir, e possui 12 vértebras, numerada de T1 a T12. A região lombar possui cinco vértebras, L1 a L5. No final da coluna vertebral, logo após a região lombar, surgem o sacro e o cóccix. 
As lesões podem ser divididas em duas classes quanto à sua origem: traumáticas e não traumáticas. As lesões traumáticas são as mais observadas, destacando-se entre elas os acidentes automobilísticos, mergulho, quedas e ferimentos por armas de fogo ou brancas. Já as lesões não traumáticas são de origem patológica, como por exemplo, disfunções vasculares, tumores, infecções, malformações e doenças degenerativas.

As lesões podem ser classificadas funcionalmente em duas categorias: tetraplegia e paraplegia. A primeira está relacionada às lesões no segmento cervical, que afeta os membros inferiores, superiores e o tronco. Já a paraplegia está relacionada às lesões nos segmentos torácicos, lombares ou sacral, podendo afetar o tronco e os membros inferiores.

A importância de normas para a avaliação e classificação precisa do nível da lesão medular tem sido reconhecida há mais de 20 anos, entretanto normas distintas eram usadas em centros de estudos, dificultando a troca de conhecimentos (MICHAELIS, 1969).

Neste sentido, a Associação Americana de Lesões Medulares (ASIA), reuniu-se quatro vezes em 1990-1991 para atingir definitivamente um consenso quanto à avaliação e classificação das lesões medulares. 
Ficou estabelecido após estudos que a avaliação e classificação seria baseada na Medida de Independência Funcional, que avalia o impacto da lesão nas atividades da vida diária e função do indivíduo (BARROS, 1994). Esta norma substitui a avaliação proposta por Frankel (1969).

\subsection{Sistema Nervoso}

Durante a evolução, mesmo os seres mais simples como a ameba, tiveram a necessidade de se ajustar ao meio ambiente. Para isso, esse ser que é unicelular, já possuía três propriedades fundamentais: irritabilidade (permite à célula detectar modificações do meio ambiente), a condutibilidade (permite a condução desse estímulo pelo protoplasma) e a contractilidade (é a resposta ao estímulo). Essas propriedades se especializaram muito no decorrer da evolução das espécies.

Com o aparecimento de metazoários pluricelulares, as células musculares eram os responsáveis pela contractilidade, e ocupavam posição mais profunda. Surgiu então a necessidade de células superficiais que captassem as variações do meio ambiente e passassem essas informações para o interior do ser. Essas células foram os primeiros neurônios. 
Outro grande passo da evolução do Sistema Nervoso foi quando ele deixou de ser difuso e passou a ser centralizado. Surgiu a partir daí o Sistema Nervoso Central (SNC) que veio acompanhado de neurônios aferentes (levam o impulso ao SNC) e eferentes (levam o impulso ao órgão efetuador).

Então surgiram os arco reflexos simples onde o neurônio aferente recebe informações do meio externo, faz sinapse com o neurônio eferente que vai estimular o órgão motor. Arcos reflexos mais complexos surgiram com o aparecimento dos neurônios de associação que ficam entre o neurônio motor e o sensitivo.

O Sistema Nervoso continuou evoluindo muito. O soma dos neurônios aferentes começou a ficar situado mais internamente nos organismos (talvez isso se deva há uma maior necessidade de proteção), surgindo assim os neurônios pseudounipolares. Outro fato marcante foi o aumento do número de neurônios de associação permitindo a realização de funções mais elaboradas.

No homem, O SNC é o ponto mais alto da evolução. É capaz, devido a grande quantidade de neurônios de associação, de realizar atividades complexas, a chamada função superior.

Como citado anteriormente, o sistema nervoso humano é o mais complexo entre os animais. Sua função básica é de receber informações sobre as 
variações externas e internas e produzir respostas a essas variações através dos músculos e glândulas. Desta forma ele contribui, juntamente com o sistema endócrino, para a homeostase do organismo (MACHADO, 2000).

Além disso, o Sistema Nervoso humano possui as chamadas funções superiores que inclui: a memória, que corresponde a capacidade de armazenar informações e depois resgatá-las, como o aprendizado, o intelecto, o pensamento e a personalidade (MACHADO, 2000).

Anatomicamente, o Sistema Nervoso divide-se em: Sistema Nervoso Central (SNC) e Sistema Nervoso Periférico (SNP). O Periférico corresponde aos nervos cranianos, aos gânglios e nervos periféricos e receptores do corpo. $\mathrm{O}$ central divide-se em encéfalo e medula. O encéfalo corresponde ao telencéfalo, diencéfalo, cerebelo, e tronco cefálico.

Funcionalmente, o Sistema Nervoso está dividido em: somático e visceral. O somático é responsável pela inervação da pele, músculos e articulações e divide-se numa parte aferente e uma eferente. Já o visceral é responsável pela inervação dos vasos sangüíneos, glândulas e vísceras. Sendo também constituído de uma parte aferente e eferente, sendo que a última corresponde ao sistema nervoso autônomo. A medula corresponde ao Sistema Nervoso Segmentar enquanto o encéfalo, ao Sistema Nervoso Suprasegmentar. 
O Sistema Nervoso Autônomo está dividido em Sistema Nervoso Simpático e Sistema Nervoso Parassimpático, que se distinguem segundo critérios anatômicos, farmacológicos e fisiológicos.

As diferenças anatômicas e farmacológicas estão descritas na Tabela 01 abaixo.

Tabela 01 - Diferenças anatômicas e farmacológicas entre o sistema simpático e parassimpático. Adaptado de (MACHADO,2000).

\begin{tabular}{ccc}
\hline \hline CRITÉRIO & SIMPÁTICO & PARASSIMPÁTICO \\
\hline \hline Posição do neurônio & & Tronco encefálico e \\
pré-ganglionar & T1 a L2 & S2, S3 e S4 \\
Posição do neurônio & Longe da Víscera & Próximo ou dentro \\
pós-ganglionar & & da Víscera \\
\hline Tamanho das fibras pré-ganglionares & Curtas & Longas \\
\hline Tamanho das fibras pós-ganglionares & Longas & Curtas \\
\hline Classificação farmacológica das fibras pós- & (a maioria) & \\
ganglionares & adrenérgicas & Colinérgicas \\
\hline \hline
\end{tabular}

Fisiologicamente, o sistema simpático e parassimpático podem ser chamados de antagônicos em determinados órgãos. Entretanto essa afirmação não pode ser generalizada para todos os órgãos, pois em casos específicos a ação resultante é similar para os dois sistemas. 
Na Figura 13 podem ser observados os efeitos fisiológicos do sistema simpático e parassimpático nos diferentes órgãos. No caso dos brônquios, temos a constrição promovida pela ação parassimpática e a dilatação promovida pela ação simpática.

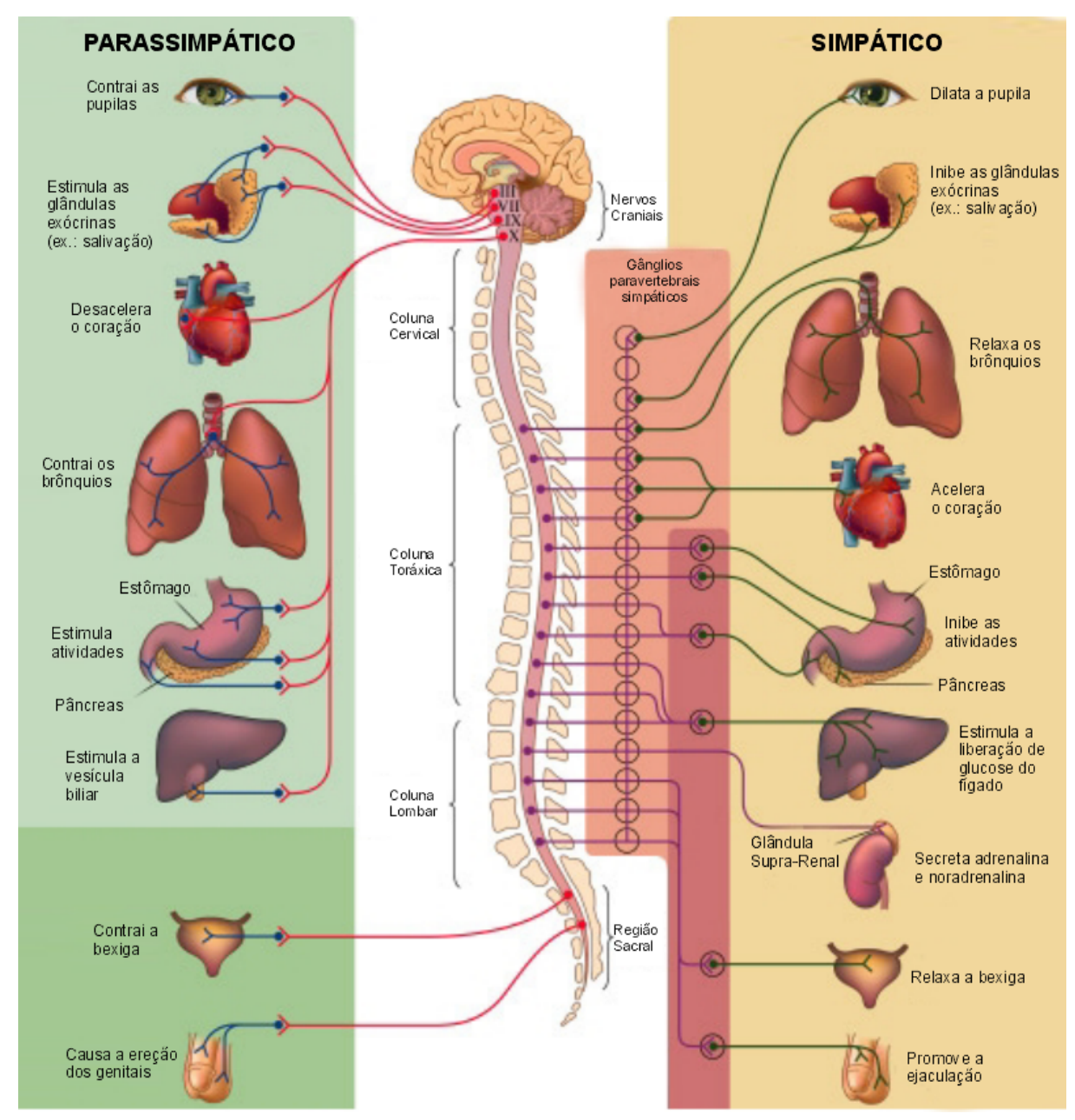

Figura 13 - Desenho esquemático mostrando de onde derivam os nervos que partem da medula e que regulam o sistema simpático e parassimpático. Adaptado (MATTHEWS, 2000). 


\section{CAPÍTULO 5}

\section{5 . ESTIMULAÇÃO ELÉTRICA NEUROMUSCULAR}

Lesões na medula espinhal atingem um grande número de pessoas e seu tratamento é extremamente caro, para os pacientes e para a sociedade, como mostra BOBET (1988). Ainda não existe cura para estas lesões e os indivíduos lesados dependem de tratamento através de fisioterapia e aparelhos que auxiliem na recuperação de possíveis funções perdidas.

Atualmente uma das técnicas que se tem mostrado muito eficiente como meio para a reabilitação dos movimentos dos membros afetados pela paralisia gerada por uma lesão medular é a Estimulação Elétrica Neuromuscular (EENM).

Esta técnica também é usada com o objetivo de reeducação muscular, prevenção de atrofias, redução temporária da espasticidade e redução das 
contraturas e edemas (QUEVEDO, 1997, CLIQUET, 1989), entretanto, o principal objetivo é aumentar suas funções motoras e subsequente independência (ANDREWS, 1997).

Por volta de 1750, obteve-se um dos primeiros relatos do uso da EENM, quando um violinista, que teve os músculos do braço paralisados devido a um acidente vascular cerebral (AVC), sendo este estimulado eletricamente com uma fonte estática. Após dois anos com este tratamento voltou a tocar violino (CLIQUET, 1990).

Em meados da década de 80, a EENM começou a ser pesquisada com o objetivo específico de reabilitar pessoas portadoras de lesões medulares ou outras disfunções do aparelho locomotor (MARSOLAIS AND KOBETIC, 1987; SCOTT et al, 1985).

Neste sentido, o primeiro paraplégico a caminhar em laboratório com a EENM ocorreu no ano de 1985, em Glasgow, Escócia (CLIQUET, 1988). Além de ser utilizado fisioterapicamente, a EENM pode ser aplicada na reabilitação, fazendo com que os movimentos de membros paralisados sejam restabelecidos (CLIQUET, 1988).

A EENM pode ser realizada usando métodos invasivos ou não-invasivos. Métodos invasivos não são muito interessantes do ponto de vista operacional, 
devido a uma série de inconveniências, como possíveis quebras dos eletrodos e infecções causadas pela abertura onde é feita a introdução dos mesmos.

Tratando-se da EENM feita com eletrodos de superfície, como é o caso da pesquisa realizada pela equipe do Professor Dr. Alberto Cliquet Jr, no Departamento de Ortopedia da Faculdade de Ciências Médicas, da UNICAMP (QUEVEDO, 1997), o sinal induz linhas de campo elétrico dentro do membro, de forma que os íons de sódio, localizados externamente à membrana do nervo motor, sofram um influxo súbito, gerando o potencial de ação. Esta perturbação se propaga então pelo axônio até a fenda sináptica e o músculo então é contraído (PEIXOTO, 1996).

Como visto, executando a estimulação em músculos e nervos específicos, de maneira controlada e cíclica, tomando certas precauções, é possível realizar a marcha em pacientes lesados medulares em laboratório.

Usando esta técnica, o paciente muda novamente sua condição, e passa a realizar de forma artificial, os movimentos que havia perdido com a lesão. Em muitos casos, o paciente está há vários anos em uma cadeira de rodas e, dentro de um curto período de tempo, passa a caminhar novamente com a ajuda da EENM. 
A idéia da utilização da EENM para restaurar a locomoção é recuperar o controle motor perdido. A maioria destas lesões causam danos acima do nível dos motoneurônios nos membros inferiores. Os músculos dos membros inferiores e seus motoneurônios normalmente permanecem intactos.

A princípio, a estimulação artificial destes músculos permite como descrito anteriormente, que o paciente fique em pé e até mesmo que ele caminhe. Neste sentido, o exercício físico é um elemento importante a ser considerado no estudo da reabilitação através dessa técnica, uma vez que a prática regular de atividade física tem efeitos benéficos nos diferentes sistemas.

Porém, não só os aspectos físicos devem ser levados em consideração no tratamento dos lesados medulares. É essencial para que esse processo ocorra satisfatoriamente que haja um entendimento entre as áreas de conhecimento e profissionais afins envolvidos direta ou indiretamente com o paciente, e que o tratamento seja dado ao sujeito como um todo e não somente à sua “deficiência”. Não é possível, portanto, obter resultados satisfatórios quando esse sujeito é visto de forma parcial ou seccionada. 


\subsection{Conceitos Básicos da Estimulação Elétrica Neuromuscular}

O estímulo deve ter certas características para promover uma contração. Essas características são amplitude e duração que devem ser iguais ou maiores que as condições fisiológicas para cada tecido.

A força da contração muscular pode ser modulada a partir da variação da carga elétrica total aplicada por unidade de tempo e o sinal é constituído basicamente por trens de pulsos.

A amplitude e a largura dos pulsos estão relacionados ao recrutamento das fibras musculares que serão excitadas e a freqüência dos pulsos controla a taxa de disparo das unidades motoras (NATHAN e TAVI, 1990).

As diferenças básicas dos limiares de excitação do músculo e do nervo devem ser compreendidas por serem importantes para a melhor utilização da técnica. Para estimular o músculo diretamente, deve-se aplicar uma carga maior do que a necessária para a excitação do nervo, uma vez que o músculo possui um limiar de excitabilidade maior. Este é um dos motivos pelo qual a EENM é aplicada primariamente ao nervo. 
Deflagrando o potencial de ação neural obtém-se um processo de contração muscular próximo ao fisiológico. Para tal, um dos pré-requisitos da EENM é que a inervação periférica esteja preservada (BENTON et. al., 1979).

A intensidade de corrente mínima para a excitação de uma fibra muscular é chamada de "reobase" e a "cronaxia" é a duração relacionada a intensidade igual ao dobro da "reobase". Os valores da "cronaxia" de um nervo estão entre 25 e 30 us e sua "reobase" está entre 22.5 e $24.5 \mathrm{~V}$, enquanto para o músculo estes valores estão respectivamente entre 12.5 e $13.8 \mu$ s e 52.5 e $56.25 \mathrm{~V}$ (BENTON et. al., 1979). Pode ser observada na Figura 14 uma curva de duração e amplitude do estímulo para um nervo e um músculo denervado.

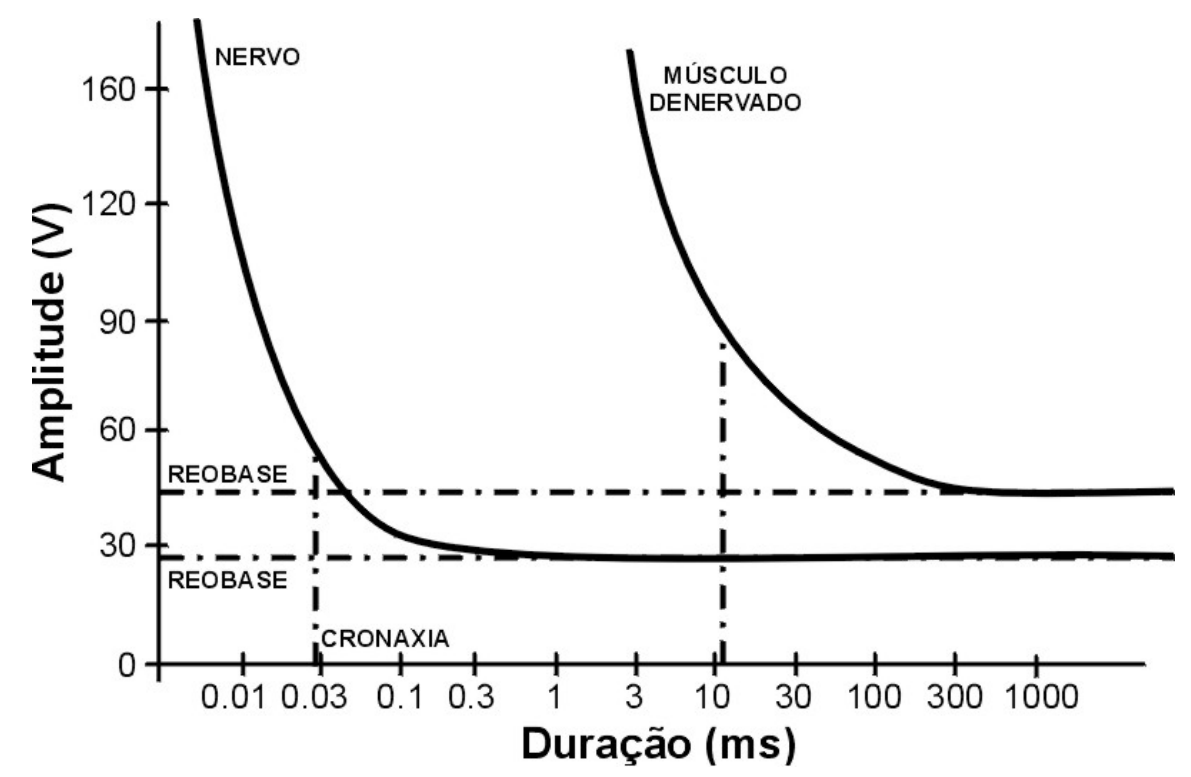

Figura 14 - Curva da Duração pela Amplitude do estímulo para um Nervo e para um Músculo Denervado (modelo de BENTON, 1979). 
Para estimular os músculos, é usada a inervação com a aplicação do estímulo na superfície da pele.

A fibra muscular pode ser considerada eletricamente refratária apenas durante a fase de elevação e próximo à fase de queda do potencial, neste período, a contração está iniciando. Porém, devido ao fato do mecanismo contrátil fisiológico não ter um período refratário, a estimulação repetida, antes do relaxamento, produz uma ativação adicional dos elementos contráteis e uma resposta que é somada à contração já presente.

Este fenômeno é conhecido como soma das contrações e a resposta máxima a estimulação de freqüência maior se chama contração tetânica ou tétano, isto é, um processo contrátil sem a fase de re-engatilhamento. Diante desse fenômeno, ressalta-se novamente a importância da modulação da freqüência do estímulo (DICARRIO \& SCHMIDTMANN, 1985; LACOURSE, 1985; WILHERE et. al., 1985).

Fisiologicamente, os motoneurônios pequenos são estimulados primeiro, mas na estimulação artificial o processo é inverso, os motoneurônios maiores são estimulados primeiro (SALMONS, 1985).

A diferença é que o recrutamento normal de fibras musculares é assíncrono, isto é, multiplexado no tempo pelo sistema nervoso central, enquanto que o 
recrutamento através da estimulação artificial é síncrono, isto é, com um grupo de fibras recrutadas simultaneamente. Este último gera problemas de fadiga do grupo muscular recrutado, perdendo por sua vez sua função e também diminuindo o tempo da sessão (WILHERE et. al., 1985; CLIQUET, 1988).

$\mathrm{Na}$ interface eletrodo-tecido, um fluxo de elétrons passa pelos fios, ligando o tecido com o estimulador (fonte externa) e uma corrente iônica atravessa o tecido. No anodo, ou eletrodo positivo, os íons positivos (mais sódio e pouco potássio) são repelidos na interface e os íons negativos (cloro) são atraídos. No catodo, ou eletrodo negativo, observa-se a atração dos íons positivos e a repulsão das cargas negativas, assim a corrente iônica atravessa o tecido com íons positivos movendo-se do anodo para o catodo (Figura 15). A despolarização da membrana celular acontece no catodo e por esse motivo ele é considerado como eletrodo ativo e consequentemente o anodo é o de referência. 


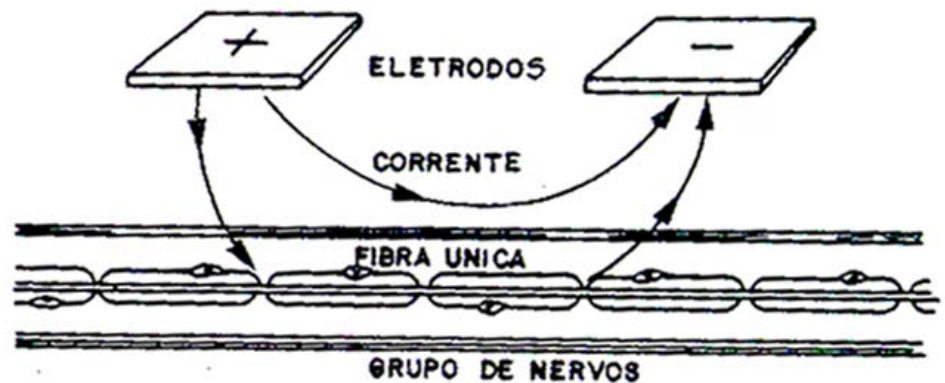

Figura 15 - Fluxos de Correntes entre eletrodos positivos e negativos (modelo de BENTON, 1979).

Para a realização da estimulação elétrica cutânea alguns fatores importantes devem ser levados em consideração: a impedância do tecido, o material, tamanho e orientação dos eletrodos, e o eletrólito de interface. A impedância da pele é de $1 \mathrm{k} \Omega$ (CLIQUET, 1988; CLIQUET, 1991).

O eletrodo ativo deve ser colocado sobre o nervo e sua área deve ser menor ou igual à área do eletrodo de referência, considerando que na interface a densidade de corrente é maior e decresce com a distância e com o tamanho do eletrodo. 


\section{METODOLOGIA}

\subsection{Delineamento do Estudo}

Para este estudo foram avaliados 5 pacientes paraplégicos, pré-selecionados, que já faziam uso da estimulação elétrica neuromuscular (EENM) e que sofreram a lesão no tempo mínimo de um ano. E um voluntário sedentário, denominado Padrão. Após serem devidamente orientados os voluntários assinaram o termo de consentimento (ANEXO A).

Este projeto não impôs riscos à saúde dos voluntários, uma vez que os testes foram não-invasivos, tendo o tempo máximo de exercício controlado pelo próprio paciente e a freqüência cardíaca monitorada em tempo real. Sendo aprovado pela Comissão de Ética da Faculdades de Ciências Médicas da Universidade Estadual de Campinas. 


\subsection{Critérios de Exclusão e de Suspensão do Projeto}

Para garantir a fidedignidade e reprodutibilidade deste estudo, foram usados os seguintes critérios para exclusão dos voluntários:

$\checkmark$ Saída espontânea do voluntário;

$\checkmark$ Problemas de Saúde

$\checkmark$ Faltas consecutivas ao Programa.

$\checkmark$ Problemas de Adaptação aos Testes;

$\checkmark$ Diminuição do número de participantes para menos de 5 .

\subsection{Gasto Energético}

Esta variável foi observada através do consumo do oxigênio, de forma direta e não-invasiva, através do uso do Analisador de Gases Vmax, modelo 29c da marca SensorMedics.

Para essa variável o protocolo proposto foi definido após estudo piloto, no qual foi verificada a dificuldade para a realização de um teste de esforço crescente, uma vez que os pacientes, mesmo treinados, apresentavam fadiga precoce. 
As avaliações foram realizadas no Ambulatório de Ortopedia do Hospital das Clínicas da Universidade Estadual de Campinas, a uma temperatura ambiente média de $25{ }^{\circ} \mathrm{C}$.

O paciente foi devidamente instruído sobre como seriam os testes e depois preparado para a EENM, com a colocação dos eletrodos, bem como pesados três vezes sendo a média destes valores utilizada. Os dados do paciente foram anotados no analisador, o qual foi calibrado antes de cada teste, para as variáveis volume, fluxo e gases.

Os dados referentes ao Repouso foram coletados em um período de 10 minutos, com o paciente sentado. Imediatamente após o término do teste em repouso, isto é, sem interrupção, o teste de marcha induzida começou. Os dados referentes ao Exercício foram coletados em um tempo de no mínimo 5 (NENE, 1990) e máxima de 10 minutos, com a distância percorrida observada.

Quando o paciente sinalizava que não conseguiria continuar a marcha, iniciavase, sem interrupção, a avaliação da Recuperação por um período de 10 minutos.

Após o término do teste os materiais utilizados foram devidamente lavados e esterilizados conforme a recomendação do equipamento. 
Para o cálculo do gasto energético foram utilizadas as seguintes fórmulas: (NENE, 1990)

$\checkmark$ Velocidade $\left(\mathrm{ms}^{-1}\right)=$ Distância Percorrida em 5 minutos $(\mathrm{m}) /(5 \times 60)$

$\checkmark$ Energia Consumida $\left(\mathrm{Jkg}^{-1} \mathrm{~s}^{-1}\right)=\left[\left(\right.\right.$ Vol. Min. $\mathrm{VO}_{2}\left(\mathrm{ml} \mathrm{min}{ }^{-1}\right) /($ Peso $(\mathrm{kg}) \times 60] \mathrm{x}$ K.

$\checkmark$ Gasto Energético $\left(\mathrm{Jkg}^{-1} \mathrm{~m}^{-1}\right)=\left(\right.$ Vol.min. $\left.\mathrm{VO}_{2}\left(\mathrm{ml} \mathrm{min} \mathrm{m}^{-1}\right)\right] /$ Vel. $\left(\mathrm{ms}^{-1}\right) \mathrm{x}$ Peso $(\mathrm{kg})] \times \mathrm{K}$

Onde, $\mathrm{K}=20.19 \mathrm{~J} \mathrm{ml}^{-1}$;

$1 \mathrm{ml} \mathrm{O} 2=4.825 \mathrm{cal}^{6}$;

$1 \mathrm{cal}=4.184 \mathrm{~J}^{1}$

\subsection{Materiais}

\subsubsection{Estimulador Elétrico Neuromuscular (EENM)}

Os parâmetros da EENM (Figura 16) utilizados foram:

- Tipo de onda: monofásica bipolar

- Ciclo de Trabalho: 4/12

- Freqüência : $25 \mathrm{~Hz}$ 
- Duração de pulso: $300 \mu \mathrm{s}$

- Amplitude: 0 a $150 \mathrm{~V}(1 \mathrm{k} \Omega)$.

Os eletrodos foram fixados da seguinte forma: 2 no quadríceps (reto femural) e 1 no nervo fibular.

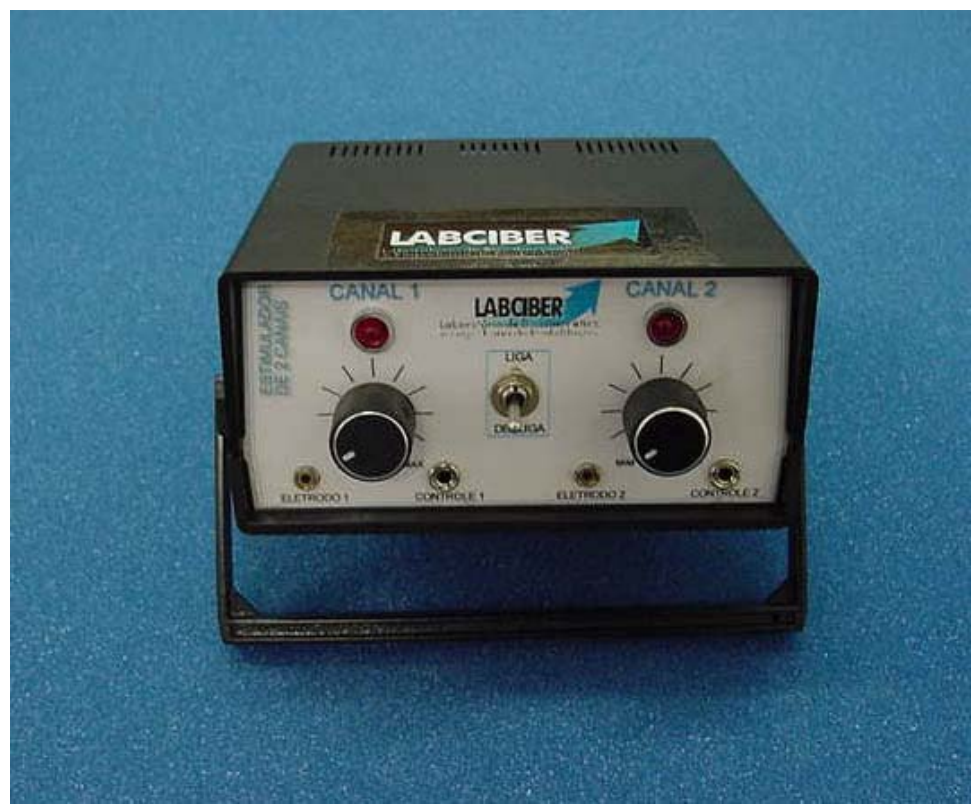

Figura 16 - Aparelho para Estimulação Elétrica Neuromuscular (2 canais). 


\subsubsection{Analisador de Gases}

Nas Figuras 17 e 18 observa-se o Analisador de Gases Vmax, modelo 29c da marca SensorMedics, utilizado para a medida direta do consumo de oxigênio e seus respectivos materiais auxiliares.

Esse equipamento possui três etapas de calibração, respectivamente, para volume, para fluxo e para concentração de gases $\left(\mathrm{CO}_{2}\right.$ e $\left.\mathrm{O}_{2}\right)$. Na primeira é utilizada uma seringa de 3 litros conectada ao sensor de fluxo, mantendo-se o fluxo constante o volume é calibrado. Na segunda, a mesma seringa é utilizada, mas o fluxo deve variar nas faixas de -1 e 1, -3 e 3 e ultrapassando esta última faixa. É o equipamento que indica se a calibração está correta.

Para calibrar os sensores de gases, são utilizadas as seguintes misturas: no Cilindro 1 temos $\mathrm{O}_{2}$ 16\% ( \pm 0.02 absoluto), $\mathrm{CO}_{2} 4 \%$ ( \pm 0.02 absoluto) e Balanço de Nitrogênio. No Cilindro 2, $\mathrm{O}_{2} 26 \%$ ( \pm 0.02 absoluto) e Balanço de Nitrogênio.

A taxa de coleta de amostras é de $500 \mathrm{ml} / \mathrm{min}$ e o tempo de resposta é menor que 150 ms. As amostras de ar inspirado e expirado são coletadas por vias diferentes. 


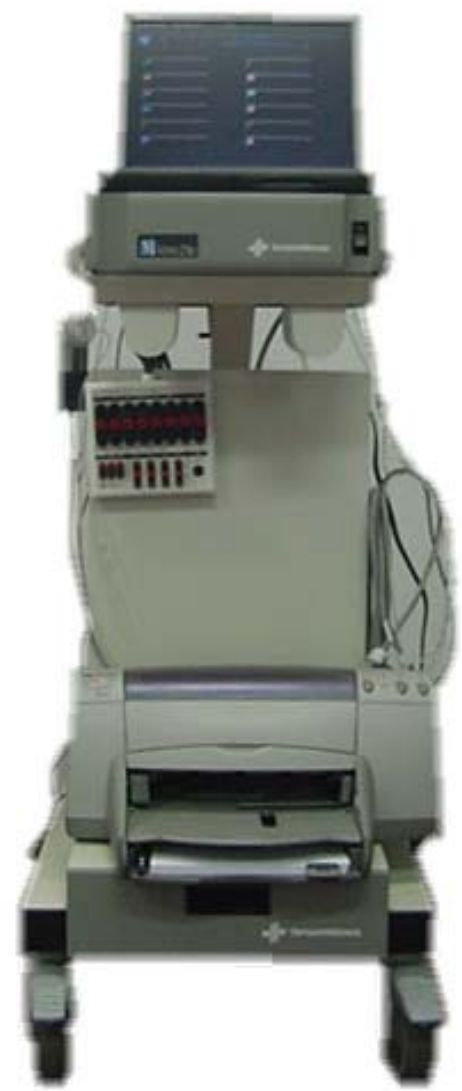

Figura 17 - Analisador de Gases Vmax, modelo 29c da marca SensorMedics.

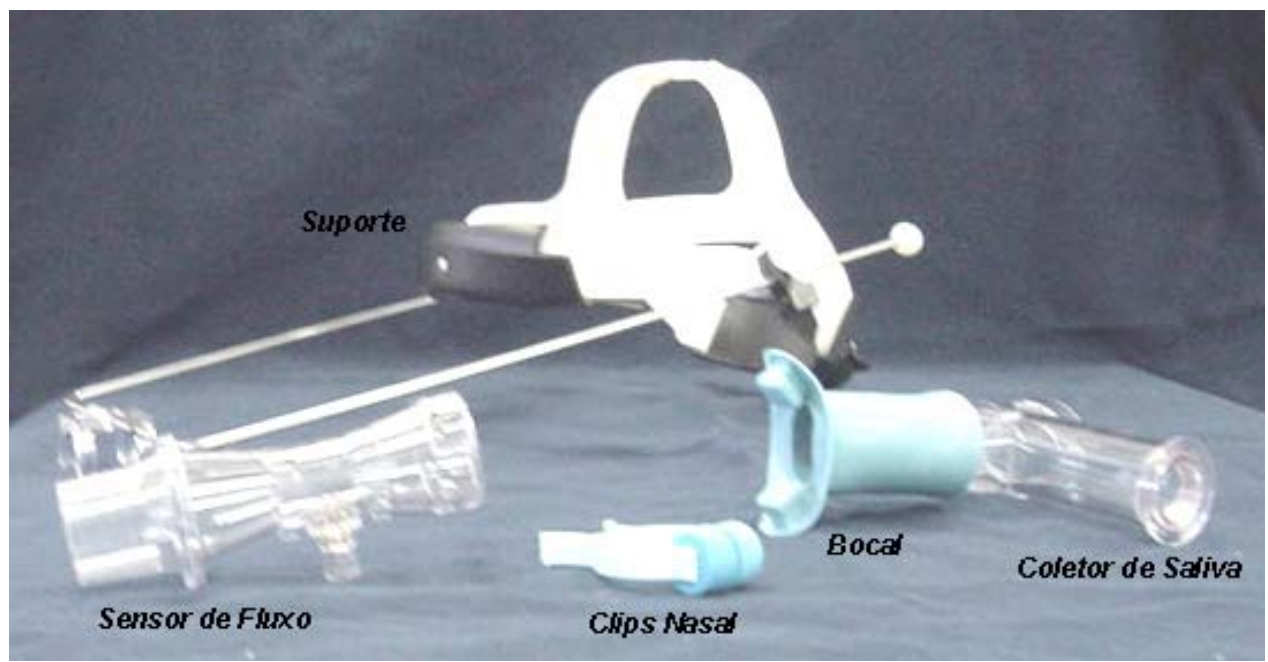

Figura 18 - Materiais do Vmax. 


\section{CAPÍTULO 7}

\section{RESULTADOS}

A seguir tem-se os resultados do presente estudo, tratados estatisticamente pelo método ANOVA ONE WAY.

TABELA 02 - Descrição dos Voluntários

\begin{tabular}{|c|c|c|c|c|}
\hline Voluntário & Nível de Lesão & Idade & Sexo & Peso \\
\hline | & T7 & 28 & $\mathrm{M}$ & 70 \\
\hline II & T9 & 28 & $M$ & 86 \\
\hline III & T9 & 33 & $M$ & 81 \\
\hline IV & T4/T5 & 26 & $M$ & 50 \\
\hline $\mathbf{V}$ & T4-T8 & 34 & $\mathrm{~F}$ & 43 \\
\hline Padrão & - & 25 & $M$ & 75 \\
\hline
\end{tabular}

TABELA 03 - Variáveis Observadas durante a Marcha

\begin{tabular}{ccccc}
\hline Voluntário & $\begin{array}{c}\text { Distância } \\
\text { Total }(\mathbf{m})\end{array}$ & $\begin{array}{c}\text { Velocidade } \\
(\mathbf{m} / \mathbf{m i n})\end{array}$ & $\begin{array}{c}\text { Tempo } \\
\text { Exercício } \\
(\mathbf{m i n})\end{array}$ & $\begin{array}{c}\text { Finalizou o Exercício } \\
\text { devido: }\end{array}$ \\
\hline \hline I & 54 & 7,2 & 7,5 & Dor nos ombros \\
& & & & Falta de resposta à EENM no \\
II & 2,5 & 1,0 & 2,5 & quadríceps direito \\
& & & 4,0 & Falta de resposta à EENM \\
III & 27 & 6,75 & 10,0 & Tempo \\
IV & 16,6 & 1,66 & 12,00 & Tempo \\
V & 81 & 6,75 & 6,0 & Desconforto \\
Padrão & 144 & 24,0 & & \\
\hline
\end{tabular}


TABELA 04 - Variáveis observadas durante o período de Repouso (10 min).

\begin{tabular}{ccccc} 
Voluntário & $\begin{array}{c}\mathrm{VO}_{2} \\
(\mathrm{mI} / \mathrm{Kg} / \mathrm{min})\end{array}$ & $\begin{array}{c}\mathrm{VCO}_{2} \\
(\mathrm{~L} / \mathrm{min})\end{array}$ & $\begin{array}{c}\mathrm{VO}_{2} \\
(\mathrm{~L} / \mathrm{min})\end{array}$ & $\mathrm{QR}$ \\
\hline I & $3,71 \pm 0,81$ & $0,218 \pm 0,01$ & $0,260 \pm 0,06$ & $0,78 \pm 0,2$ \\
II & $2,97 \pm 0,44^{*}$ & $0,189 \pm 0,03$ & $0,259 \pm 0,04$ & $0,73 \pm 0,02$ \\
III & $4,11 \pm 0,73^{\vee}$ & $0,251 \pm 0,06$ & $0,336 \pm 0,06$ & $0,74 \pm 0,06$ \\
IV & $5,99 \pm 1,45^{*}+{ }^{\vee} \varnothing \nabla$ & $0,239 \pm 0,07$ & $0,302 \pm 0,07$ & $0,79 \pm 0,07$ \\
V & $4,40 \pm 1,2^{\vee}$ & $0,130 \pm 0,05$ & $0,184 \pm 0,05$ & $0,71 \pm 0,04$ \\
Padrão & $4,38 \pm 0,38$ & $0,226 \pm 0,02$ & $0,329 \pm 0,03$ & $0,69 \pm 0,02$ \\
\hline
\end{tabular}

* Diferença significativa quando comparado aos valores Padrão, $p<0,001$.

+ Voluntário I x Voluntário II, $p<0,05$

- Voluntário I x Voluntário IV , $p<0,001$

$\checkmark$ Voluntário II x Voluntários III, IV e V, $p<0,001$

${ }^{\varnothing}$ Voluntário III x IV, p<0,001

${ }^{\nabla}$ Voluntário $V \times I V, p<0,001$ 
TABELA 05- Variáveis observadas durante o período de Exercício.

\begin{tabular}{|c|c|c|c|c|}
\hline Voluntário & $\begin{array}{c}\mathrm{VO}_{2} \\
(\mathrm{ml} / \mathrm{Kg} / \mathrm{min})\end{array}$ & $\begin{array}{c}\mathrm{VCO}_{2} \\
(\mathrm{~L} / \mathrm{min})\end{array}$ & $\begin{array}{c}\mathrm{VO}_{2} \\
(\mathrm{~L} / \mathrm{min})\end{array}$ & QR \\
\hline I & $14,95 \pm 3,2^{*} \bullet$ & $0,763 \pm 0,45$ & $1,05 \pm 0,23$ & $0,72 \pm 0,21$ \\
\hline II & $10,11 \pm 5,7^{\nabla}$ & $0,809 \pm 0,52$ & $0,870 \pm 0,49$ & $0,89 \pm 0,12$ \\
\hline III & $14,68 \pm 5,1 \bullet^{* *}$ & $1,02 \pm 0,24$ & $1,31 \pm 0,26$ & $0,77 \pm 0,08$ \\
\hline IV & $19,09 \pm 3,8^{*}+{ }^{\downarrow \varnothing \nabla}$ & $0,797 \pm 0,11$ & $0,975 \pm 0,14$ & $0,83 \pm 0,12$ \\
\hline $\mathbf{V}$ & $9,35 \pm 1,41$ & $0,300 \pm 0,04$ & $0,403 \pm 0,06$ & $0,79 \pm 0,06$ \\
\hline Padrão & $10,0 \pm 1,2$ & $0,431 \pm 0,05$ & $0,749 \pm 0,09$ & $0,58 \pm 0,03$ \\
\hline \multicolumn{5}{|c|}{$\begin{array}{l}\text { * Padrão x I e IV p<0,001. } \\
\text { ** Padrão x III p<0,01. } \\
\text { + Voluntário I x IV e V, p<0,001 } \\
\text { V Voluntário II x IV , p<0,001 } \\
\text { • Voluntário II x I e III p<0,05 } \\
\text { ø Voluntário III x IV, p<0,01 } \\
{ }^{\nabla} \text { Voluntário V x II e IV, p<0,001 }\end{array}$} \\
\hline
\end{tabular}


TABELA 06- Variáveis observadas durante o período de Recuperação (10 min).

\begin{tabular}{|c|c|c|c|c|}
\hline Voluntário & $\begin{array}{c}\mathrm{VO}_{2} \\
(\mathrm{ml} / \mathrm{Kg} / \mathrm{min})\end{array}$ & $\begin{array}{c}\mathrm{VCO}_{2} \\
(\mathrm{~L} / \mathrm{min})\end{array}$ & $\begin{array}{c}\mathrm{VO}_{2} \\
(\mathrm{~L} / \mathrm{min})\end{array}$ & QR \\
\hline 1 & $6,54 \pm 3,4$ & $0,438 \pm 0,63$ & $0,458 \pm 0,24$ & $0,93 \pm 0,10$ \\
\hline II & $4,78 \pm 2,45+$ & $0,420 \pm 0,29$ & $0,412 \pm 0,21$ & $0,96 \pm 0,16$ \\
\hline III & $6,90 \pm 3,73^{\vee}$ & $0,532 \pm 0,31$ & $0,520 \pm 0,25$ & $0,98 \pm 0,14$ \\
\hline IV & $7,83 \pm 3,2^{* \sqrt{ }}$ & $0,327 \pm 0,13$ & $0,371 \pm 0,13$ & $0,87 \pm 0,06$ \\
\hline V & $3,16 \pm 3,5$ & $0,213 \pm 0,13$ & $0,265 \pm 0,15$ & $0,80 \pm 0,04$ \\
\hline Padrão & $4,95 \pm 2,17$ & $0,258 \pm 0,10$ & $0,371 \pm 0,16$ & $0,70 \pm 0,02$ \\
\hline \multicolumn{5}{|c|}{ 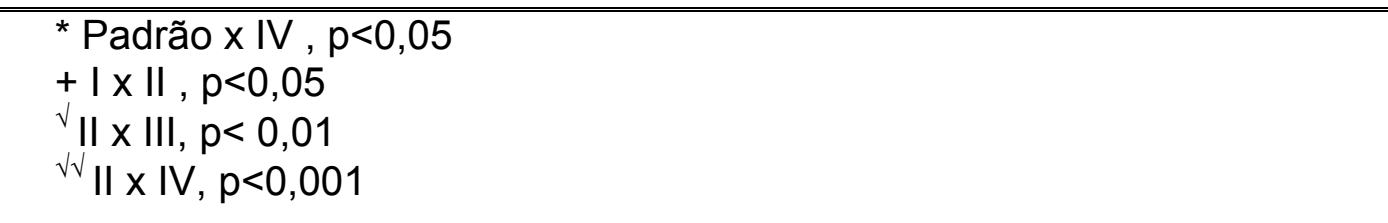 } \\
\hline
\end{tabular}

TABELA 07- Energia Consumida (J/Kgs)

\section{Energia Consumida (J/Kgs)}

\begin{tabular}{ccccccc} 
& I & II & III & IV & V & Padrão \\
\hline Repouso & $1,25 \pm 0,27^{* *}$ & $1,01 \pm 0,15^{*}$ & $1,38 \pm 0,24$ & $2,01 \pm 0,49^{*}$ & $1,48 \pm 0,42^{*}$ & $1,15 \pm 0,13$ \\
Exercício & $5,03 \pm 1,09^{*}$ & $3,4 \pm 1,9$ & $5,01 \pm 1,6+$ & $6,4 \pm 1,27^{*}$ & $3,15 \pm 0,47$ & $3,45 \pm 0,41$ \\
\hline \hline
\end{tabular}

${ }^{*}$ I, II, IV e V x Padrão, p<0,001.

** I x Padrão, $p<0,05$.

+ III x Padrão, $p<0,01$. 
TABELA 08- Comparação entre estudos - Energia Consumida (J/Kgs) Adaptado de NENE (1990).

\begin{tabular}{lc}
\hline \hline $\begin{array}{l}\text { Estudo } \\
\text { Nível de Lesão } \\
\text { Número de Sujeitos } \\
\text { Órtese }\end{array}$ & $\begin{array}{c}\text { Energia Consumida } \\
\text { (J/Kgs) }\end{array}$ \\
\hline \hline CLINKINGBEARD, (1964) & \\
T4- cauda equina & 3,29 \\
8 & \\
KAFO bilateral & \\
HUANG, (1979) & \\
T4--T12 & 3,77 \\
8 & \\
KAFO bilateral & \\
MERKEL, (1984) & \\
C7-T12 & \\
8 & 4,67 \\
KAFO bilateral com muletas & \\
NENE, (1989) & \\
T4-T9 & \\
10 & 3,10 \\
Parawalker & \\
PRESENTE ESTUDO & \\
T4-T9 & \\
5 & \\
EENM & 4,60 \\
\hline \hline
\end{tabular}


TABELA 09 - Gasto Energético (J/Kgm)

\begin{tabular}{|c|c|c|c|c|c|}
\hline \multicolumn{6}{|c|}{ "Gasto Energético (J/Kgm) } \\
\hline $\mathbf{I}$ & II & III & IV & $\mathbf{V}$ & Padrão \\
\hline $41,93 \pm 16,37$ & $204,15 \pm 115,5^{*}+\varnothing \nabla$ & $48,31 \pm 9,45$ & $232,17 \pm 46,12^{*}+\varnothing \nabla$ & $28,01 \pm 4,23$ & $8,6 \pm 1,02$ \\
\hline $\begin{array}{l}{ }^{*} \text { Padr } \\
+ \text { Volunt } \\
\varnothing \text { Volun } \\
{ }^{\nabla} \text { Volur }\end{array}$ & $\begin{array}{l}\text { ão x II e IV, } p<0,001 \\
\text { ário I x II e IV, } p<0,001 \\
\text { tário III x II e IV, } p<0,001 \\
\text { ntário V x II e IV, } p<0\end{array}$ & 0.001. & & & \\
\hline
\end{tabular}

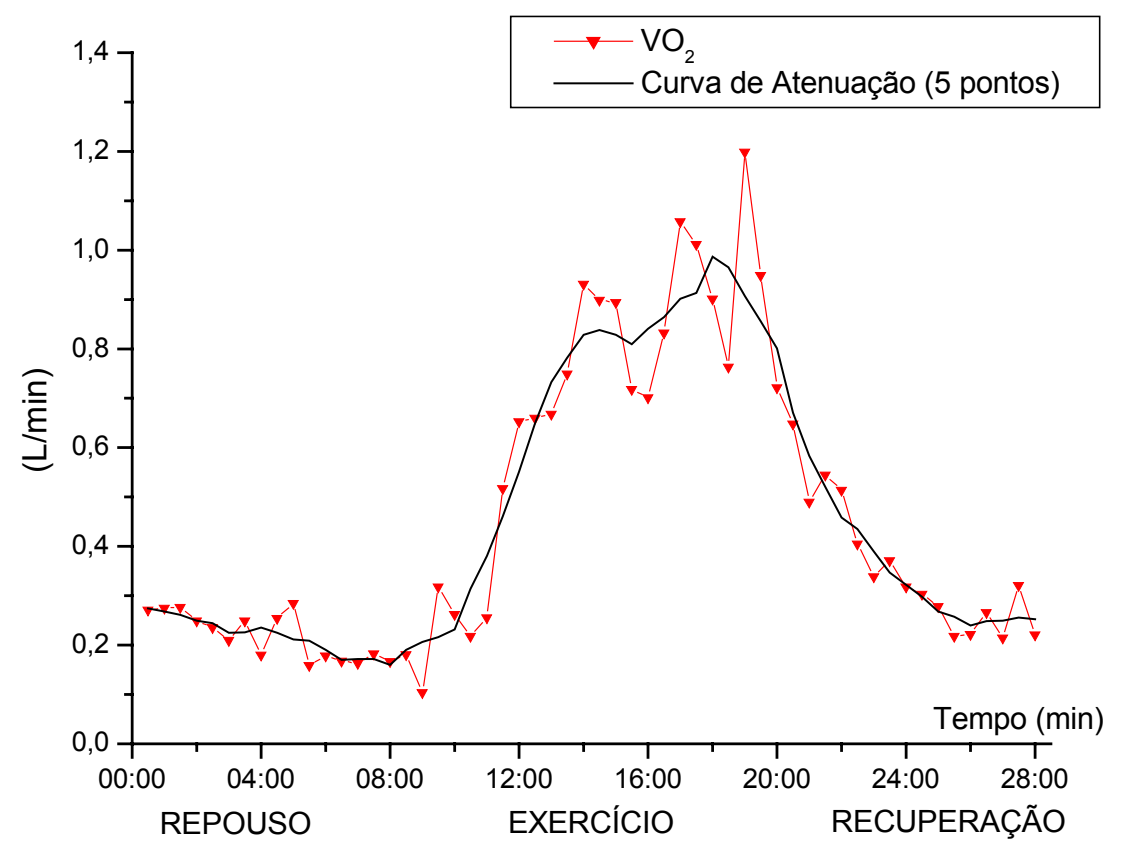

Figura 19 -Consumo de Oxigênio $\left(\mathrm{VO}_{2}\right)$ do Voluntário I. 


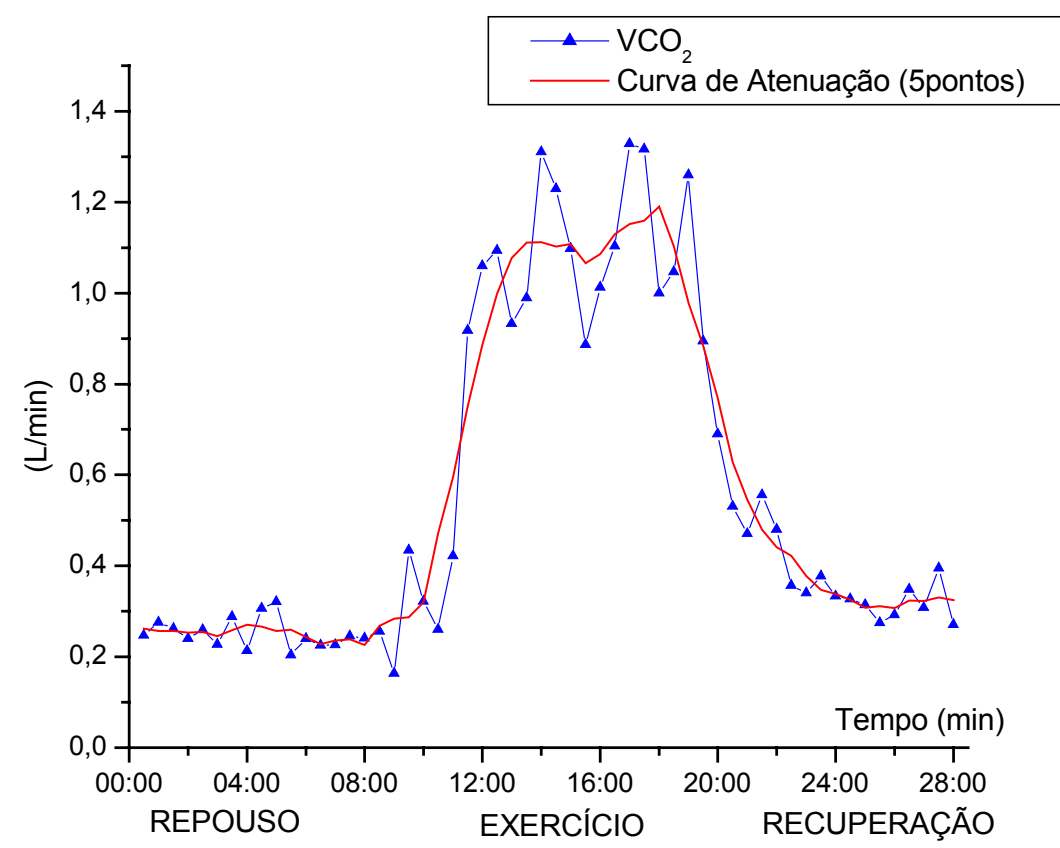

Figura 20 - Produção de Dióxido de Carbono $\left(\mathrm{VCO}_{2}\right)$ do Voluntário I.

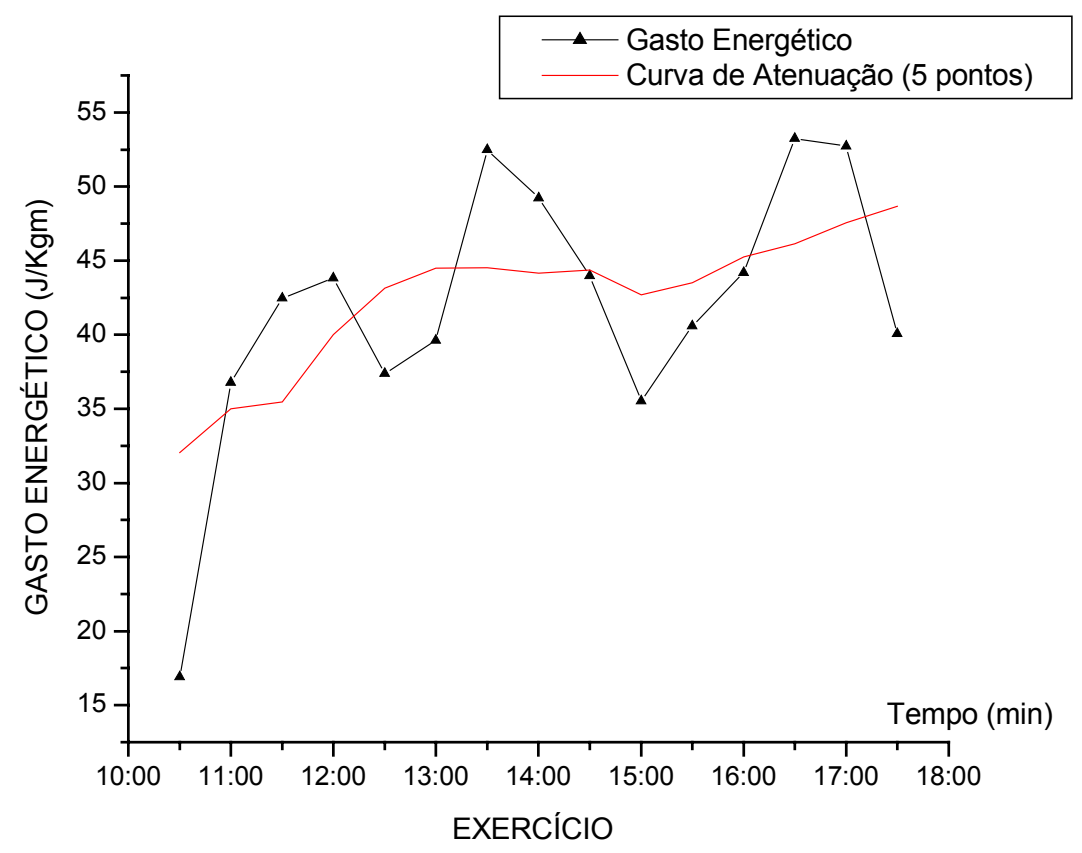

Figura 21 - Gasto Energético do Voluntário I. 


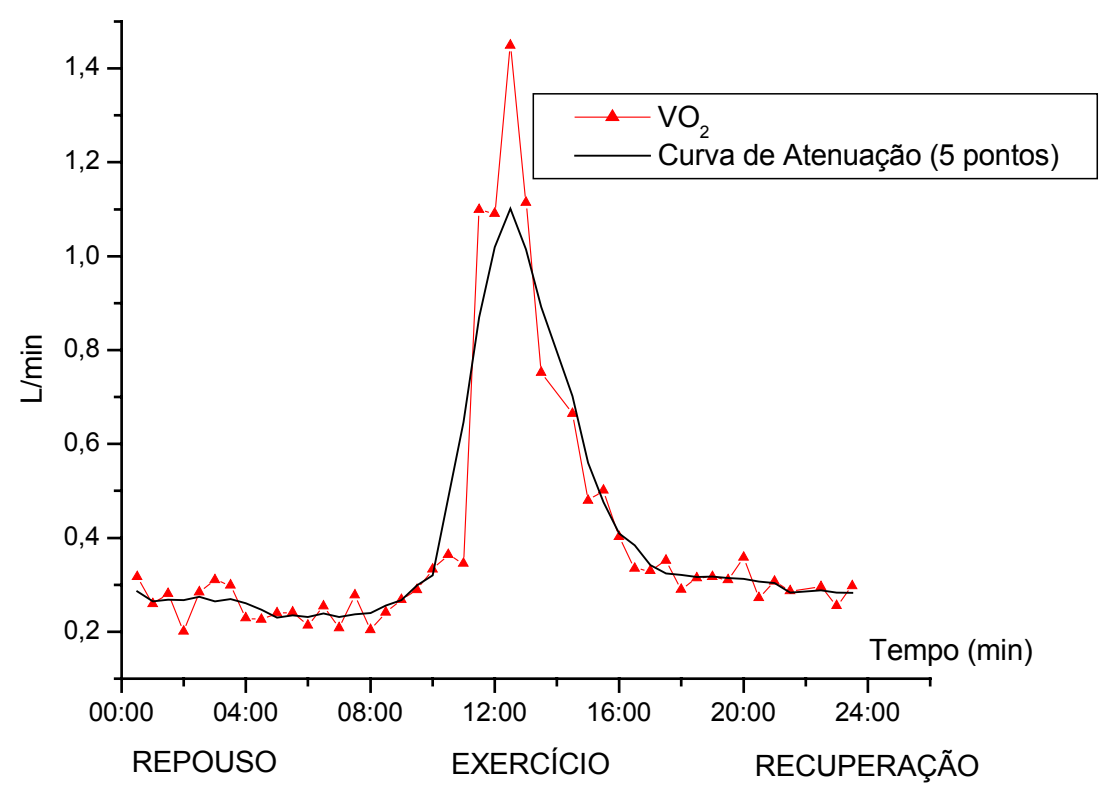

Figura 22 - Consumo de Oxigênio $\left(\mathrm{VO}_{2}\right)$ do Voluntário II.

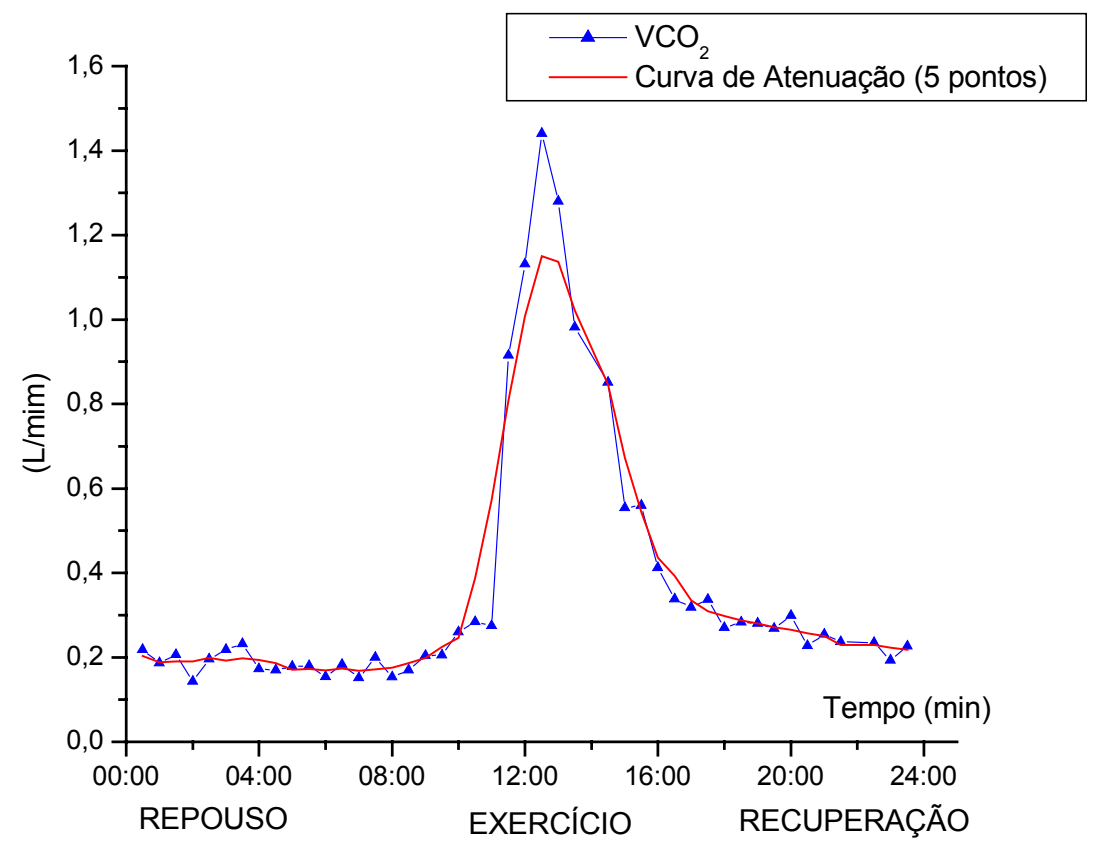

Figura 23 - Produção de Dióxido de Carbono $\left(\mathrm{VCO}_{2}\right)$ do Voluntário II. 


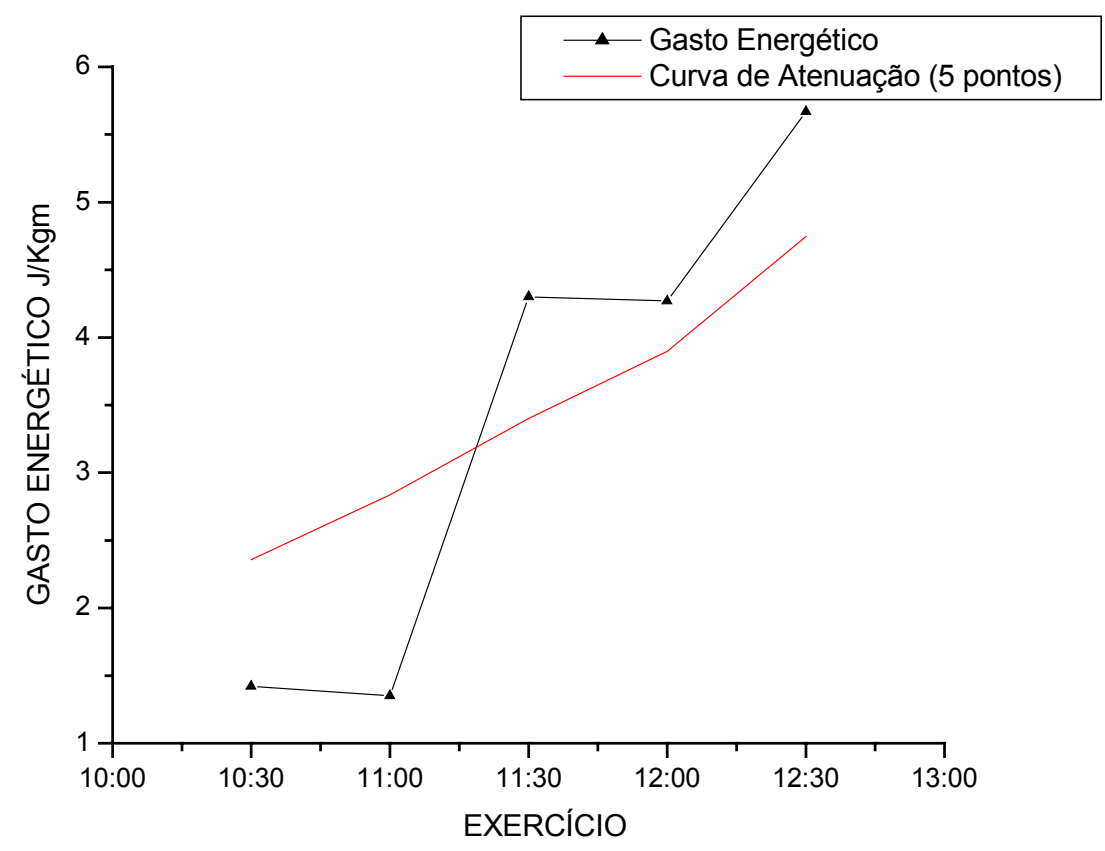

Figura 24 - Gasto Energético do Voluntário II. 


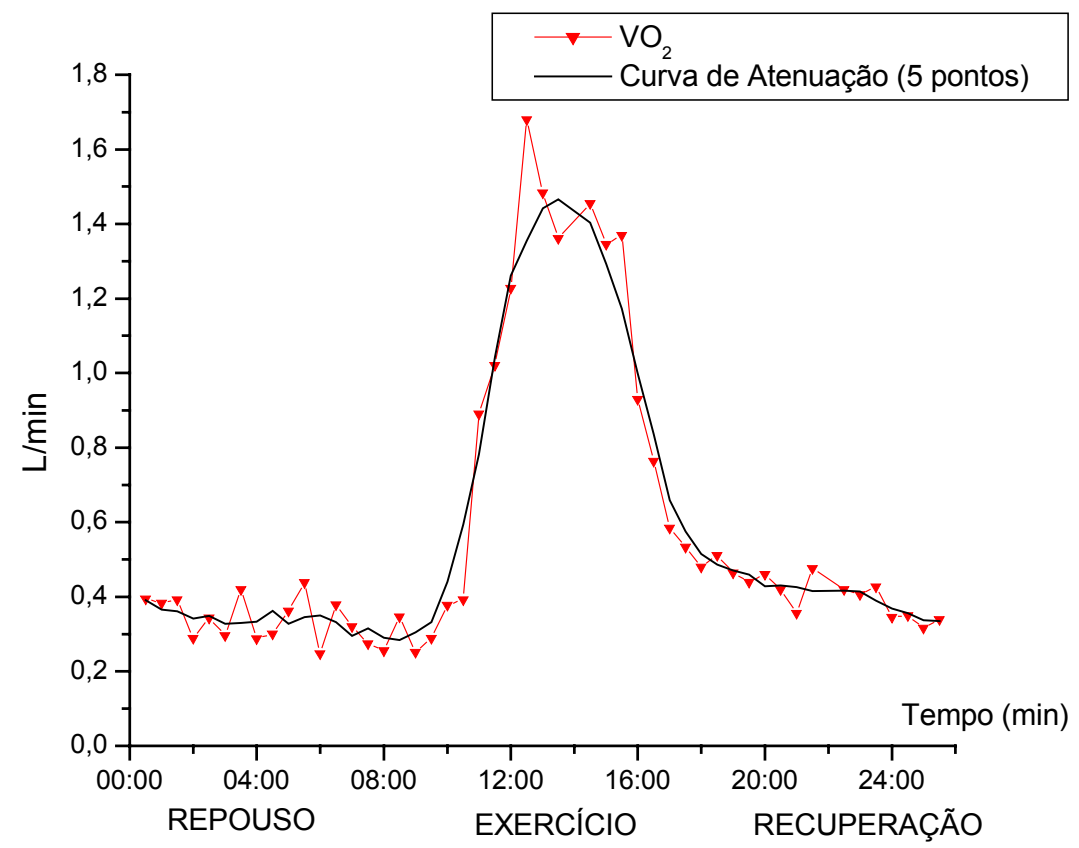

Figura 25 -Consumo de Oxigênio $\left(\mathrm{VO}_{2}\right)$ do Voluntário III.

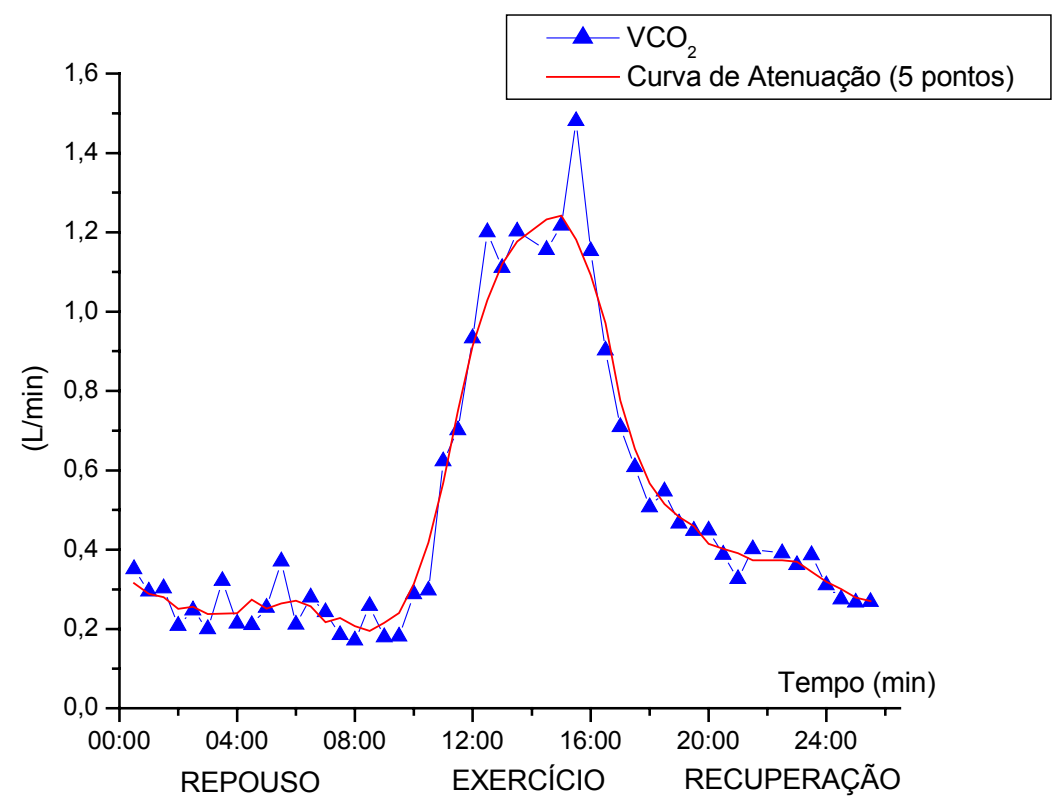

Figura 26 - Produção de Dióxido de Carbono $\left(\mathrm{VCO}_{2}\right)$ Voluntário III. 


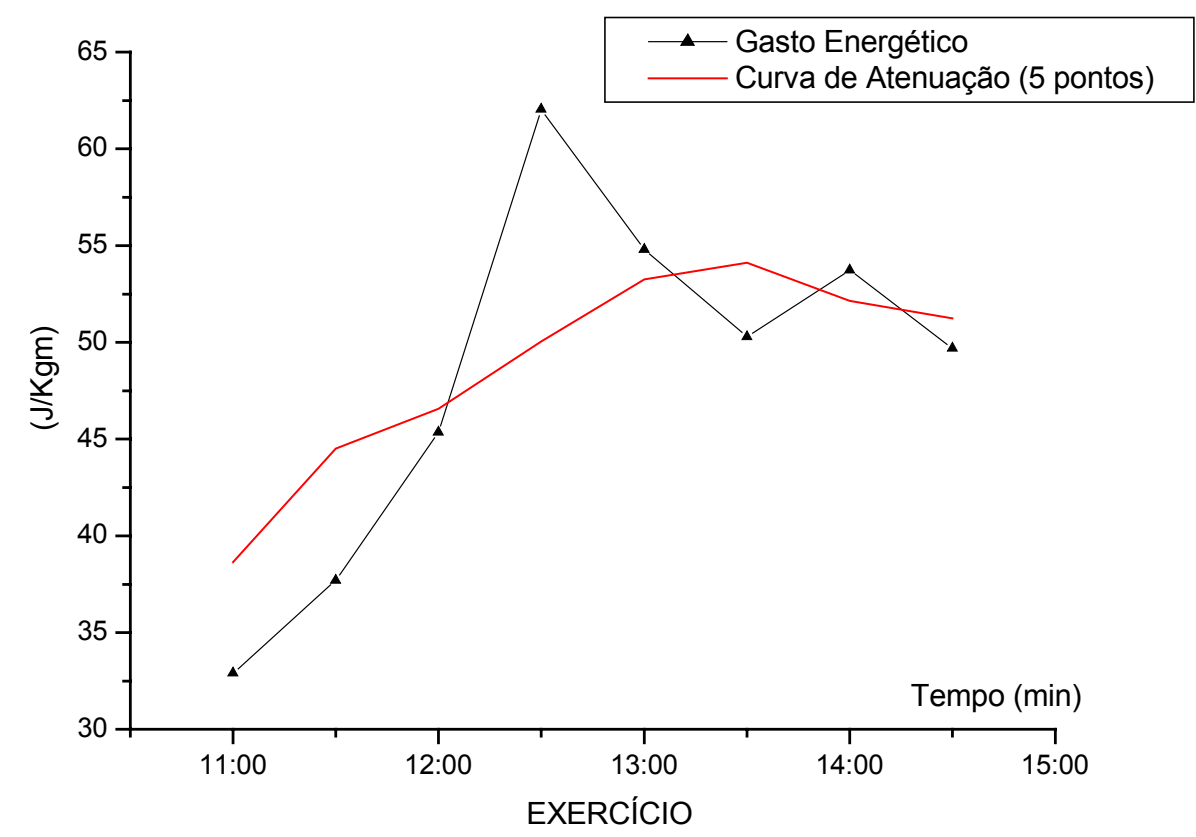

Figura 27 - Gasto Energético do Voluntário III.

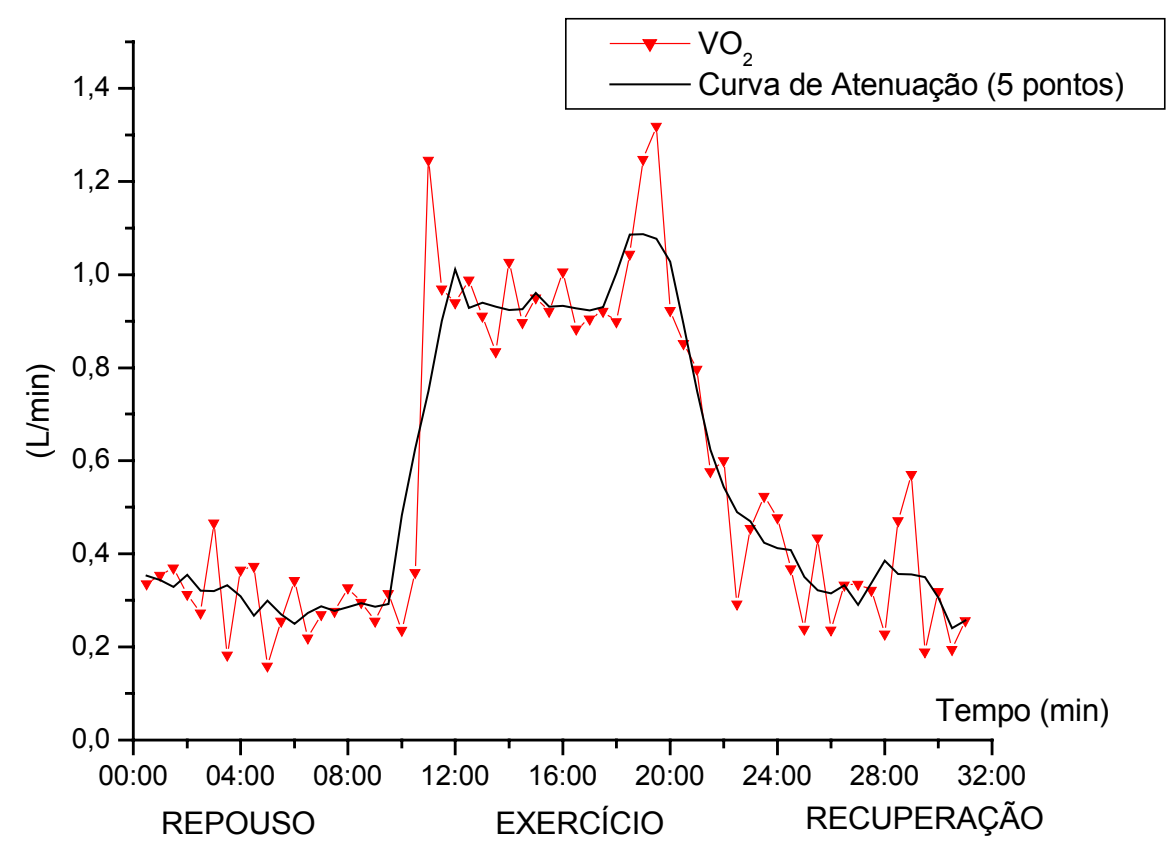

Figura 28 - Consumo de Oxigênio $\left(\mathrm{VO}_{2}\right)$ do Voluntário IV. 


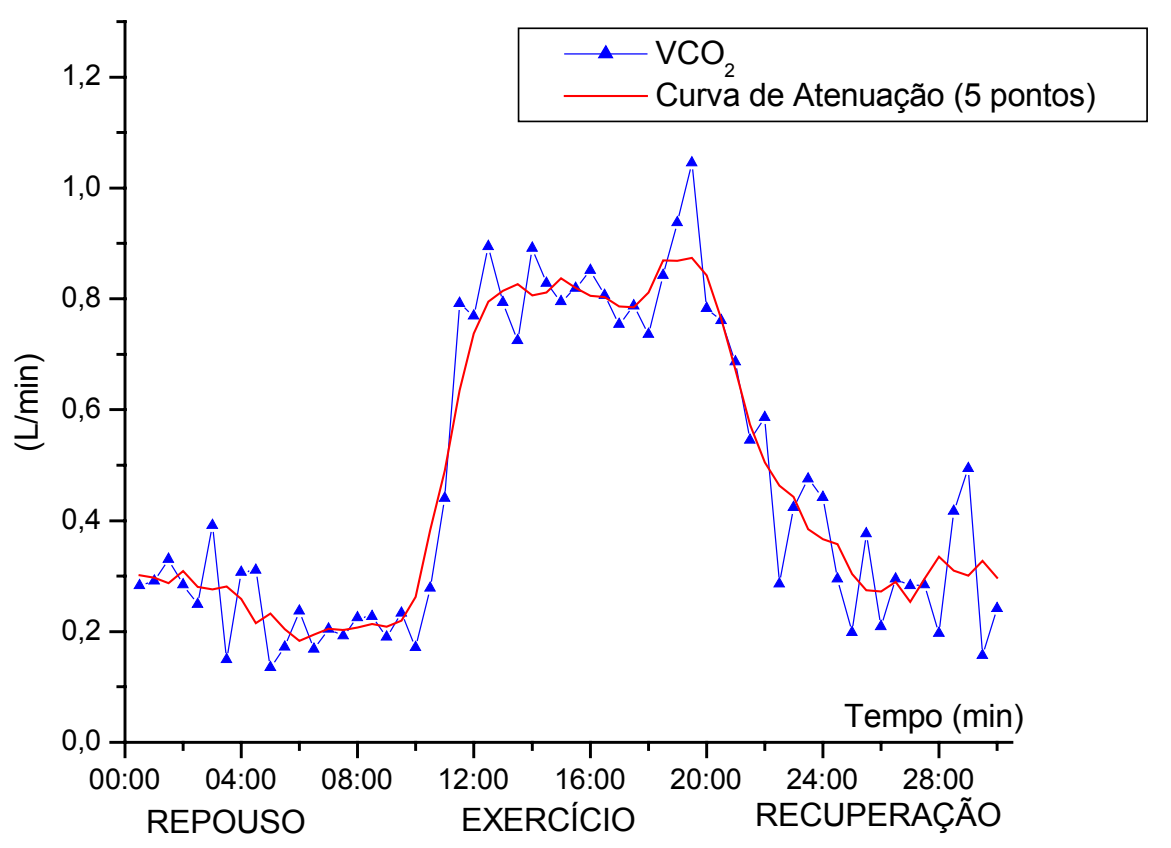

Figura 29 - Produção de Dióxido de Carbono $\left(\mathrm{VCO}_{2}\right)$ do Voluntário IV.

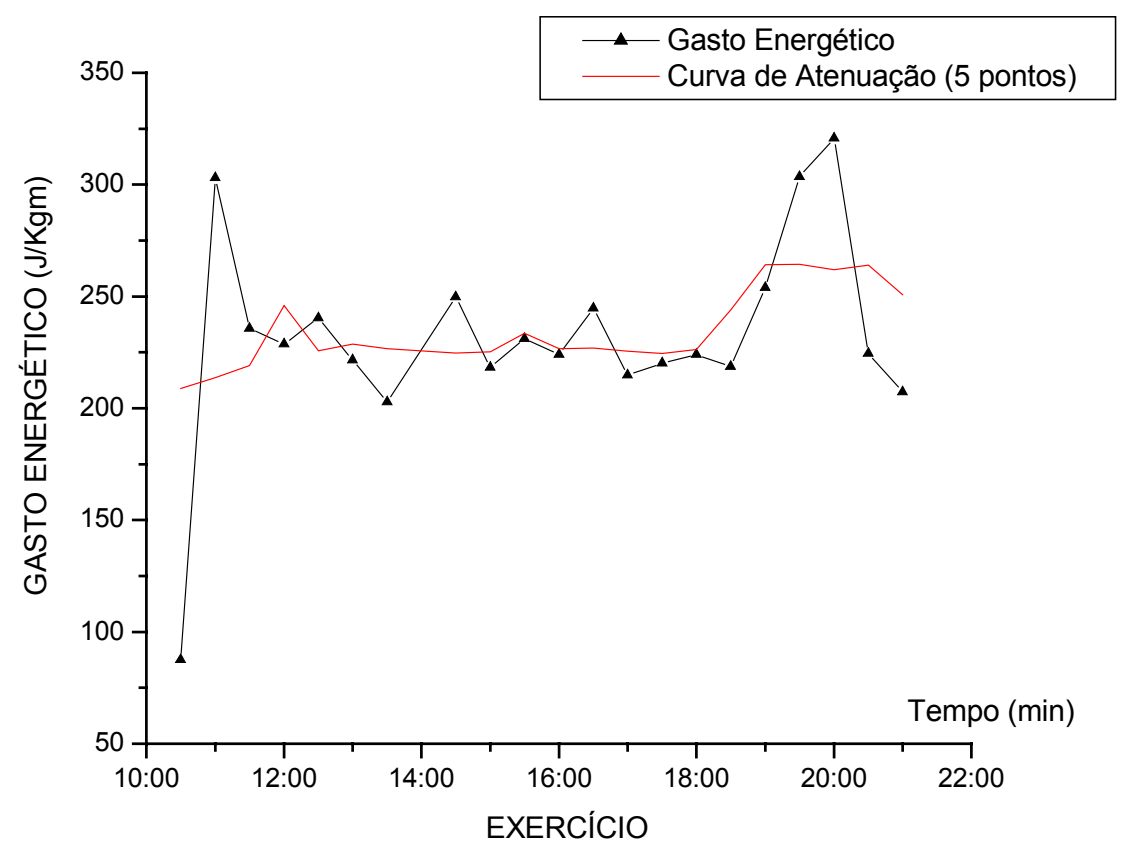

Figura 30 - Gasto Energético do Voluntário IV. 


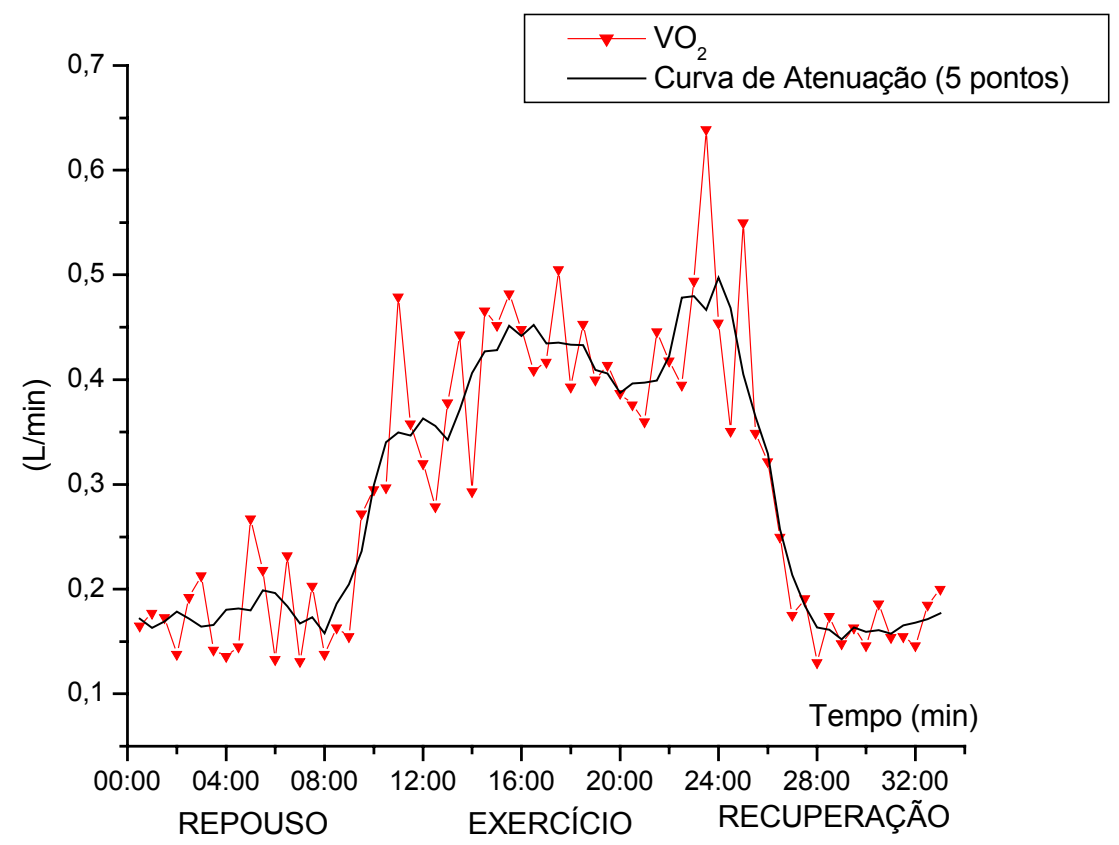

Figura 31 - Consumo de Oxigênio $\left(\mathrm{VO}_{2}\right)$ do Voluntário $\mathrm{V}$.

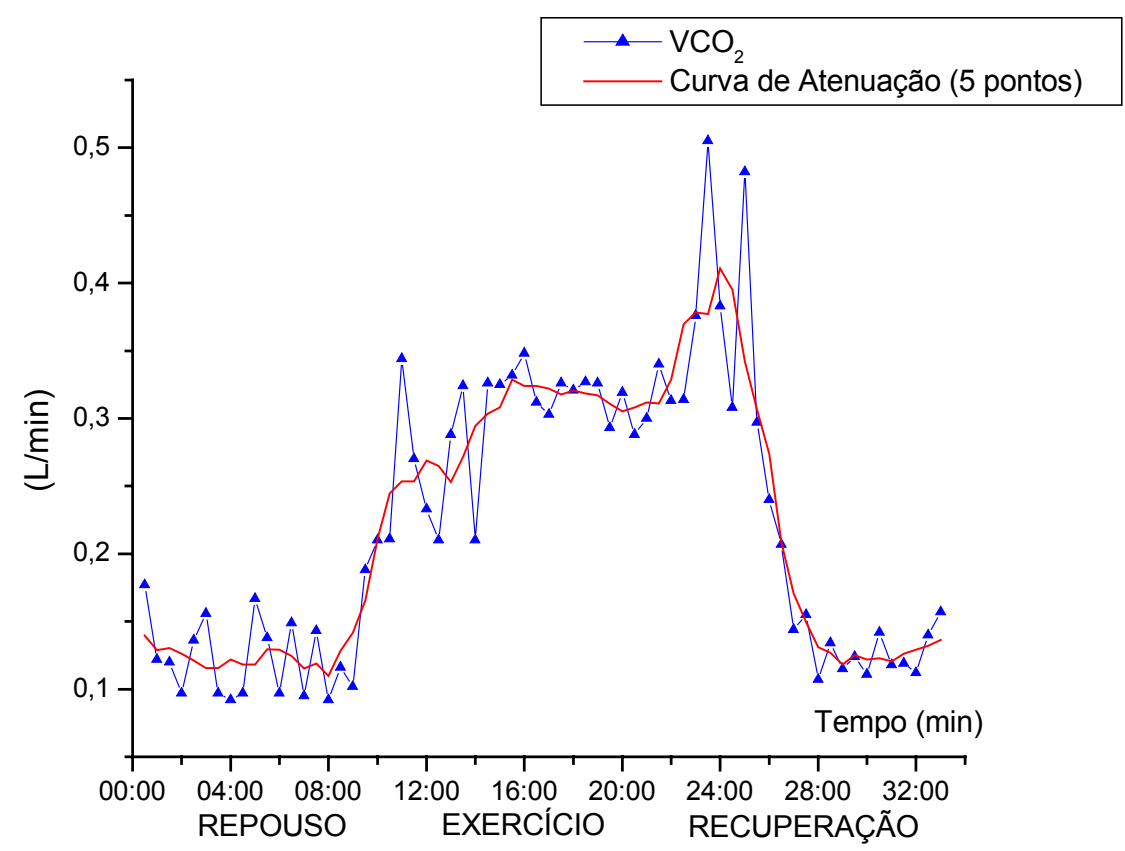

Figura 32 - Produção de Dióxido de Carbono $\left(\mathrm{VCO}_{2}\right)$ do Voluntário V. 


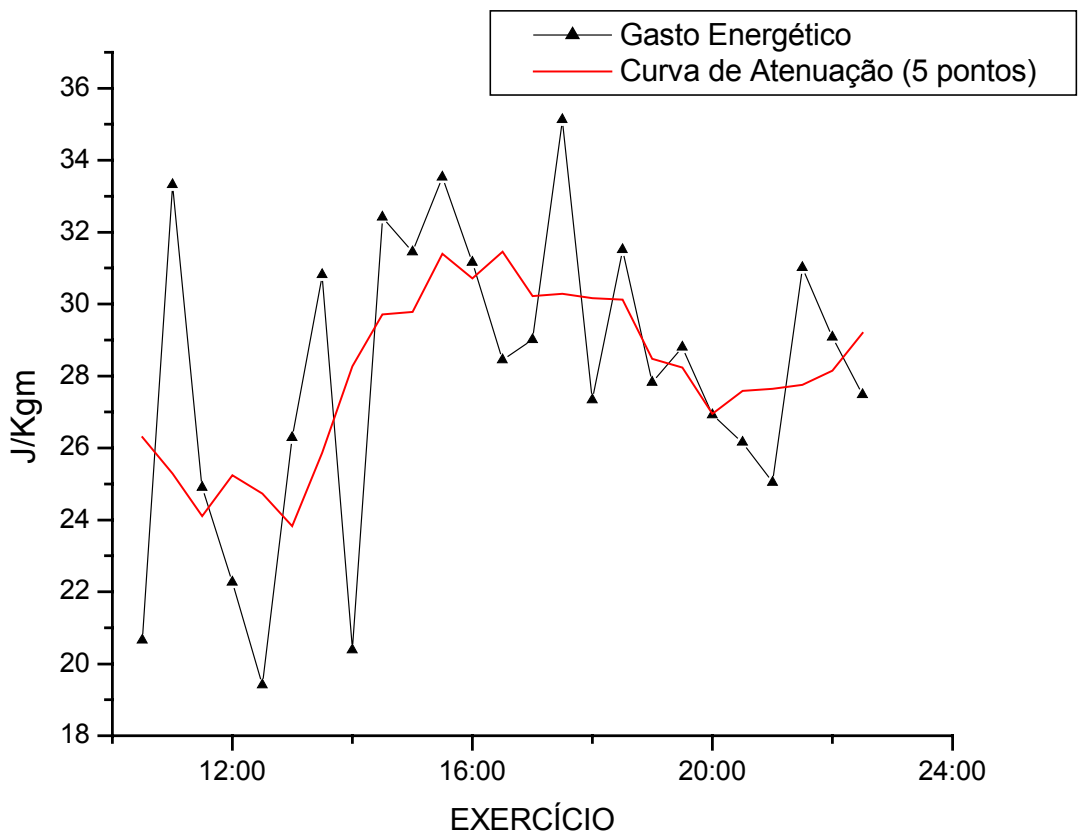

Figura 33 - Gasto Energético do Voluntário V.

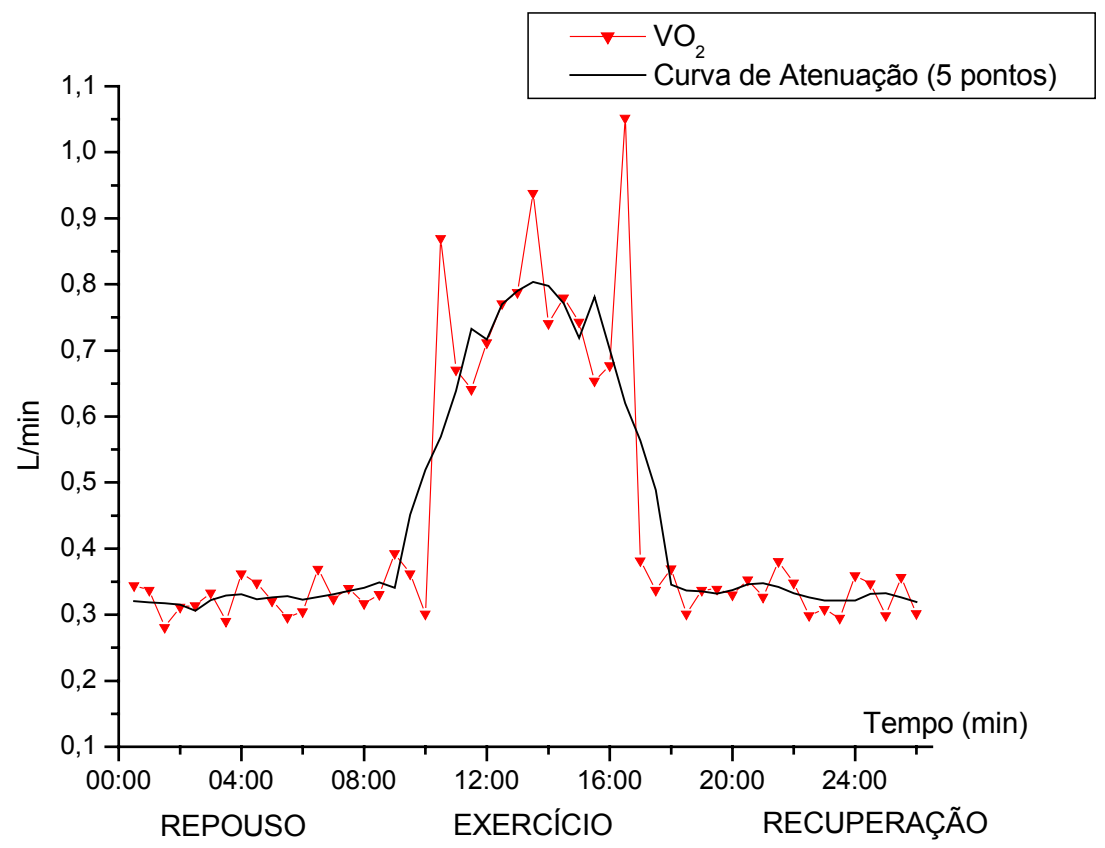

Figura 34 - Consumo de Oxigênio $\left(\mathrm{VO}_{2}\right)$ do Padrão. 


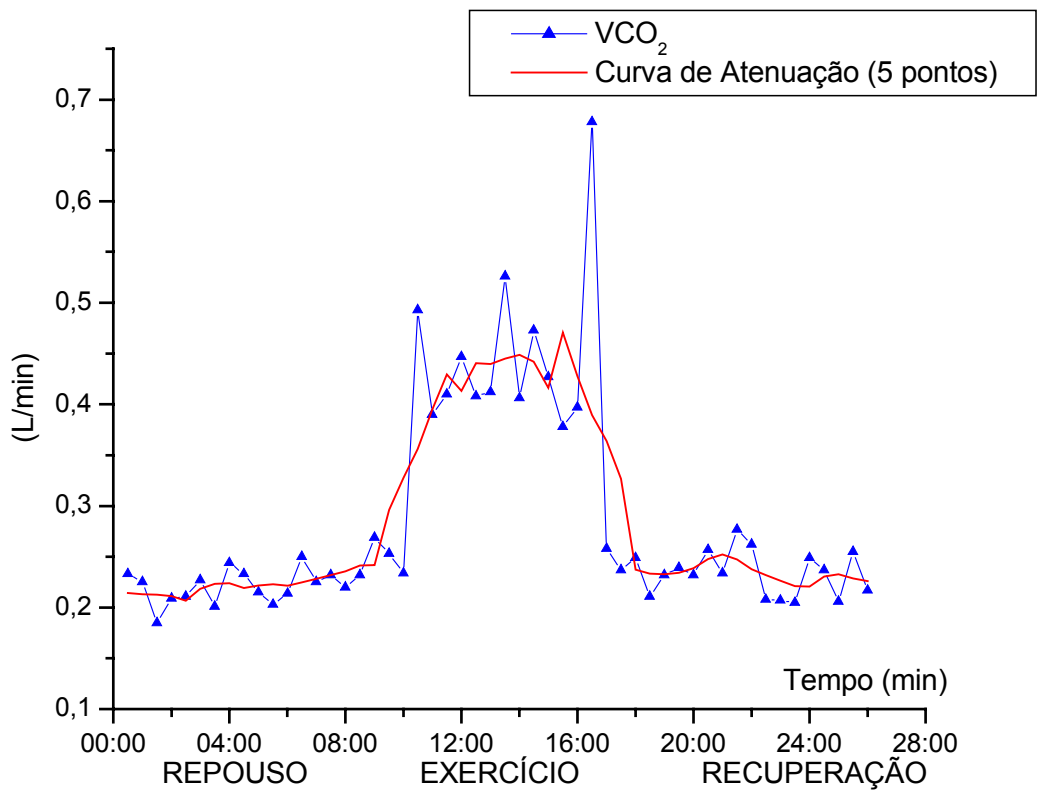

Figura 35 - Produção de Dióxido de Carbono $\left(\mathrm{VCO}_{2}\right)$ do Padrão.

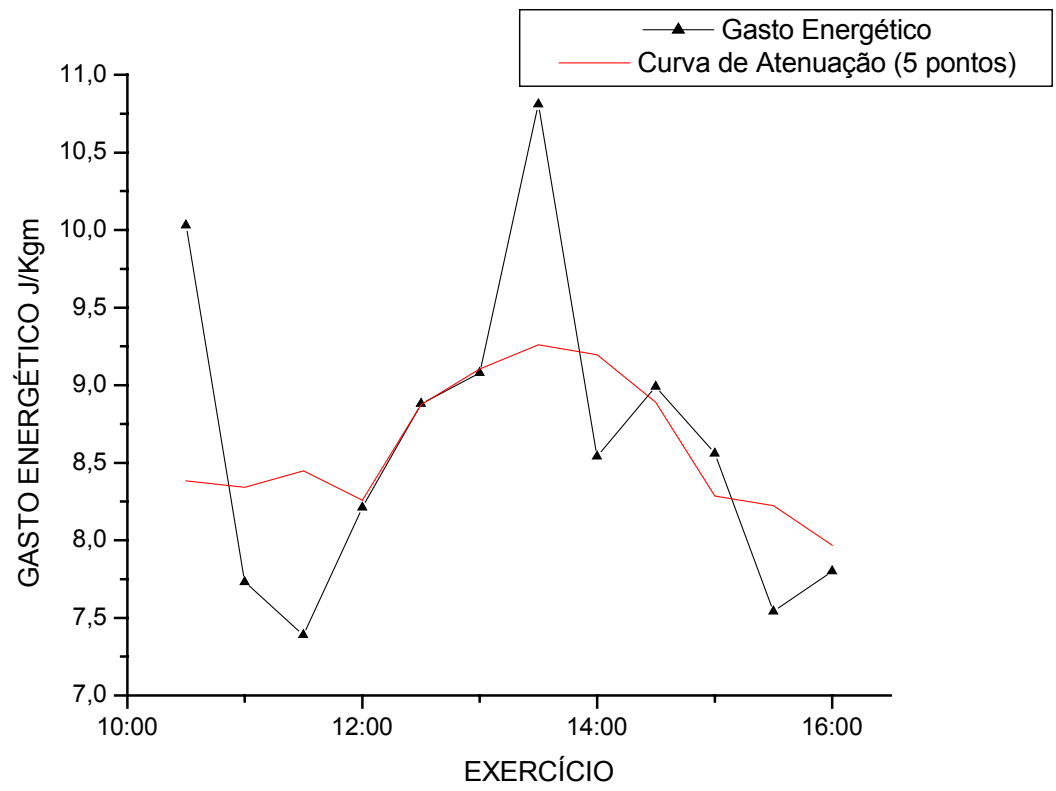

Figura 36 - Gasto Energético do Padrão. 


\section{CAPÍTULO 8}

\section{DISCUSSÃO}

Com relação a velocidade de marcha, em estudo realizado por CLIQUET et al. (1989), onde lesados medulares (T4 -T9) caminharam com diferentes sistemas, foi observado valores semelhantes para essa variável quando o paciente andou só com EENM de 4 canais $(7,66)$, CAL ou muleta canadense $(6,55)$, KAFO bilateral e EENM de 8 canais $(4,8)$, órtose LSURGO $(7,2)$ e órtese LSURGO mais estimulação peroneal $(7,06)$, comparados com os dados dos voluntários do presente estudo (Tabela 3).

Em outro estudo, onde voluntários andaram com auxílio da EENM, foi observada uma velocidade média de $6,2 \mathrm{~m} / \mathrm{min}$ (ISAKOV, 1986), similar às dos voluntários I, III e IV do presente estudo (Tabela 3). Entretanto, em trabalho posterior (ISAKOV, 1992) um paciente com lesão de nível T4 realizou marcha 
com sistema híbrido, formado por EENM e órtese RGO a uma velocidade média de $25,2 \mathrm{~m} / \mathrm{min}$.

Diversos estudos observaram essa diferença de velocidade entre sistemas híbridos, órtese e EENM, demonstrando que a velocidade de marcha com EENM é inferior a observada em sistemas híbridos e órtese (NENE,1989, 1990; HUANG, 1979; CLIQUET,1989; ISAKOV, 1992). Entretanto, a velocidade pode variar de acordo com a habilidade individual, bem como a adaptação à marcha ou ao sistema utilizado.

Antes de avaliar o gasto e o consumo energético de cada sujeito, deve-se primeiramente compreender e analisar o comportamento do sistema cardiorespiratório dos lesados medulares.

Na década de 80 houve uma controvérsia sobre a influência da severidade do trauma, o nível de lesão e de atividade física pós-lesão dos pacientes no desempenho cardiorespiratório (DAVIS, 1981;1984). Neste período muitos estudos mudaram o seu ponto de vista com relação o desempenho cardiorespiratório, que era baseado somente no nível e na severidade da lesão, associando a esses fatores o nível de atividade física do paciente pós - trauma.

Essa busca de novos parâmetros para avaliar o sistema cardiorespiratório dos lesados medulares foi importante na determinação dos fatores que mais 
influenciam nesse sistema. Vários estudos foram desenvolvidos e os dados sugerem que o nível da lesão tem menor influência no desempenho físico dos indivíduos, com exceção dos que tem profundas restrições neuromusculares dos membros inferiores (RIDING,1989; WINNICK,1984). A maior influência é a qualidade e quantidade (ou freqüência) da atividade física (KOFSKY, 1983).

Então, a $\mathrm{VO}_{2}$ pode variar de acordo com o nível de lesão, entretanto, durante o exercício observa-se um comportamento similar, mesmo entre níveis de lesão diferentes. Os primeiros dois minutos são caracterizados por um aumento gradual tanto da Ventilação, quanto da $\mathrm{VO}_{2}$ e $\mathrm{VCO}_{2}$. Após esse período temos a estabilização (steady-state) dessas variáveis (NENE,1990) como pode ser observado na Figura 37.

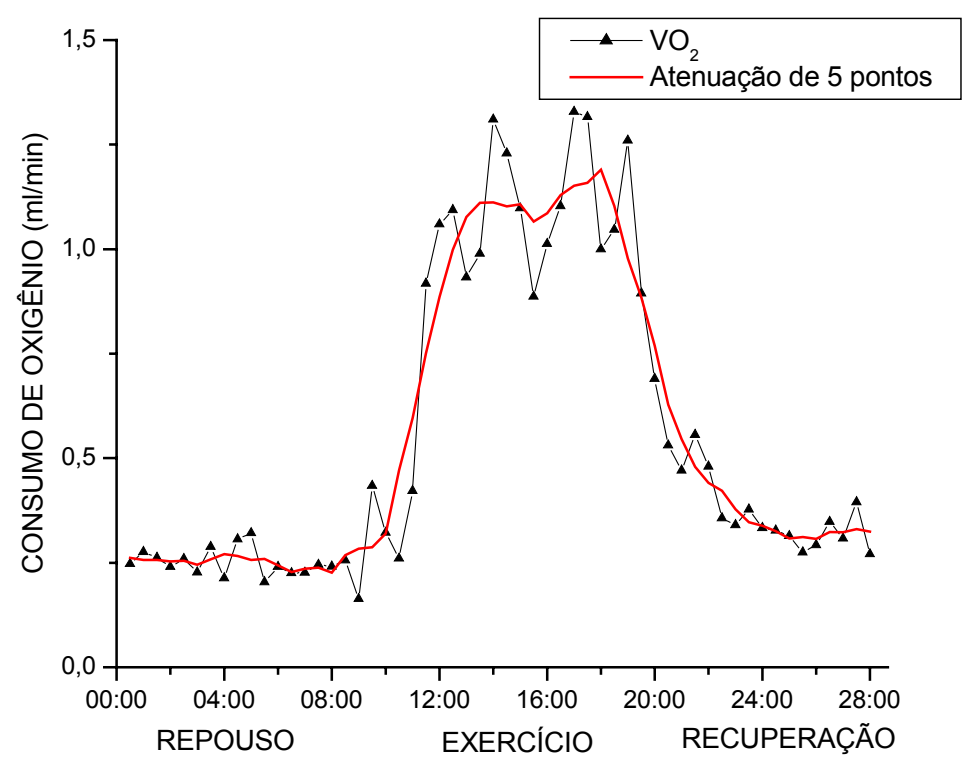

Figura 37 - Comportamento do Consumo de Oxigênio $\left(\mathrm{VO}_{2}\right)$. 
Essas características foram também observadas em pesquisa realizada com nove pacientes (C5 - S1), realizando exercício de membros superiores em ciclo ergômetro, no período denominado pós-treinamento (BARSTOW et al., 1996).

$\mathrm{Na}$ Tabela 04 temos os dados obtidos durante o período de repouso. Com relação a $\mathrm{VO}_{2}(\mathrm{mlKg} / \mathrm{min})$, apenas os valores dos voluntários II e IV tem diferença significativa $(p<0,001)$ quando comparados aos valores do padrão. No caso do primeiro, esses resultados podem estar relacionados ao fato do paciente não ter alcançado o steady-state (NENE 1990). Este também possui diferenças significativas com os voluntários III,IV e V $(p<0,001)$ e I $(p<0,05)$.

Já para o outro voluntário (IV), essa diferença pode estar relacionada com o nível da lesão ser alta (T4/T5), uma vez que seus valores de $\mathrm{VO}_{2}(\mathrm{mlKg} / \mathrm{min})$, tem diferença significativa com todos os avaliados $(p<0,001)$ e todos fazem $o$ mesmo número de sessões de EENM por semana. Estando também relacionado ao fato de que para níveis de lesão entre T1 e T4, há o comprometimento da via simpática e dependendo do grau de denervação, afeta a liberação de hormônios como a epinefrina e noraepinefrina durante atividades físicas. Estando esses hormônios diretamente relacionados às adaptações metabólicas, cardiovasculares e respiratórias durante o repouso e exercício (SCHIMID, 1998). 
Em um estudo realizado com lesados medulares ativos e inativos, nível de lesão de T6 a L2, também não foi observada diferença significativa da $\mathrm{VO}_{2}$ durante o repouso (DAVIS, 1988).

Pode ser observado também que a $\mathrm{VCO}_{2}(\mathrm{~L} / \mathrm{min})$ durante o repouso manteve um comportamento fisiológico, isto é, valores inferiores aos da $\mathrm{VO}_{2}(\mathrm{~L} / \mathrm{min})$, com exceção do voluntário I, que levou dois minutos para apresentar esse comportamento, podendo estar relacionado com a adaptação ao bocal, uma vez que o equipamento não oferece nenhuma resistência.

O quociente respiratório $(Q R)$, que é dado pela divisão do $\mathrm{CO}_{2}$ expirado pelo $\mathrm{O}_{2}$ inspirado, sugere qual é o substrato energético predominante durante cada fase. Em períodos de repouso ou atividades cotidianas (trabalhar, estudar, etc), o substrato predominante é o lipídio (McARDLE, 1992). Ao observarmos os dados da Tabela 04, nota-se que durante o repouso, para todos os voluntários, o substrato predominante foi o lipídio. Entretanto, os percentuais variaram de $100 \%$ a $70 \%$, sendo o restante da energia proveniente dos carboidratos. Os valores de referência estão na Tabela do Quociente Respiratório (Apêndice 2).

Já durante o exercício, a $\mathrm{VO}_{2}(\mathrm{ml} / \mathrm{Kg} / \mathrm{min})$ dos voluntários I, IV e III apresentaram diferença significativa ( $p<0,001$ para I e IV; $p<0,01$ para III) quando comparados aos valores do Padrão (Tabela05). 
Em pesquisa, onde um lesado medular (T5-T6) realizou marcha durante dez minutos com auxílio de EENM e andador, obteve-se um consumo de oxigênio médio de $17,29 \mathrm{ml} / \mathrm{Kg} / \mathrm{min}$, sendo em valores absolutos similares aos observados nos voluntários I $(14,95 \pm 3,2)$, II $(10,5 \pm 5,7)$, III $(14,68 \pm 5,1)$ e IV $(19,09 \pm 3,8)$ do presente estudo. O mesmo foi observado para os pacientes que utilizavam sistemas híbridos ou somente órtese (CLIQUET, 1989).

Durante um teste de esforço crescente para membros superiores até o nível submáximo utilizando um ciclo ergômetro, foi observado diferenças significativas entre a $\mathrm{VO}_{2}(\mathrm{~L} / \mathrm{min})$ para pessoas ativas $(1,03 \pm 0,07)$ e inativas $(0,69 \pm 0,06)$ (DAVIS, 1988). Comparando esses resultados com os dados obtidos no presente estudo temos que os voluntários I $(1,04 \pm 0,41)$ e III $(1,31 \pm$ 0,26) são semelhantes aos obtidos para as pessoas ativas. Já o voluntário $V$ $(0,403 \pm 0,06)$ está mais para o grupo inativo (Tabela 04). Deve-se ressaltar que no referido estudo, os pacientes ativos foram submetidos a sessões de EENM três vezes por semana, enquanto no presente estudo apenas uma vez por semana.

Nota-se o mesmo comportamento observado durante o repouso, com relação ao voluntário IV, é visto no período de exercício. $A \mathrm{VO}_{2}(\mathrm{ml} / \mathrm{Kg} / \mathrm{min})$ dele é significativamente diferente quando comparado com os pacientes I, II e V $(p<0,001)$ e III $(p<0,01)$. Sendo o seu resultado maior em valor absoluto. 
Durante a realização do exercício a $\mathrm{VCO}_{2}$ teve um aumento que variou de 1,9 a 4,3 vezes e a $\mathrm{VO}_{2}$ de 2,19 a 4,04 com relação ao repouso. Esses aumentos são normais, uma vez que para os lesados medulares a marcha induzida pode ser considerada uma atividade física, havendo a necessidade maior de captação e utilização de $\mathrm{O}_{2}$ pelo organismo, liberando por sua vez mais $\mathrm{CO}_{2}$.

A intensidade da atividade física irá determinar qual o substrato energético que será utilizado com maior predominância. Se o exercício for intenso haverá déficit de $\mathrm{O}_{2}$, sendo predominante os carboidratos, pois seu valor calórico é maior do que os lipídios $\left(5,04-4,6 \mathrm{Kcal}\right.$ por litro de $\left.\mathrm{O}_{2}\right)$. Mas se o exercício for leve ou moderado, isto é, com abundância de $\mathrm{O}_{2}$, os lipídios serão predominantes, pois o QR é menor e o fornecimento calórico é quase o dobro comparado aos carboidratos $(9,46-4,18$ cal). Todos esses valores são para cada $1 \mathrm{~g}$ utilizado desses substratos (KATCH, 1996).

Desta forma, os resultados do QR sugerem qual foi à intensidade do exercício para cada indivíduo. Foi observada uma diminuição dos percentuais de lipídios utilizados com relação ao repouso para os voluntários III (88,7 - 76,7\%), IV (70 - 56,7\%) e V $(97,6-70)$, entretanto mantiveram-se os lipídios como substrato predominante, indicando que o exercício pode ter variado de moderado a intenso, por isso o aumento na utilização dos carboidratos (Tabela 05). 
O inverso ocorreu para o voluntário I, que apresentou um aumento nos percentuais de utilização dos lipídios (73,3 - 93,3\%). Esse aumento sugere que o aporte de $\mathrm{O}_{2}$ foi suficiente, sendo o exercício de intensidade moderada. Para o Padrão não houve mudança no substrato energético, mantendo-se os lipídios como substrato predominante $(100 \%)$, sugerindo que, a atividade proposta não provocou alterações significativas suficientes para a mudança do substrato.

Apenas para o voluntário $\mathrm{II}$, o substrato predominante durante o exercício passou a ser o carboidrato (10 - 63,3\%). Essa mudança pode estar relacionada ao fato do músculo quadríceps não ter respondido a EENM, causando sobrecarga nos membros superiores, aumentando o esforço o que levou ao término da atividade.

ARNOLD e seus colaboradores (1992) realizaram um estudo longitudinal, durante 6 meses, dividindo em 3 fases distintas o treinamento de lesados medulares (C5-T4; 22,8 anos) com EENM em uma bicicleta ergométrica. Na fase 1 , onde os pacientes apenas realizavam extensão da perna, considerando essa fase como basal, o QR observado $(0,732 \pm 0,138)$ foi semelhante ao do voluntário I $(0,72 \pm 0,21)$, sugerindo que para ele essa atividade foi de intensidade leve ou moderada. 
Na fase 2, depois de dois meses e meio de treino ergométrico com bicicleta a 50 rpm, foi observado um $Q R$ de $0,78 \pm 0,152$, sendo similar aos dos voluntários III $(0,77 \pm 0,08)$ e IV $(0,79 \pm 0,06)$. Já os valores da fase 3 , onde foi oferecido um aumento gradual de resistência na bicicleta, temos um QR de $0,886 \pm 0,1$ e os voluntários II $(0,89 \pm 0,12)$ e IV $(0,83 \pm 0,12)$. Essa semelhança sugere que para os voluntários do presente estudo a atividade proposta foi de resistência, requisitando mais carboidrato como substrato. Todos os pacientes do referido estudo fizeram uso da EENM de duas a três vezes por semana (ARNOLD, 1992).

Uma das etapas mais importantes para avaliarmos os efeitos da EENM sobre variáveis metabólicas é a recuperação. Depois do término de uma atividade física, a respiração, a freqüência cardíaca e outras funções corporais, não retornam imediatamente aos valores de repouso. Se o exercício for leve, a recuperação é mais rápida, mas se a atividade for intensa precisaremos de mais tempo para voltar ao repouso. A recuperação das funções orgânicas, excitadas pela atividade física moderada ou intensa, está intimamente associada aos processos metabólicos envolvidos (KATCH, 1996).

Se o exercício for leve ou moderado, a metade do volume total de oxigênio consumido durante a recuperação é suprida nos primeiros 30 segundos e em 1 ou 2 minutos ele retorna aos valores de repouso. O oxigênio adicionalmente 
consumido está associado ao restabelecimento das reservas dos fosfatos ATP e CP que foram gastos. E um pequeno volume também é utilizado para reoxigenar o sangue e suprir os níveis das demandas energéticas do coração e dos músculos ventilatórios (KATCH, 1996).

Por sua vez, exercícios intensos estão relacionados a um grande acúmulo de lactato sangüíneo e a um aumento significativo da temperatura corporal. Existe uma fase rápida de consumo de $\mathrm{O}_{2}$ e uma fase lenta. $\mathrm{O}$ ácido lático que não foi tamponado pelo bicarbonato, é reconvertido em ácido pirúvico e submetido ao ciclo de Krebs (Apêndice 3) durante essa fase para o suprimento de energia, enquanto uma parte pode ser reconvertida em glicogênio no fígado.

A elevação da temperatura corporal ocasionada pelo exercício intenso estimula o diretamente o metabolismo, aumentado, por sua vez o consumo de oxigênio na recuperação. Às vezes, dependendo da intensidade do exercício, há um grande acúmulo de lactato e a recuperação pode levar horas (KATCH, 1996).

Resultados similares ao presente estudo (Tabela 06), foram os observados na pesquisa de CLIQUET (1989), onde a $\mathrm{VO}_{2}$ do paciente que andou com EENM foi de $441 \mathrm{ml} / \mathrm{min}$ no período de recuperação que teve a duração de 10 minutos.

Com relação a $\mathrm{VO}_{2}(\mathrm{ml} / \mathrm{Kg} / \mathrm{min})$, apenas os dados do voluntário IV apresentaram diferença significativa quando comparados aos do Padrão 
$(p<0,05)$. Entretanto, se compararmos com os seus valores de repouso temos que eles não apresentam diferenças significativas (5,99 $\pm 1,45 ; 7,83 \pm 3,2)$, indicando que durante a recuperação os valores da $\mathrm{VO}_{2} \quad(\mathrm{ml} / \mathrm{Kg} / \mathrm{min})$ alcançaram os valores anteriores ao exercício. O mesmo ocorrendo para os voluntários II $(2,97 \pm 0,44 ; 4,78 \pm 2,45), V(4,40 \pm 1,2 ; 3,16 \pm 3,5)$ e Padrão $(4,38 \pm 0,38 ; 4,95 \pm 2,17)$ (Tabela 06 e Figuras 22, 31,34).

Já para os voluntários I e III foi observada diferença significativa $(p<0,05)$ entre a $\mathrm{VO}_{2}(\mathrm{mlKg} / \mathrm{min})$ do repouso com a recuperação, sugerindo que o exercício foi intenso, precisando assim de mais tempo para se recuperar (KATCH, 1996) (Figuras 19,25).

Essa hipótese pode ser reforçada com os resultados da $\mathrm{VCO}_{2}$ (L.min), como pode ser observado nos gráficos individuais de $\mathrm{VO}_{2}$ e $\mathrm{VCO}_{2}$ (Figuras 20, 26 respectivamente), que são superiores aos da $\mathrm{VO}_{2}(\mathrm{~L} / \mathrm{min})$ para os dois voluntários, o que sugere a presença de $\mathrm{CO}_{2}$ proveniente do tamponamento do ácido lático (ver página 27). Para o voluntário I, durante os primeiros quatro minutos da recuperação observou-se essa alteração. Para o III, durou quatro minutos e meio.

Através do QR do período de recuperação, podemos avaliar qual foi a intensidade do exercício e se o metabolismo tem as respostas fisiológicas esperadas frente ao esforço. Como descrito anteriormente, em caso de 
exercício intenso haverá um aumento do consumo de oxigênio na recuperação conseqüentemente aumentará $O \mathrm{QR}$, sendo mais vantajoso o uso de carboidrato, por ele liberar mais Kcal por litro de $\mathrm{O}_{2}(\mathrm{KATCH}, 1996)$. Essa adaptação pode ser observada nos voluntários I, II, III e IV. Já o voluntário V e o Padrão mantiveram a predominância do lipídio como substrato, sugerindo que para eles o exercício foi moderado.

A energia média consumida durante o período de repouso e exercício está descrita na Tabela 07. Observa-se uma diferença significativa entre II, IV e V quando comparados ao Padrão $(p<0,001)$ e I $(p<0,05)$, sendo que os voluntários IV e $\mathrm{V}$ consumiram mais energia durante o repouso.

No estudo desenvolvido por NENE (1990), a média da energia consumida em repouso pelos pacientes (T4-T7; 25 a 30 anos) foi de $0,76 \mathrm{~J} / \mathrm{Kgs}$. Valor este inferior aos obtidos no presente trabalho.

Durante o exercício, os valores de I e IV são superiores comparados ao Padrão, com diferença significativa de $(p<0,001)$ e $(p<0,01)$ para III. Este resultado era esperado, uma vez que essa variável é diretamente proporcional ao $\mathrm{VO}_{2}$.

Foi observada uma diminuição na energia consumida com a utilização de um sistema híbrido (órtese e EENM) comparado com só a órtese, durante a marcha (NENE, 1990). Os resultados desse estudo, realizados em lesados medulares 
(T4-T7), com idade entre 25 e 30 anos, também foram inferiores aos obtidos na presente pesquisa (órtese: 2,59 J/Kgs; sistema híbrido: 2,50 J/Kgs), que se utilizou somente EENM (voluntários de I a IV; 4,60 J/Kgs).

Em contraposição, em estudos que utilizaram somente órtese (Tabela 08), foram observadas semelhanças com este trabalho, o que gera um dilema sobre a causa dessa diferença. Podendo ser devido ao condicionamento físico dos pacientes, a técnica utilizada para a realização da marcha ou ambas.

A energia gasta para a realização de uma atividade tem uma correlação estreita com a massa e a composição corporal, a idade e o nível de atividade física dos praticantes (KATCH, 1996; DÂMASO, 2001). Duas pessoas com a mesma massa corpórea, idade e sexo, podem ter gastos energéticos diferentes na prática de uma mesma atividade. Isso se deve principalmente aos percentuais de massa magra, que são tecidos metabolicamente mais ativos durante um exercício (KATCH, 1996; DÂMASO, 2001).

No caso específico dos lesados medulares, algumas alterações ocorrem devido à lesão, como redução na massa magra, na densidade mineral óssea, na atividade simpática e o aumento da massa gorda. Essas alterações predispõem os lesados medulares a um ganho de peso e até mesmo a obesidade, quando a ingestão é maior que o gasto (MONROE, 1998). Entretanto, essas modificações variam de acordo com nível e o grau da lesão. 
Pode ser observado nas Figuras 21, 24, 27, 30, 33 e 36, o gasto energético dos voluntários durante o exercício de marcha. Apenas os voluntários I e IV apresentaram diferenças significativas comparados ao Padrão $(p<0,001)$ e com todos os outros voluntários $(p<0,001)$. Para o primeiro, os dados sugerem que este resultado foi em conseqüência tempo e da intensidade do exercício, uma vez que a causa do término do exercício foi falta de resposta a EENM. No caso do segundo, este alto gasto pode estar relacionado ao nível de lesão (T4-T5) e a pouca massa corporal, uma vez que ele teve um período de recuperação considerado fisiológico. Esses valores são mais de 20 vezes maiores do que os do Padrão.

Os valores do gasto energético dos voluntários I e II foram similares aos observados no estudo de CLIQUET (1989), no paciente que utilizou EENM (45,6 J/Kgm). Já os do avaliado $\mathrm{V}(28,01 \pm 4,23 \mathrm{~J} / \mathrm{Kgm})$, tem correlação com os resultados dos pacientes que utilizaram órtese KAFO bilateral $(25,5 \mathrm{~J} / \mathrm{Kgm})$ e órtese KAFO bilateral com EENM de 8 canais $(36,5 \mathrm{~J} / \mathrm{Kgm})$.

O gasto energético de pacientes que utilizaram órtese foi menor aos observados no presente estudo, quando comparados aos estudos de NENE, (1989) e HUANG, (1979), bem como na utilização de sistemas híbridos (NENE, 1990). 
Apesar dos gastos dos voluntários I, III e V serem respectivamente 4,87; 5,61 e 3,25 vezes maiores que Padrão, todos tiveram comportamentos fisiológicos esperados durante os três períodos da avaliação, o que pode ser observado nos gráficos de $\mathrm{VO}_{2}$ e $\mathrm{VCO}_{2}$.

A dificuldade de comparação entre estudos ainda é grande, devido a uma série de fatores que devem ser controlados, como a composição corporal, as taxas metabólicas, a freqüência do treinamento, a integridade do sistema simpático e parassimpático, entre outras, bem como a padronização de testes específicos para lesados medulares. Isso gera modificações nas respostas do organismo frente a esforços físicos.

Havendo um maior controle dessas variáveis, fica mais claro o real efeito da EENM sobre o gasto energético. Em um primeiro momento, os dados sugerem que frente ao esforço, alguns pacientes tiveram uma resposta fisiológica, porém aumentada devido a outros fatores que interferem, como a falta de propiocepção, por exemplo.

Em suma, maiores estudos devem ser realizados, buscando cobrir um número maior dessas variáveis, bem como acompanhar a evolução dos pacientes durante o processo de reabilitação. 


\section{CAPÍTULO 9}

\section{9 .CONCLUSÕES}

$\checkmark$ O gasto energético dos pacientes variou de 3 a 26 vezes ao observado no voluntário Padrão. Apesar disso, todos tiveram uma recuperação fisiológica ao esforço, variando de acordo com a intensidade do esforço.

$\checkmark \mathrm{O}$ comportamento da $\mathrm{VCO}_{2}$ durante a recuperação de alguns voluntários indicou a participação de $\mathrm{CO}_{2}$ metabólico, advindo do tamponamento do ácido láctico. A participação de metabolismos anaeróbios deve ser investigada de maneira mais direta.

$\checkmark$ A freqüência do treinamento ou tratamento com a EENM é diretamente proporcional ao desempenho no exercício; bem como as características físicas dos indivíduos.

$\checkmark$ Novas pesquisas devem ser realizadas, controlando, sobretudo os diferentes tipos de metabolismo e a composição corporal, durante um período longo de treinamento e também entre os períodos de recesso. 


\section{ANEXOS}

\section{A - Termo de Consentimento Pós- Informação}

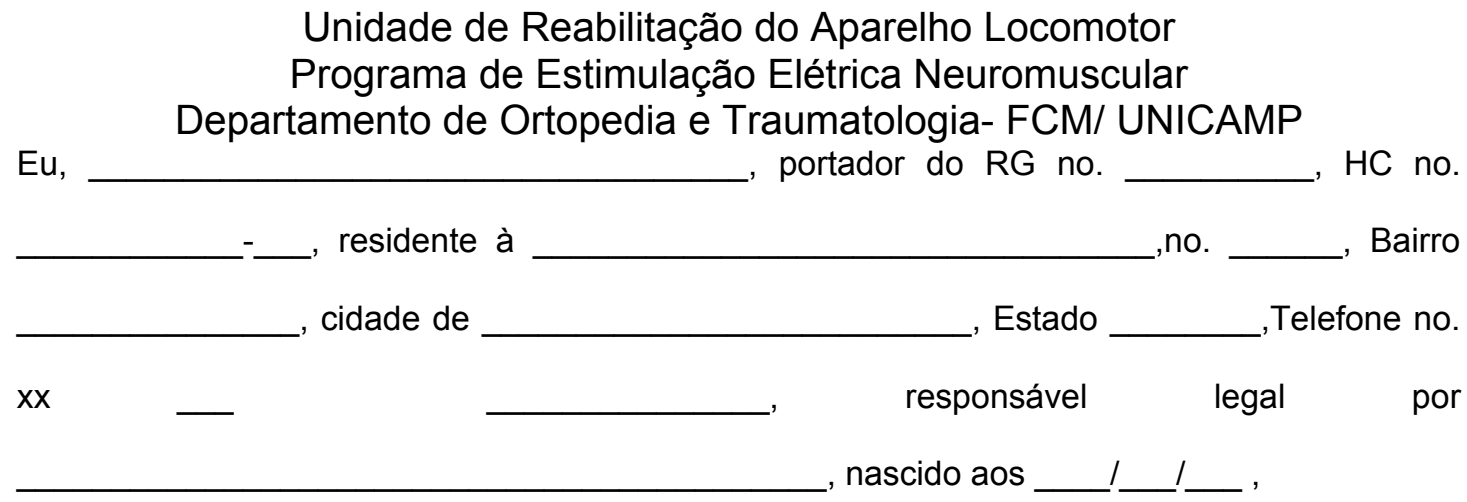

declaro que contatei a Unidade de Reabilitação do Aparelho Locomotor com o intuito de solicitar que meu filho(a) participe do Programa de Estimulação Elétrica Neuromuscular.

Nesta Unidade fui devidamente informado sobre o seguinte: $1^{\circ}$ ) que a EENM é um procedimento não invasivo, realizado externamente na pele e, desse modo, não tem efeitos colaterais e não traz qualquer risco para a integridade física do lesado medular; $2^{\circ}$ ) que o objetivo geral do programa é a busca pela restauração dos movimentos dos membros paralisados e a prevenção e/ou redução da osteoporose; $3^{\circ}$ ) que pesquisadores pósgraduandos desenvolvem projetos de pesquisa específicos dentro do Programa de Estimulação Elétrica Neuromuscular, coordenados pelo Prof. Dr. Alberto Cliquet Jr., e serei devidamente informado se meu filho(a) venha a fazer parte de algum destes projetos; $4^{\circ}$ ) que poderei, a qualquer momento, retirar meu filho(a) do programa, sem que com isso ele(a) venha a prejudicá-lo(a) nos demais atendimentos do HC/ÚNICAMP. Por fim, comprometo-me a informar a equipe sobre todo e qualquer tipo de procedimentos (e/ou tratamentos) externos concomitantes à EENM que são ou que venham a ser realizados no futuro.

Campinas SP, , de de 200_. 


\section{B - Músculo Estriado Esquelético - Estruturas Macroscópicas e Microscópicas}

O músculo estriado esquelético é o único que está sob o controle voluntário, possui estrias regulares nas fibras musculares que são visíveis apenas através de microfotografia eletrônica (BERGMAN, 1989; McARDLE, 1994; MACHADO, 2000). As maiores partes dos músculos esqueléticos estão fixadas em suas extremidades através dos tendões (exceto os músculos faciais). E as forças musculares que agem sobre o sistema de alavancas ósseas do corpo fazem com que um ou mais ossos do corpo se movimente. Um indivíduo sadio tem a capacidade de desenvolver a quantidade exata de contração muscular para realizar uma infinidade de tarefas motoras. Isso permite a pessoa impulsionar um objeto, tocar algum instrumento, andar, correr, entre outras atividades (McARDLE, 1994; MACHADO, 2000).

Macroscopicamente, o músculo esquelético é composto de feixes de fibras. Circundado por uma fáscia de tecido conjuntivo fibroso chamado de epimísio. Essa bainha se estreita em sua extremidade distal ao incorporar-se às bainhas do tecido intramuscular para formar o denso e resistente tecido conjuntivo dos tendões. Os tendões unem as extremidades do músculo à cobertura mais externa do esqueleto que é o periósteo, sendo que $70 \%$ da massa seca dos tendões é constituído de proteínas colagenosas. (McARDLE, 1994; MACHADO, 2000) (Figura 38). 
A camada seguinte é o perimísio, que circunda um feixe de até 150 fibras musculares, recebendo o nome de fascículo. Cada fibra é envolta e separada das fibras vizinhas pelo endomísio, no qual localizam-se os capilares sangüíneos e linfáticos.

Abaixo do endomísio encontra-se o sarcolema, que é uma membrana fina e elástica que envolve o conteúdo celular da fibra. Este, por sua vez, está dividido em membrana plasmática e membrana basal. A primeira é uma estrutura lipídica de duas camadas, cuja principal função é conduzir a onda eletroquímica de despolarização sobre a superfície da fibra muscular. A segunda contém proteínas e filamentos de fibrilas colágenas, que permitem a fusão dessa fibra com as fibras colágenas existentes na cobertura externa do tendão. Entre essas membranas existem células satélites, que atuam no crescimento celular regenerativo e após lesões. No sarcoplasma, que é a parte interior do sarcolema, tem-se enzimas, partículas gordurosas, glicogênio, núcleos, mitocôndrias e organelas especializadas (BERGMAN, 1989; MACHADO, 2000)

No sarcolema fica embutida uma extensa rede longitudinal, interligada por canais transversos tubulares, que é chamado de retículo sarcoplasmático. Este retículo ocupa $10 \%$ do volume das fibras musculares esqueléticas, sendo que $80 \%$ do seu peso seco é composto de proteína ( $\mathrm{Ca}^{++} \mathrm{Mg}$ ATPase) e a maioria da proteína restante é calsequestrina, que pode armazenar até 40 íons de $\mathrm{Ca}^{++}$ 
por molécula. E é formados por longos túbulos longitudinais, sistema tubular transverso e cisternas terminais.

Os sistemas tubulares transversos são invaginações do sarcolema, que se originam na membrana celular e ficam abertos para o exterior, comunicando-se com o líquido que banha a fibra muscular, contendo líquido extracelular em seu lúmem, são também chamados de túbulos T (BERGMAN, 1989; MACHADO, 2000) (Figura 38). Já as cisternas terminais apresentam-se com extremidades alargadas estabelecendo contato com os túbulos transversos. Duas cisternas mais um túbulo transverso é denominado tríade. A principal função do retículo sarcoplasmático é o armazenamento de cálcio (BERGMAN, 1989; MACHADO, 2000).

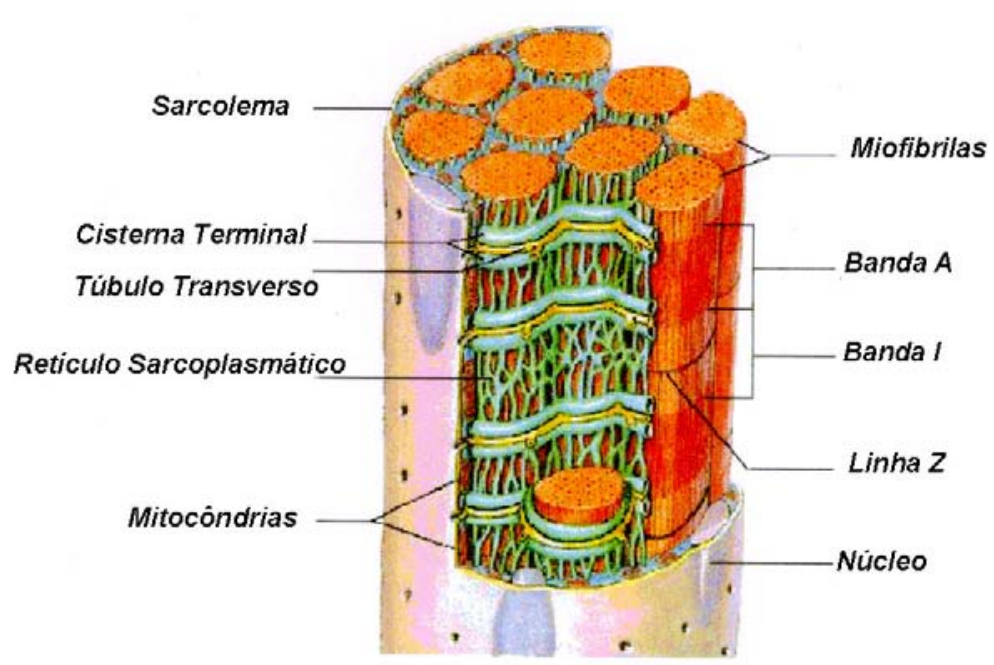

Figura 38 - Visão Microscópica do Músculo Esquelético: Adaptado (PAOLINI, 1998). 
Quimicamente, tem-se $75 \%$ de água, 20\% de proteína (miosina, actina, tropomiosona) e 5\% de sais inorgânicos e outras substâncias, como fosfatos que armazenam alta energia química, uréia, ácido láctico, minerais de cálcio, magnésio, fósforo, íons de $\mathrm{Na}^{+}$, aminoácidos, gorduras e carboidratos (BERGMAN, 1989; MACHADO, 2000).

Microscopicamente, cada fibra muscular é formada por unidades funcionais menores, localizadas paralelas ao eixo longitudinal da fibra, que são as miofibrilas. A miofibrila também apresenta várias unidades funcionais que são chamadas de sarcômero, sendo que cada um deles está entre duas linhas Z (BERGMAN, 1989; MACHADO, 2000) (Figura 39).

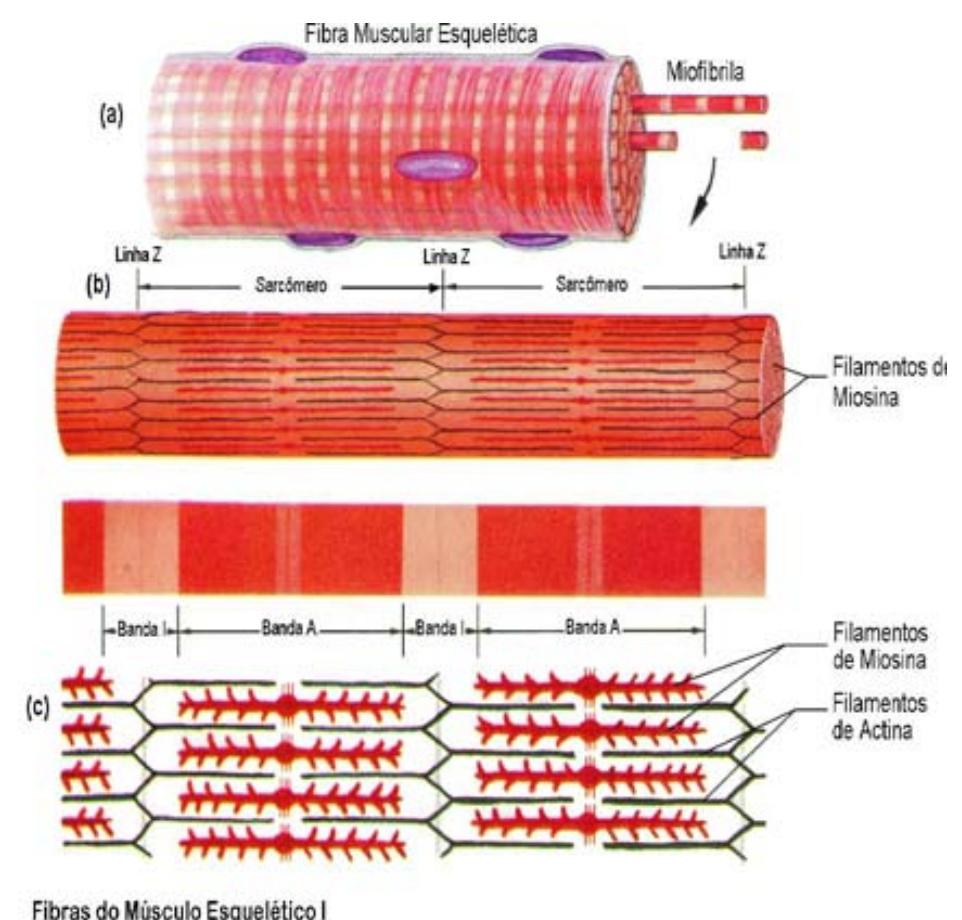

Figura 39 - Visão Microscópica do Músculo Esquelético: Adaptado (MATTHEWS, 2000). 
O sarcômero é constituído por miofilamentos de actina e miosina (85\%) e outras proteínas, como a tropomiosona, que está localizada entre os filamentos de actina; a troponina e beta actinina, também localizada nos filamentos de actina; alfa actinina, distribuída na região da linha Z; proteína $M$, que se encontra nas regiões da linha $\mathrm{M}$ e a proteína $\mathrm{C}$, que contribui para a integridade estrutural do sarcômero (BERGMAN, 1989; MACHADO, 2000) (Figura 39).

Estruturalmente tem-se: a linha $\mathrm{M}$, localizada no centro da zona $\mathrm{H}$ que auxilia os filamentos espessos de miosina a manterem uma organização regular; miomesina, e creatina fosfato transferase, enzima que transforma fosfato de creatina em ATP e está localizada próxima a cabeça da miosina.

A banda A, apresenta tanto filamentos grossos e finos de actina. A banda I apresenta filamentos finos de actina e a zona $H$ apresenta somente os filamentos grossos de miosina (BERGMAN, 1989; MACHADO, 2000).

O monômero básico de actina é denominado actina $\mathrm{G}$, esta tem forma globular e tem um ATP ligado à ela. Cada molécula de actina G liga-se fortemente a um íon de cálcio e uma molécula de ATP, que na presença de $\mathrm{Mg}^{++}$, polimeriza-se em formas fibrosas de proteína-actina F. Formando-se dois filamentos de actina F, que se enrolam formando uma estrutura espacial de dupla hélice. Existem 13 subunidades globulares por turno completo da hélice (BERGMAN, 1989; MACHADO, 2000). 
Miosina são filamentos grossos formados de cadeias polipeptídicas longas. Quando uma molécula de miosina é exposta a tratamento enzimático (tripsina), ela dissociasse em 2 fragmentos: meromiosina leve (baixo peso molecular), que correspondem as duas cadeias peptídicas em alfa hélice formando o cilindro base do filamento, e meromiosina pesada, que correspondem às pontes transversas.

Quando a meromiosina pesada sofre a ação da enzima papaína, esta se dividirá em subfragmentos S1 e S2. O subfragmento S2 se liga em uma extremidade pela meromiosina leve e a outra com S1. Já S1, é constituído de duas unidades globulares idênticas, e o tratamento com uréia ou guanidina divide cada unidade globular em uma cadeia pesada e duas cadeias leves. A cadeia pesada faz parte da estrutura globular. Já a cadeia leve, tem atividade ATPásica (Figura 40).

S2

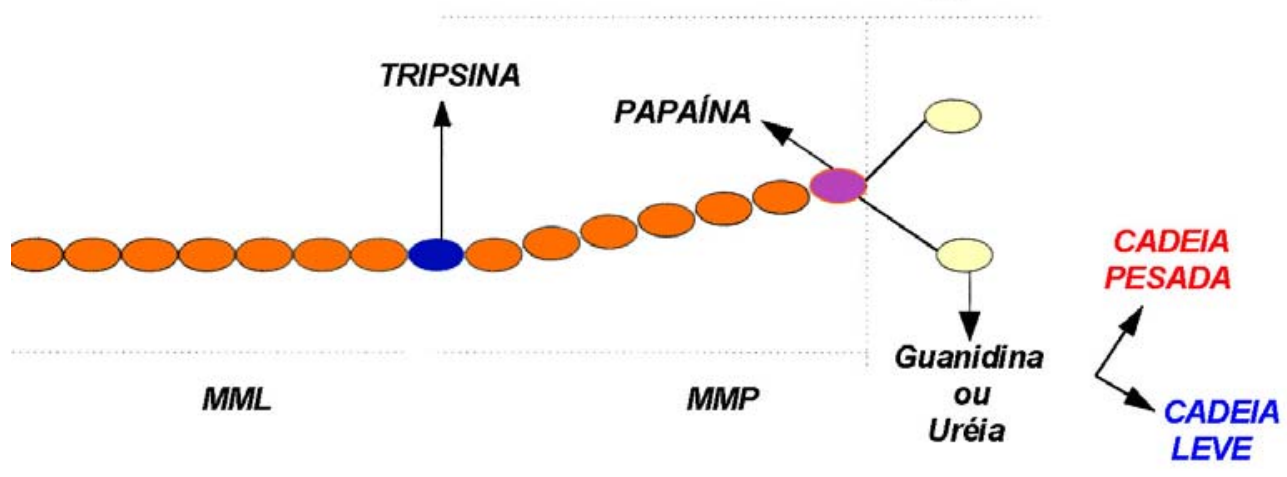

Figura 40 - Representação Esquemática de uma molécula de miosina. 
Para que ocorra o encurtamento do sarcômero, é necessária a liberação da energia acumulada sob forma de ATP. Esse evento ocorre devido a atividade ATPásica das cadeias leves da meromiosina pesada.

Nos locais onde ocorreu a ação enzimática da tripsina e papaína, entre a meromiosina leve e meromiosina pesada e S1 e S2 ocorre a formação de dobradiças que irão atuar no processo de contração (BERGMAN,1989; McARDLE, 1994, 1996; MACHADO, 2000).

A troponina é uma proteína globular que atua no processo da contração muscular. Ela está ligada a uma região específica do filamento de tropomiosina, sendo encontrada uma a cada $40 \mathrm{~nm}$ de tropomiosina. Cada molécula de troponina é composta de três subunidades polipeptídicas, sendo que cada uma delas tem funções específicas (BERGMAN, 1989; McARDLE, 1994; MACHADO, 2000).

O TNC é sítio de ligação do cálcio. Esta subunidade da troponina é carregada negativamente, tendo alta avidez com os íons cálcio. Após unirem-se ao cálcio ocorre uma mudança de conformação espacial da molécula (Figura 41). 
O TNI é a subunidade inibidora, que apresenta sítio específico de ligação com a actina, mas não com o cálcio. Sua função é inibir a interação do sítio ativo da actina com as pontes transversas da miosina. E finalmente, o TNT, que é sítio de ligação com a tropomiosina (BERGMAN, 1989; McARDLE, 1994; MACHADO, 2000) (Figura 41).

Troponina

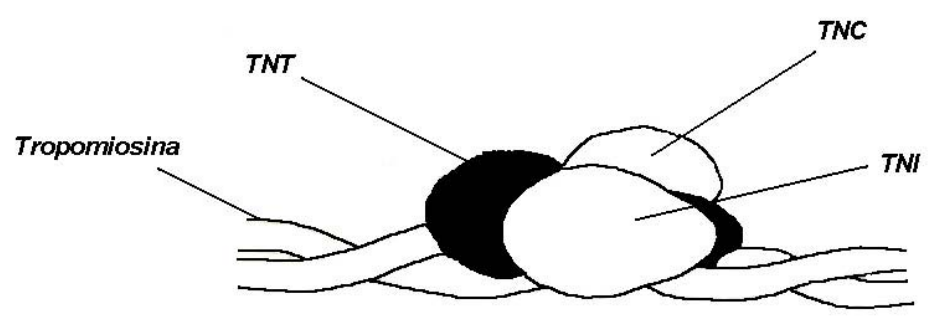

Figura 41 - Modelo de localização das subunidades TNC, TNI e TNT na molécula de troponina.

Outra proteína que faz parte dos miofilamentos é a tropomiosina, que é delgada e longa. É formada por duas cadeias polipeptídicas em alfa hélice, que se localizam nos sulcos dos filamentos de actina e se estendem a cada sete monômeros de actina G. Estes filamentos não são fixos na actina $F$, eles deslizam nos sulcos formados pela actina G (BERGMAN, 1989; McARDLE, 1994; MACHADO, 2000). 


\section{REFERENCIAS BIBLIOGRAFICAS}

ANDREWS, B.; CLIQUET JR., A.; OLIN, M.; BURNHAM, R.; TRASHER, A. Paraplegic locomotion: a linked knee-ankle-foot hybrid system. In: 2nd Annual IFESS Conference and Neural Prosthesis: Motor Systems 5. Burnaby, Canada, 1997, p. 165-167.

ARNOLD, P. B.; MACVEY, P.P.; FARRELL, W.J.; DEURLOO, T.M; GRASSO, A. R. Funcional Eletrical Stimulation: Its Efficacy and Safety in Improving Pulmonary Function and Muscoloskeletal Fitness. Arch. Phys. Med. Rehabil, V. 73, p. 665-668, July, 1992.

ASTRAND, P.O.; RODAHL, K. Tratado de Fisiologia do Exercício, $2^{a}$ Ed., Rio de Janeiro, Interamericana, 1977.

BARROS, T. E. P.; OLIVEIRA, R. P.; KALIL, E.M.; PRADA, F.S. Avaliação Padronizada nos Traumatismos Raquimedulares. Revista Brasileira de Ortopedia, v. 29, n. 3, p. 99-106, Março, 1994.

BARSTOW, T. J.; SCREMIN, A.M.; MUTTON, D.L..; KUNKEL, C.F.; CAGLE, T. G.; WHIPP, B.J. Changes in gas exchange kinetics with training in patients with spinal cord injury. Med. Sci. Sports Exerc., v. 28, n. 10, p. 1221-1228,1996.

BENTON, L. A.; BAKER, L.L.; BOWMAN, B.R. \& WATERS, R.L. Functional Electrical Stimulation - A Practical Clinical Guide The Professional Staff Associantion of Rancho Los Amigos Hospital, 2a Ed., 1979.

BERGMAN, R. A. Atlas of microscopic anatomy: a functional approach: companion to histology and neuroanatomy, $2^{\mathrm{a}}$ Ed., Philadelphia, 1989. 
BJÖRNTORP, P. Classification of obese patients and complications related to the distribution of surplus fat. American Journal of Clinical Nutrition, v. 45, p.1120-25, 1987.

BJÖRNTORP, P.; OTTOSSON, M.; REBUFFÉ-SCRIVE, M.; XU, X. Regional obesity and steroid hormone interactions in human adipose tissue. In: BRAY, G. A.; RICQUIER, D.; SPIEGELMAN, B., eds. Obesity towards a molecular approach. SYMPOSIA ON MOLECULAR AND CELLULAR BIOLOGY, New York: Wiley-Liss, UCLA, v. 132, p. 147 - 157, 1990.

BOBET, J., "Can Muscle Model Improve FES-Assisted Walking After Spinal Cord Injury?". Journal of Electromyography and Kinesiology, v. 8, p. 125132, 1998.

BRAY, G. A. Exercise and obesity. In: BOUCHARD,C.; SHEPARD R.J.; et. al. eds., Exercise, fitness, and health: a consensus of current knowledge. Illinois, Champaign III, Human Kinetics Books, p. 479-510, 1990.

BROOKE \& KAISER Muscle fiber types: How many and what kind?. Arch Neurol., v.23, p. $369-378,1970$.

BROMLEY, I. Paraplegia \& Tetraplegia - Um guia prático para fisioterapeutas. $4^{\text {a }}$ Ed., Editora Revinter, Rio de Janeiro, 1997.

CLINKINGBEARD, J.R.; GERSTON, J.W.; HOEHN, D. Energy cost of ambulation in traumatic paraplegic. Am. J. Phys. Med., v.43, p.157-165, 1984. apud NENE, A. V.; PATRICK, J.H. Energy Cost of Paraplegic Locomotion Using the Parawalker- Eletrical Stimulation "Hybrid"Orthosis. Arch. Phys. Med. Rehabil, v. 71, p. 116-120, February, 1990.

CLIQUET JR., A.; SOLOMONIDIS, S. E.; ANDREWS, B. J. Paraplegic locomotion with neuromuscular electrical stimulation. In: NORTH SEA CONFERENCE ON BIOMEDICAL ENGINEERING. INTERNATIONAL FEDERATION FOR MEDICAL AND BIOLOGICAL ENGINEERING, Antwerp, Bélgica, 1990.

CLIQUET JR., A.; SOLOMONIDIS, S. E.; ANDREWS, B. J.; PAUL, J. P. Fes in standing up paralyzed person - a biomechanical assessment. Clinical Applications of Biomechanics. Biological Engineering Society, University of Salford, GB, 1988.

CLIQUET JR., A.; BAXENDALE, R. H.; ANDREWS, B. J. Paraplegic Locomotion and its metabolic energy expenditure. In: Comprehensive Neurologic Rehabilitation. V. 3 - Neuromuscular Stimulation: Basic Concepts 
and Clinical Implications, Ed. Rose, Jones and Vrborá, New York, EUA, p. 139146, 1989, cap. 11.

CLIQUET JR. Paraplegic Gait Restoration Through Neuromuscular Eletrical Stimulation based Strategy In: IV INTERNATIONAL SYMPOSION ON BIOMEDICAL ENGINEERING, PENSICOLA, Espanha, 1991, Anais p. 214215, 1991.

DÂMASO, A.R.; TEIXEIRA, L.R.; NASCIMENTO CURI, C.M.O. Atividades motoras na obesidade: prevenção e intervenção. In: FISBERG, M. Org. Obesidade na infância e adolescência. São Paulo, Byk, p. 91-99, 1995, cap. 12.

DÂMASO, A. R. Efeitos do exercício agudo e crônico sobre o metabolismo lipídico e a celularidade adiposa de ratas no período de lactação e após o desmame. São Paulo, p. 120, Tese (Doutorado em Nutrição), UNIFESP-EPM, 1996.

DÂMASO, A. R. Nutrição e Exercício na Prevenção de Doenças 1a Ed., Ed. MEDSI, p. 155-182, 2001.

DAVIS, G.M.; KOFSKY, P.R.; KELSEY J.C.; SHEPARD, R.J. Cardiorespiratory fitness and muscular strength of weelchair users. Can. Med. Assoc. J., v. 125, p. $1313-1323,1981$.

DAVIS, G.M.; SERVEDIO, F.J.; GLASER, R.M.; GUPTA, S.C.; SURYAPRASAD, A.G. Cardiovascular responses to arm cranking ans FNSinduced leg exercise in paraplegics. J. Appl. Physiol., v. 69, p. 671-679,1990.

DAVIS, G.M.; SHEPHARD, R.J. Cardiorespiratory fitness in highly active versus inactive paraplegics. Med. Sci. Sports Exerc., v. 20, n. 5, p. 463-468,1988.

DICARRIO, R.A. \& SCHIMIDTMANN A multichanel Counter Timer Interface for the Acquisition of Neuronal Spike Trains. IEEE Transactions on Biomedical Engineering, v. BME 32, n. 5, p. 345-347, 1985.

FAGHIRI, P.D.; GLASER, R.M.; FIGONI, S.F. Functional Eletrical Stimulation Leg Cycle Ergometer Exercise: Training Effects on Cardiorespiratory Responses of Spinal Cord Injured Subjects at Rest and During Submaximal Exercise. Arch. Phys. Med. Rehabil, v. 73, p. 1085-1093, November, 1992.

FRANKEL, H.L.; HANCOCK, D.O.; HYSLOP, G. e col. The value of postural reduction in the initial management of closed injuries of the spine with paraplegia and tetraplegia. Paraplegia, v. 7, p. 179-192, 1969. 
FERRARETTO, I., Julho de 2000. "Dores nas Costas - Home Page" [on line], Disponível: http://www.doresnascostas.com.br/coluna.html [Capturado em 24/09/2001]

GEERLING, B.J.; ALLES, M. S.; MURGATROYD, P. R.; GOLDBERG, G.R.; HARDING, M.; PRENTICE, A.M. Fatness in relation to substrate oxidation during exercise. International Journal of Obesity, v. 18, n.7, p. 453-59, 1994.

GUYTON, M.D.A.C. Tratado de Fisiologia Médica. 8a Ed., Ed. Guanabara Koogan S.A, p. 831-2, 1992a.

GUYTON, M.D.A.C. Basic Neuroscience : Anatomy \& Physiology. 2a Ed., Philadelphia W.B. Saunders Company, p. 341-347, 1992b.

HARVEY, L. A., DAVIS, G. M.; SMITH, M. B.; ENGEL, S. Energy Expenditure During Gait Using the Walkabout and Isocentric Reciprocal Gait Orthoses in persons With Paraplegia. Arch. Phys. Med. Rehabil, v. 79, p. 945-49, August, 1998.

HUANG, C. T.; KUHLEMEIER,K.V.; MOORE, M. B.; FINE, P. R. Energy cost of ambulation in paraplegic patients using craig scott braces. Arch. Phys. Med. Rehabil., v. 600, p. 595 -600, 1979 apud NENE, A. V.; PATRICK, J.H. Energy Cost of Paraplegic Locomotion Using the Parawalker- Eletrical Stimulation "Hybrid"Orthosis. Arch. Phys. Med. Rehabil, v. 71, p. 116-120, February, 1990.

INSTITUTO BRASILEIRO DE GEOGRAFIA E ESTATÍSTICA - Censo Demográfico 1991 - Sistema do IBGE de Recuperação Automática - SIDRA. Disponível: http:/ www.sidra.ibge.gov.br [Capturado em 26/02/2002).

ISAKOV, E.; DOUGLAS, R.; BERNS, P. Ambulation using reciprocating gait orthosis and functional eletrical stimulation. Paraplegia, v. 30, p. 239-245, 1992.

ISAKOV, E.; MIZRAHI, J. ; NAJENSON, T. Biomechanical and physiological evaluation of FES-activated paraplegic patients. J. Reahabil Res Dev, v. 23, n. 3, p. 9-19, 1986 apud ISAKOV, E.; DOUGLAS, R.; BERNS, P. Ambulation using reciprocating gait orthosis and functional eletrical stimulation. Paraplegia, v. 30, p. 239-245, 1992.

JACKSON, R.W.; DAVIS, G.M.; KOFSKY, P.R.; SHEPHARD, R.J.; KEENE, G.C.R. Fitness levels in the lower limb disabled. Transactions of the $27^{\text {th }}$ Annual Meeting of the Orthopaedic Reserch Society, v.6, p. 12-14, 1981 apud DAVIS, G.M. Exercise capacity of individuals with paraplegia. Med. Sci. Sport Exerc., Oct, p. 423-432,1992. 
JAKEMAN, P.M. Amino Acid metabolism, branched-chain amino acid feeding and brain monoamine function. Proceedings of the Nutrition Society., v. 57, p. 34-41, 1998.

KATCH, F. I.; McARDLE, W.D. Nutrição Exercício e Saúde. Rio de Janeiro: Medsi, 4ª Edição, 1996.

KHANNA, N. Effects of exercise on pregnancy. Am. Family Physician., v. 57, n. 8, p. 1764-1771, 1998.

KRALJ, A.; BAJD, T.; Funtional Electrical Stimulatin: Standing and Walking after Spinal Cord Injury, Boca Raton, Flórida, CRC Press, Inc., 1989.

KRALJ, A.; BAJD, T.; TURK, R. Electrical stimulation providing functional use of paraplegic patient muscles. Med Prog Technol, v. 7(1 ), p. 3-9, April, 1980.

KOFSKY, P.R.; DAVIS, G.M.; JACKSON, R.W.; KEENE, G.C.R.; SHEPHARD, R.J. Field testing- assessment of physical fitness of disable adults. Eur. J. Appl. Physiol., v. 51, p. 109-120, 1983.

LACOURSE, J.R.; MILLER W.T.; VOGT, M. \& SELIKOWITZ, S.M. Effect of High-Frequency Current on Nerve and Muscle Tissue. IEEE Transactions on Biomedical Engineering, v. BME-32, n. 1, p. 82-86, 1985.

LANGBEIN, W.E.; MAKI, M. S. Predicting Oxygen Uptake During Counterclockwise Arm Crank Ergometry in Men Lower Limb Disabilities, Arch. Phys. Med. Rehabil, v. 76, p. 642-646, July,1995.

LIN, K.H.; LAI, J.S.; KAO, M. J.; LIEN, I. N. Anaerobic Threshold and Maximal Oxygen Consumption During Arm Cranking Exercise in Paraplegia. Arch. Phys. Med. Rehabil, v. 74, p. 515-520, May, 1993.

MACHADO, A. B. M. Neuroanatomia Funcional. $2^{a}$ Ed., Rio de Janeiro: Livraria Atheneu, 2000.

MALEZIC, M.; HESSE, S. Restoration of gait by functional electrical stimulation in paraplegic patients: a modified program of treatment. Paraplegia, v. 33(3), p. 126-131, Mar, 1995.

MARSOLAIS, E. B.; KOBETIC, R. Functional Electrical Stimulation for Walking in Paraplegia. The Journal of Bone and Joint Surgery, v. 69a, n. 5, p. 728733, June, 1987.

MATTHEWS, G. G., Novembro de 2000. "Neurobiology: Molecules, Cells and Systems" [online], Disponível: http://www.s2smed.com/matthews/index.html [Capturado em 24/09/2001]. 
MATSUNAGA T, SHIMADA $\mathrm{Y}$, SATO $\mathrm{K}$ Muscle fatigue from intermittent stimulation with low and high frequency electrical pulses. Arch Phys Med Rehabil, v. 80(1), p. 48-53, Jan, 1999.

McARDLE, W. D.; KATCH, F. I.; KATCH, V. L. Fisiologia do ExercícioEnergia, Nutrição e Desempenho Humano. 3a Ed., Ed. Guanabara Koogan S.A., 1992.

McARDLE, W. D.; KATCH, F. I. Introduction Exercise and Health 4a ed., Ed. Guanabara Koogan S.A., 1993.

McARDLE, W. D.; KATCH, F. I. Essential of Exercise Physiology. 4a Ed., Philadelphia: Lea \& Febiger, 1994.

MERKEL, K.D.; MILLER, N.E.,WESTBROOKE, P.R.; MERRITT, J.L. Energy expenditure of paraplegic patients standind and walking with two knee-anklefoot orthoses. Arch. Phys. Med. Rehabil., v. 65, p. 121-124 apud NENE, A. V.; PATRICK, J.H. Energy Cost of Paraplegic Locomotion Using the ParawalkerEletrical Stimulation "Hybrid"Orthosis. Arch. Phys. Med. Rehabil, v. 71, p. 116120, February, 1990.

MICHAELIS, J.S.; International inquiry on neurological terminology and prognosis in paraplegia and tetraplegia. Paraplegia, v. 7, p. 1-5, 1969.

MONROE, M.B.; TATARANNI, P.A.; PRATLEY, R.; MANORE, M.M.; SKINNER, J.S.; RAVUSIN, E. Lower daily energy expenditure as measured by a respiratory chamber in subjects with spinal cord injury compared with control subjects. Am. J. Clin. Nutr., v. 68, p. 1223-1227.

NATHAN, R.; TAVI, M. The influence of Stimulation Pulse Frequency on the Generation of Joint Movement in upper limb. IEEE- Transactions on Biomedical Engineering, v. 37(3), p. 317-322, 1990.

NENE, A. V.; PARTICK, J.H. Energy Cost of Paraplegic Locomotion Using the Parawalker - Eletrical Stimulation "Hybrid"Orthosis. Arch. Phys. Med. Rehabil, v. 71, p. 116-120, February, 1990.

NENE, A. V.; PARTICK, J.H. Energy Cost of Paraplegic Locomotion with the ORLAU Parawalker. Paraplegia, v. 27, p. 5-18,1989.

OLLE, M.M.; PIVARNIK, J.M.; KLISH, W.J.; MORROW, J.R. Jr. Body Composition of Sedentary and Physically Active Spinal Cord Injured Individuals Estimated From Total Body Eletrical Conductivity. Arch. Phys. Med. Rehabil, v. 74, p. 706-710, July, 1993. 
PEIXOTO, B. O.; CLIQUET JR., A. Redução da fadiga muscular através da Estimulação Elétrica Neuromuscular em pacientes portadores de lesão medular. Revista de Bioengenharia, Caderno de Engenharia Biomédica. Sociedade Brasileira de Engenharia Biomédica, Rio de Janeiro, v. 12, n. 2, p. 21-46, julho /dez 1996.

QUEVEDO, A. A. F.; SEPÚlVEDA, F.; CASTRO M. C. F.; SOVI, F. X.; NOHANA, P.; CLIQUET JR., A. Development of control strategies for restoring function to paralyzed upper and lower limbs. In: IEEE ANNUAL MEETING ENGINEERING IN MEDICINE AND BIOLOGY SOCIETY. The Institute of Electrical and Electronics Engineers, Chicago, EUA, pp. 1946-1949, 1997.

REDE SARAH, 2001. Disponível: http:/ www.sarah.br/Cepes/ [Capturado em 10/07/2002).

REYBROUCK, T. et al. Cardiorespiratory function during exercise in obese children. Acta Pediátrica Scandinavica, v. 76, p. 342-348, 1987.

RIDING, M.; BOURKE, J. The functional Track and Field Classification. Melbourne: Australian Wheelchair Sports Federation, 1989 apud DAVIS, G.M. Exercise capacity of individuals with paraplegia. Med. Sci. Sports and Exerc., Oct, p. 423-432,1992.

SALMONS, S. The adaptative capacity of skeletal muscle and its relevance to some therapeutic uses of eletrical stimulation. Proc Int Symp Cell Biology and Clinical Management, v. 71, p. 28-30, 1985.

SCHIMID, A.; HUONKER, M.; BARTUREN, J.M.; STAHL, F.; SCHMIDTTRUCKSÄSS,A.; KONIG,D.; GRATHWOHL,D.; LEHMANN, M. \& KEUL, J.,1998, Catecholamines, heart rate, and oxygen uptake during exercise in persons with spinal cord injury. J. Appl. Physiol., v.85 (2), pp. 635-641.

SCOTT, O.M.; VRBOVA, G.; HYDE, A.S.; DUBOWITZ, V. "Effects of Chronic Low Frequency Electrical Stimulation on Normal Human Tibialis Anterior Muscle". J Neurol Neurosurg Psychiatry, v. 48, p. 774-781, 1985.

SNYDER, A. C. Overtraining and glycogen depletion hypothesis. Med. Sci. Sports Exerc., v. 30 (7), p. 1146-1150, 1998.

SOBOTTA, J. Atlas de Anatomia, Rio de Janeiro, Editora Guanabara Koogan, 2000.

SPUNGEN, A.M.; BAUMAN, W. A.; WANG, J.PIERSON, R. N. Jr. The relationship Between Total Body Potassium and Resting Energy Expenditure in 
Individuals with Paraplegia. Arch. Phys. Med. Rehabil, v. 74, p. 965-968, September, 1993.

STEFANOVSKA, A.; VODONIK, L.; GROS, N.; REBERSEKS \& ACINOVICJANEZIC R. Fes and Spasticity. IEEE Transactions on Biomedical Engineering, v. 36, n. 7, p. 738-745, 1986.

WILHERE, G.F.; GRACO, P. E. \& CHIZECK, H.J. Design and Evaluation of Digital Closed-Loop Controller for the Regulation of Muscle Force by Recruitment Modulation. IEEE Transactions on Biomedical Engineering, $v$. BME 32, n. 9, p. 668-676, 1985.

WILMORE, J.; COSTILL, D. L. Physiology of Sport and Exercise. Human Kinetics, 1994.

WINNICK, J.P.; SHORT, F.X. The physical fitness of youngsters with spinal neuromuscular conditions. APAQ, v.1, p. 37-51, 1984.

YOUNG, J.; BURNS, P.; BOWEN, A. M.; MCCUTCHEN, R. "Spinal Cord Injury Statistics", Phoenix, Arizona: Good Samaritan Medical Center, 1982. 


\section{APÊNDICES}

Apêndice 1 - Tabelas e Gráficos Individuais

\begin{tabular}{|c|c|c|c|c|c|c|}
\hline Voluntário I & $\begin{array}{c}\mathrm{VO}_{2} \\
\mathrm{mlKg} / \mathrm{min}\end{array}$ & $\begin{array}{l}\mathrm{VO}_{2} \\
\mathrm{~L} / \mathrm{min}\end{array}$ & $\begin{array}{l}\mathrm{VCO}_{2} \\
\mathrm{~L} / \mathrm{min}\end{array}$ & 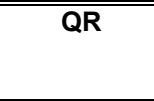 & $\begin{array}{c}\text { Energia } \\
\text { Consumida } \\
\text { J/Kgs }\end{array}$ & $\begin{array}{c}\text { Gasto } \\
\text { Energético } \\
\text { J/Kgm }\end{array}$ \\
\hline \multirow{20}{*}{ 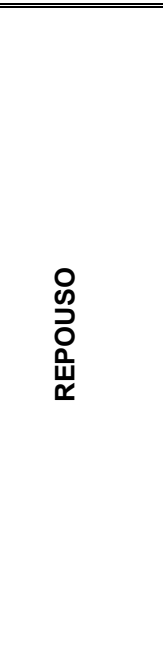 } & 3,53 & 0,247 & 0,271 & $1,1,10$ & $1,1,19$ & \\
\hline & 3,94 & 0,276 & 0,275 & 1,0 & 1,33 & \\
\hline & 3,74 & 0,262 & 0,277 & 1,06 & 1,26 & \\
\hline & 3,43 & 0,240 & 0,249 & 1,04 & 1,15 & \\
\hline & 3,70 & 0,259 & 0,236 & 0,91 & 1,25 & \\
\hline & 3,24 & 0,227 & 70,210 & 0,93 & 1,09 & \\
\hline & 4,11 & 0,288 & 0,249 & 0,86 & 1,38 & \\
\hline & 3,04 & 0,213 & 0,180 & 0,85 & 1,02 & \\
\hline & 4,37 & 0,306 & 0,254 & 0,83 & 1,47 & \\
\hline & 4,59 & 0,321 & 0,285 & 0,89 & 1,54 & \\
\hline & 2,91 & 0,204 & 0,159 & 0,78 & 0,98 & \\
\hline & 3,43 & 0,240 & 0,178 & 0,74 & 1,15 & \\
\hline & 3,21 & 0,225 & 0,168 & 0,75 & 1,08 & \\
\hline & 3,23 & 0,226 & 0,163 & 0,72 & 1,09 & \\
\hline & 3,50 & 0,245 & 0,182 & 0,74 & 1,18 & \\
\hline & 3,44 & 0,241 & 0,167 & 0,69 & 1,16 & \\
\hline & 3,66 & 0,256 & 0,181 & 0,71 & 1,23 & \\
\hline & 2,34 & 0,164 & 0,104 & 0,63 & 0,79 & \\
\hline & 6,20 & 0,434 & 0,318 & 0,73 & 2,09 & \\
\hline & 4,60 & 0,322 & 0,262 & 0,81 & 1,55 & \\
\hline \multirow[t]{16}{*}{ Média \pm DP } & $3,71 \pm 0,81$ & $0,260 \pm 0,05$ & $0,218 \pm 0,01$ & $0,78 \pm 0,2$ & $1,25 \pm 0,25$ & \\
\hline & 6,03 & 0,422 & 0,256 & 0,61 & 2,03 & 16,91 \\
\hline & 13,11 & 0,918 & 0,517 & 0,56 & 4,41 & 36,77 \\
\hline & 15,14 & 1,06 & 0,653 & 0,62 & 5,10 & 42,46 \\
\hline & 15,63 & 1,094 & 0,660 & 0,60 & 5,26 & 43,83 \\
\hline & 13,33 & 0,933 & 0,668 & 0,72 & 4,49 & 37,38 \\
\hline & 14,13 & 0,989 & 0,750 & 0,76 & 4,75 & 39,62 \\
\hline & 18,71 & 1,31 & 0,931 & 0,71 & 6,30 & 52,48 \\
\hline & 17,56 & 1,229 & 0,899 & 0,73 & 5,91 & 49,23 \\
\hline & 15,69 & 1,098 & 0,894 & 0,81 & 5,28 & 43,99 \\
\hline & 12,67 & 0,887 & 0,718 & 0,81 & 4,26 & 35,53 \\
\hline & 14,47 & 1,013 & 0,701 & 0,69 & 4,87 & 40,58 \\
\hline & 15,76 & 1,103 & 0,833 & 0,76 & 5,30 & 44,19 \\
\hline & 18,99 & 1,329 & 1,058 & 0,80 & 6,39 & 53,24 \\
\hline & 18,80 & 1,316 & 1,012 & 0,77 & 6,33 & 52,72 \\
\hline & 14,29 & 1,00 & 0,901 & 0,90 & 4,81 & 40,06 \\
\hline \multirow[t]{17}{*}{ Média \pm DP } & $14,95 \pm 3,23$ & $1,047 \pm 0,41$ & $0,763 \pm 0,45$ & $0,72 \pm 0,21$ & $5,03 \pm 1,96$ & $41,93 \pm 16,37$ \\
\hline & 18,00 & 1,26 & 1,199 & 0,95 & 6,06 & \\
\hline & 12,77 & 0,894 & 0,949 & 1,06 & 4,30 & \\
\hline & 9,86 & 0,690 & 0,721 & 1,04 & 3,32 & \\
\hline & 7,59 & 0,531 & 0,648 & 1,22 & 2,55 & \\
\hline & 6,73 & 0,471 & 0,490 & 1,04 & 2,26 & \\
\hline & 7,94 & 0,556 & 0,545 & 0,98 & 2,67 & \\
\hline & 6,86 & 0,480 & 0,514 & 1,07 & 2,31 & \\
\hline & 5,10 & 0,357 & 0,405 & 1,13 & 1,72 & \\
\hline & 4,86 & 0,340 & 0,339 & 1,00 & 1,63 & \\
\hline & 5,40 & 0,378 & 0,371 & 0,98 & 1,82 & \\
\hline & 4,76 & 0,333 & 0,318 & 0,95 & 1,60 & \\
\hline & 4,67 & 0,327 & 0,303 & 0,93 & 1,57 & \\
\hline & 4,49 & 0,314 & 0,278 & 0,89 & 1,51 & \\
\hline & 3,93 & 0,275 & 0,218 & 0,79 & 1,32 & \\
\hline & 4,17 & 0,292 & 0,222 & 0,76 & 1,40 & \\
\hline & 4,97 & 0,348 & 0,266 & 0,76 & 1,67 & \\
\hline
\end{tabular}




\begin{tabular}{rccccc} 
& 4,40 & 0,308 & 0,215 & 0,70 & 1,48 \\
& 5,64 & 0,395 & 0,321 & 0,81 & 1,90 \\
& 3,87 & 0,271 & 0,221 & 0,82 & 1,30 \\
& 6,01 & 0,421 & 0,354 & 0,84 & 2,02 \\
Média \pm DP & $\mathbf{5 3 , 1}$ & 0,372 & 0,300 & 0,81 & 1,79 \\
\hline \hline
\end{tabular}

\begin{tabular}{|c|c|c|c|c|c|c|}
\hline $\begin{array}{c}\text { Voluntário } \\
\text { II }\end{array}$ & $\begin{array}{c}\mathrm{VO}_{2} \\
\mathrm{mIKg} / \mathrm{min}\end{array}$ & $\begin{array}{l}\mathrm{VO}_{2} \\
\mathrm{~L} / \mathrm{min}\end{array}$ & $\begin{array}{l}\mathrm{VCO}_{2} \\
\mathrm{~L} / \mathrm{min}\end{array}$ & $\overline{\text { QR }}$ & $\begin{array}{c}\text { Energia } \\
\text { Consumida } \\
\text { J/Kgs }\end{array}$ & $\begin{array}{c}\text { Gasto Energético } \\
\mathrm{J} / \mathrm{Kgm}\end{array}$ \\
\hline \multirow{20}{*}{ 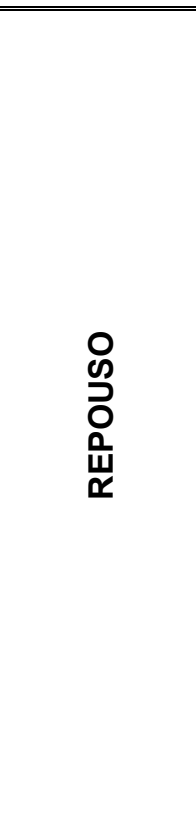 } & 3,69 & 0,317 & 0,218 & 0,69 & $1,1,24$ & \\
\hline & 3,01 & 0,259 & 0,187 & 0,72 & 1,01 & \\
\hline & 3,27 & 0,281 & 0,206 & 0,73 & 1,10 & \\
\hline & 2,34 & 0,201 & 0,143 & 0,71 & 0,79 & \\
\hline & 3,30 & 0,284 & 0,196 & 0,69 & 1,11 & \\
\hline & 3,60 & 0,310 & 0,218 & 0,70 & 1,21 & \\
\hline & 3,48 & 0,299 & 0,232 & 0,78 & 1,17 & \\
\hline & 2,66 & 0,229 & 0,173 & 0,76 & 0,90 & \\
\hline & 2,63 & 0,226 & 0,170 & 0,75 & 0,88 & \\
\hline & 2,79 & 0,240 & 0,178 & 0,74 & 0,94 & \\
\hline & 2,80 & 0,241 & 0,180 & 0,75 & 0,94 & \\
\hline & 2,49 & 0,214 & 0,154 & 0,72 & 0,84 & \\
\hline & 2,95 & 0,254 & 0,183 & 0,72 & 0,99 & \\
\hline & 2,42 & 0,208 & 0,151 & 0,73 & 0,81 & \\
\hline & 3,23 & 0,278 & 0,200 & 0,72 & 1,09 & \\
\hline & 2,37 & 0,204 & 0,153 & 0,75 & 0,80 & \\
\hline & 2,80 & 0,241 & 0,170 & 0,71 & 0,94 & \\
\hline & 3,12 & 0,268 & 0,204 & 0,76 & 1,05 & \\
\hline & 3,36 & 0,289 & 0,205 & 0,71 & 1,13 & \\
\hline & 3,87 & 0,333 & 0,260 & 0,78 & 1,30 & \\
\hline \multirow[t]{6}{*}{ Média \pm DP } & $3,01 \pm 0,46$ & $0,259 \pm 0,04$ & $0,198 \pm 0,03$ & $0,73 \pm 0,02$ & $1,01 \pm 0,15$ & \\
\hline & 4,23 & 0,364 & 0,284 & 0,78 & 1,42 & 85,46 \\
\hline & 4,01 & 0,345 & 0,275 & 0,80 & 1,35 & 80,99 \\
\hline & 12,78 & 1,099 & 0,915 & 0,83 & 4,30 & 258,01 \\
\hline & 12,69 & 1,091 & 1,131 & 1,04 & 4,27 & 256,13 \\
\hline & 16,85 & 1,449 & 1,44 & 0,99 & 5,67 & 340,18 \\
\hline \multirow[t]{14}{*}{ Média \pm DP } & $10,11 \pm 5,72$ & $0,870 \pm 0,49$ & $0,809 \pm 0,52$ & $0,89 \pm 0,12$ & $3,40 \pm 1,92$ & $204,15 \pm 115,50$ \\
\hline & 12,95 & 1,114 & 1,28 & 1,15 & 4,36 & \\
\hline & 8,74 & 0,752 & 0,982 & 1,31 & 2,94 & \\
\hline & 7,72 & 0,664 & 0,851 & 1,28 & 2,60 & \\
\hline & 5,57 & 0,479 & 0,554 & 1,16 & 1,87 & \\
\hline & 5,83 & 0,501 & 0,560 & 1,12 & 1,96 & \\
\hline & 4,67 & 0,402 & 0,412 & 1,02 & 1,57 & \\
\hline & 3,90 & 0,335 & 0,338 & 1,01 & 1,31 & \\
\hline & 3,84 & 0,330 & 0,318 & 0,96 & 1,29 & \\
\hline & 4,09 & 0,352 & 0,337 & 0,96 & 1,38 & \\
\hline & 3,37 & 0,290 & 0,270 & 0,93 & 1,13 & \\
\hline & 3,65 & 0,314 & 0,283 & 0,90 & 1,23 & \\
\hline & 3,69 & 0,317 & 0,280 & 0,88 & 1,24 & \\
\hline & 3,60 & 0,310 & 0,268 & 0,86 & 1,21 & \\
\hline
\end{tabular}




\begin{tabular}{rccccc} 
& 4,16 & 0,358 & 0,299 & 0,84 & 1,40 \\
& 3,16 & 0,272 & 0,227 & 0,83 & 1,06 \\
3,57 & 0,307 & 0,254 & 0,83 & 1,20 \\
& 3,34 & 0,287 & 0,267 & 0,83 & 1,12 \\
& 3,44 & 0,296 & 0,235 & 0,79 & 1,16 \\
& 2,97 & 0,255 & 0,193 & 0,76 & 1,00 \\
Média \pm DP & $\mathbf{4 , 4 9} \pm \mathbf{2 , 4 5}$ & $\mathbf{0 , 4 1 2} \pm \mathbf{0 , 2 1}$ & $\mathbf{0 , 4 2 0} \pm \mathbf{0 , 2 9}$ & $\mathbf{0 , 9 6 \pm 0 , 1 6}$ & $\mathbf{1 , 6 1} \pm \mathbf{0 , 8 3}$ \\
\hline \hline
\end{tabular}

\begin{tabular}{|c|c|c|c|c|c|c|}
\hline $\begin{array}{c}\text { Voluntário } \\
\text { III }\end{array}$ & $\begin{array}{c}\mathrm{VO}_{2} \\
\mathrm{mIKg} / \mathrm{min}\end{array}$ & $\begin{array}{l}\mathrm{VO}_{2} \\
\mathrm{~L} / \mathrm{min}\end{array}$ & $\begin{array}{l}\mathrm{VCO}_{2} \\
\mathrm{~L} / \mathrm{min}\end{array}$ & 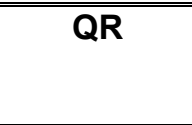 & $\begin{array}{c}\text { Energia } \\
\text { Consumida } \\
\mathrm{J} / \mathrm{Kgs}\end{array}$ & $\begin{array}{c}\text { Gasto } \\
\text { Energético } \\
\text { J/Kgm }\end{array}$ \\
\hline \multirow{21}{*}{ 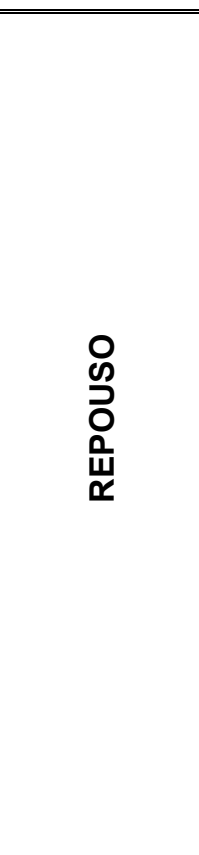 } & 4,88 & 0,395 & 0,351 & 0,89 & 1,64 & \\
\hline & 4,73 & 0,383 & 0,294 & 0,77 & 1,59 & \\
\hline & 4,85 & 0,393 & 0,303 & 0,77 & 1,63 & \\
\hline & 3,57 & 0,289 & 0,280 & 0,72 & 1,20 & \\
\hline & 4,25 & 0,344 & 0,247 & 0,72 & 1,43 & \\
\hline & 3,65 & 0,296 & 0,200 & 0,68 & 1,23 & \\
\hline & 5,19 & 0,420 & 0,321 & 0,76 & 1,74 & \\
\hline & 3,56 & 0,288 & 0,213 & 0,74 & 1,20 & \\
\hline & 3,72 & 0,301 & 0,210 & 0,70 & 1,25 & \\
\hline & 4,47 & 0,362 & 0,253 & 0,70 & 1,50 & \\
\hline & 5,42 & 0,439 & 0,370 & 0,84 & 1,82 & \\
\hline & 3,05 & 0,247 & 0,211 & 0,85 & 1,03 & \\
\hline & 4,68 & 0,379 & 0,279 & 0,74 & 1,57 & \\
\hline & 3,96 & 0,321 & 0,242 & 0,75 & 1,33 & \\
\hline & 3,40 & 0,275 & 0,185 & 0,67 & 1,14 & \\
\hline & 3,16 & 0,256 & 0,171 & 0,67 & 1,06 & \\
\hline & 4,28 & 0,347 & 0,258 & 0,74 & 1,44 & \\
\hline & 3,11 & 0,252 & 0,179 & 0,71 & 1,05 & \\
\hline & 3,57 & 0,289 & 0,181 & 0,63 & 1,20 & \\
\hline & 4,67 & 0,378 & 0,288 & 0,76 & 1,57 & \\
\hline & 4,85 & 0,393 & 0,297 & 0,76 & 1,63 & \\
\hline \multirow[t]{2}{*}{ Média \pm DP } & $4,11 \pm 0,73$ & $0,336 \pm 0,06$ & $0,251 \pm 0,06$ & $0,74 \pm 0,06$ & $1,39 \pm 0,24$ & \\
\hline & 11,00 & 0,891 & 0,623 & 0,70 & 3,70 & 32,90 \\
\hline \multirow{7}{*}{$\begin{array}{l}\frac{O}{U} \\
\frac{U}{U} \\
\frac{x}{\Psi} \\
\text { U }\end{array}$} & 12,60 & 1,021 & 0,701 & 0,69 & 4,24 & 37,70 \\
\hline & 15,16 & 1,228 & 0,933 & 0,76 & 5,10 & 45,35 \\
\hline & 20,74 & 1,680 & 1,200 & 0,71 & 6,98 & 62,04 \\
\hline & 18,32 & 1,484 & 1,110 & 0,75 & 6,17 & 54,80 \\
\hline & 16,81 & 1,362 & 1,202 & 0,88 & 5,66 & 50,29 \\
\hline & 17,96 & 1,455 & 1,155 & 0,79 & 6,04 & 53,73 \\
\hline & 16,62 & 1,346 & 1,217 & 0,90 & 5,59 & 49,70 \\
\hline Média \pm DP & $14,68 \pm 5,07$ & $1,308 \pm 0,26$ & $1,018 \pm 0,24$ & $0,77 \pm 0,08$ & $5,44 \pm 1,06$ & $48,31 \pm 9,45$ \\
\hline \multirow{6}{*}{ 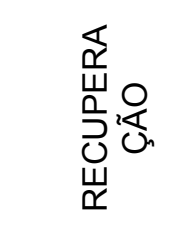 } & 16,91 & 1,370 & 1,480 & 1,08 & 5,69 & \\
\hline & 11,48 & 0,930 & 1,153 & 1,24 & 3,86 & \\
\hline & 9,43 & 0,764 & 0,902 & 1,18 & 3,17 & \\
\hline & 7,22 & 0,585 & 0,709 & 1,21 & 2,43 & \\
\hline & 6,59 & 0,534 & 0,608 & 1,14 & 2,22 & \\
\hline & 5,93 & 0,480 & 0,507 & 1,06 & 1,99 & \\
\hline
\end{tabular}




$\begin{array}{lllll}6,32 & 0,512 & 0,547 & 1,07 & 2,13 \\ 5,74 & 0,465 & 0,466 & 1,00 & 1,93 \\ 5,43 & 0,440 & 0,447 & 1,02 & 1,83 \\ 5,68 & 0,460 & 0,448 & 0,97 & 1,91 \\ 5,19 & 0,420 & 0,387 & 0,92 & 1,74 \\ 4,40 & 0,356 & 0,326 & 0,92 & 1,48 \\ 5,88 & 0,476 & 0,401 & 0,84 & 1,98 \\ 5,19 & 0,420 & 0,391 & 0,93 & 1,74 \\ 5,01 & 0,406 & 0,361 & 0,89 & 1,69 \\ 5,27 & 0,427 & 0,386 & 0,90 & 1,77 \\ 4,27 & 0,346 & 0,310 & 0,90 & 1,44 \\ 4,32 & 0,350 & 0,275 & 0,79 & 1,45 \\ 3,90 & 0,316 & 0,266 & 0,84 & 1,31 \\ 4,19 & 0,339 & 0,268 & 0,79 & 1,41\end{array}$

$\begin{array}{llllll}\text { Média } \pm \text { DP } & 6,90 \pm 3,73 & 0,520 \pm 0,25 & 0,532 \pm 0,31 & 0,98 \pm 0,14 & 2,16 \pm 1,03\end{array}$

\begin{tabular}{|c|c|c|c|c|c|c|}
\hline $\begin{array}{c}\text { Voluntário } \\
\text { IV }\end{array}$ & $\begin{array}{c}\mathrm{VO}_{2} \\
\mathrm{mlKg} / \mathrm{min}\end{array}$ & $\begin{array}{l}\mathrm{VO}_{2} \\
\mathrm{~L} / \mathrm{min}\end{array}$ & $\begin{array}{l}\mathrm{VCO}_{2} \\
\mathrm{~L} / \mathrm{min}\end{array}$ & QR & $\begin{array}{c}\text { Energia } \\
\text { Consumida } \\
\text { J/Kgs }\end{array}$ & $\begin{array}{c}\text { Gasto } \\
\text { Energético } \\
\text { J/Kgm }\end{array}$ \\
\hline \multirow{21}{*}{ 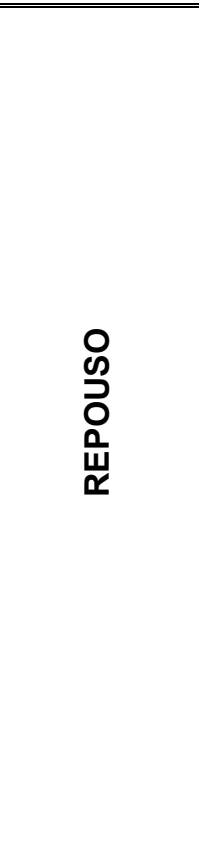 } & 6,72 & 0,336 & 0,283 & 0,84 & 2,26 & \\
\hline & 7,08 & 0,354 & 0,291 & 0,82 & 2,38 & \\
\hline & 7,40 & 0,370 & 0,330 & 0,89 & 2,49 & \\
\hline & 6,26 & 0,313 & 0,284 & 0,91 & 2,11 & \\
\hline & 5,46 & 0,273 & 0,249 & 0,91 & 1,84 & \\
\hline & 9,32 & 0,466 & 0,391 & 0,84 & 3,14 & \\
\hline & 3,66 & 0,183 & 0,149 & 0,81 & 1,23 & \\
\hline & 7,30 & 0,365 & 0,307 & 0,84 & 2,46 & \\
\hline & 7,46 & 0,373 & 0,311 & 0,83 & 2,51 & \\
\hline & 3,18 & 0,159 & 0,135 & 0,85 & 1,07 & \\
\hline & 5,12 & 0,256 & 0,172 & 0,67 & 1,72 & \\
\hline & 6,86 & 0,343 & 0,237 & 0,69 & 2,31 & \\
\hline & 4,38 & 0,219 & 0,168 & 0,77 & 1,47 & \\
\hline & 5,40 & 0,270 & 0,204 & 0,76 & 1,82 & \\
\hline & 5,54 & 0,277 & 0,192 & 0,69 & 1,86 & \\
\hline & 6,54 & 0,327 & 0,225 & 0,69 & 2,20 & \\
\hline & 5,92 & 0,296 & 0,227 & 0,77 & 1,99 & \\
\hline & 5,12 & 0,256 & 0,190 & 0,74 & 1,72 & \\
\hline & 6,30 & 0,315 & 0,233 & 0,74 & 2,12 & \\
\hline & 4,72 & 0,236 & 0,171 & 0,72 & 1,59 & \\
\hline & 7,2 & 0,360 & 0,278 & 0,77 & 2,42 & \\
\hline Média \pm DP & $5,99 \pm 1,45$ & $0,302 \pm 0,07$ & $0,239 \pm 0,07$ & $0,79 \pm 0,07$ & $2,03 \pm 0,48$ & \\
\hline & 24,92 & 1,246 & 0,440 & 0,35 & 8,39 & 87,57 \\
\hline$\frac{u}{U}$ & 19,38 & 0,969 & 0,792 & 0,82 & 6,52 & 303,09 \\
\hline$\frac{0}{U}$ & 18,8 & 0,940 & 0,769 & 0,82 & 6,33 & 253,71 \\
\hline 品 & 19,76 & 0,988 & 0,894 & 0,90 & 6,65 & 228,66 \\
\hline 岗 & 18,22 & 0,911 & 0,793 & 0,87 & 6,13 & 240,33 \\
\hline & 16,68 & 0,834 & 0,725 & 0,87 & 5,61 & 221,60 \\
\hline
\end{tabular}




\begin{tabular}{|c|c|c|c|c|c|c|}
\hline & 20,54 & 1,027 & 0,891 & 0,87 & 6,91 & 202,87 \\
\hline & 17,94 & 0,897 & 0,828 & 0,92 & 6,04 & 249,82 \\
\hline & 19,00 & 0,950 & 0,795 & 0,84 & 6,39 & 218,20 \\
\hline & 18,42 & 0,921 & 0,819 & 0,89 & 6,20 & 231,09 \\
\hline & 20,12 & 1,006 & 0,851 & 0,85 & 6,77 & 224,04 \\
\hline & 17,66 & 0,883 & 0,806 & 0,91 & 5,94 & 244,71 \\
\hline & 18,1 & 0,905 & 0,754 & 0,83 & 6,09 & 214,79 \\
\hline & 18,42 & 0,921 & 0,787 & 0,58 & 6,20 & 220,14 \\
\hline & 17,98 & 0,899 & 0,736 & 0,82 & 6,05 & 224,047 \\
\hline & 20,88 & 1,044 & 0,842 & 0,81 & 7,03 & 218,68 \\
\hline & 24,96 & 1,248 & 0,937 & 0,75 & 8,40 & 253,96 \\
\hline & 26,38 & 1,319 & 1,045 & 0,79 & 8,88 & 303,58 \\
\hline & 18,46 & 0,923 & 0,783 & 0,85 & 6,21 & 320,85 \\
\hline & 17,04 & 0,852 & 0,761 & 0,89 & 5,73 & 224,52 \\
\hline & 15,94 & 0,797 & 0,686 & 0,86 & 5,36 & 207,25 \\
\hline \multirow[t]{21}{*}{ Média \pm DP } & $19,09 \pm 3,74$ & $0,975 \pm 0,14$ & $0,797 \pm 0,11$ & $0,83 \pm 0,12$ & $6,56 \pm 0,93$ & $232,17 \pm 46,12$ \\
\hline & 11,54 & 0,577 & 0,545 & 0,94 & 3,88 & \\
\hline & 12,00 & 0,600 & 0,586 & 0,98 & 4,04 & \\
\hline & 5,84 & 0,292 & 0,286 & 0,98 & 1,97 & \\
\hline & 9,1 & 0,455 & 0,424 & 0,93 & 3,06 & \\
\hline & 10,48 & 0,524 & 0,475 & 0,91 & 3,53 & \\
\hline & 9,56 & 0,478 & 0,442 & 0,92 & 3,22 & \\
\hline & 7,36 & 0,368 & 0,295 & 0,80 & 2,48 & \\
\hline & 4,76 & 0,238 & 0,198 & 0,83 & 1,60 & \\
\hline & 8,68 & 0,434 & 0,376 & 0,87 & 2,92 & \\
\hline & 4,74 & 0,237 & 0,209 & 0,88 & 1,60 & \\
\hline & 6,66 & 0,333 & 0,295 & 0,89 & 2,24 & \\
\hline & 6,70 & 0,335 & 0,283 & 0,84 & 2,25 & \\
\hline & 6,44 & 0,322 & 0,284 & 0,88 & 2,17 & \\
\hline & 4,56 & 0,228 & 0,197 & 0,86 & 1,53 & \\
\hline & 9,44 & 0,472 & 0,417 & 0,88 & 3,18 & \\
\hline & 11,42 & 0,571 & 0,494 & 0,87 & 3,84 & \\
\hline & 3,08 & 0,190 & 0,157 & 0,83 & 1,28 & \\
\hline & 6,38 & 0,319 & 0,241 & 0,76 & 2,15 & \\
\hline & 3,90 & 0,195 & 0,150 & 0,77 & 1,31 & \\
\hline & 5,14 & 0,257 & 0,189 & 0,74 & 1,73 & \\
\hline Média \pm DP & $7,83 \pm 3,20$ & $0,371 \pm 0,13$ & $0,327 \pm 0,13$ & $0,87 \pm 0,06$ & $2,50 \pm 0,90$ & \\
\hline
\end{tabular}

\begin{tabular}{|c|c|c|c|c|c|c|}
\hline $\begin{array}{c}\text { Voluntário } \\
\text { V }\end{array}$ & $\begin{array}{c}\mathrm{VO}_{2} \\
\mathrm{mIKg} / \mathrm{min}\end{array}$ & $\begin{array}{l}\mathrm{VO}_{2} \\
\mathrm{~L} / \mathrm{min}\end{array}$ & $\begin{array}{l}\mathrm{VCO}_{2} \\
\mathrm{~L} / \mathrm{min}\end{array}$ & $\overline{\text { QR }}$ & $\begin{array}{c}\text { Energia } \\
\text { Consumida } \\
\text { J/Kgs }\end{array}$ & $\begin{array}{c}\text { Gasto } \\
\text { Energético } \\
\text { J/Kgm }\end{array}$ \\
\hline \multirow{8}{*}{ 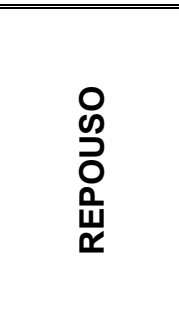 } & 3,8 & 0,165 & 0,177 & 0,71 & 1,29 & \\
\hline & 4,1 & 0,177 & 0,122 & 0,70 & 1,39 & \\
\hline & 4,0 & 0,173 & 0,120 & 0,71 & 1,35 & \\
\hline & 3,2 & 0,138 & 0,097 & 0,73 & 1,08 & \\
\hline & 4,5 & 0,192 & 0,136 & 0,71 & 1,50 & \\
\hline & 5,0 & 0,213 & 0,156 & 0,73 & 1,67 & \\
\hline & 3,3 & 0,142 & 0,097 & 0,70 & 1,11 & \\
\hline & 3,2 & 0,136 & 0,092 & 0,71 & 1,06 & \\
\hline
\end{tabular}




\begin{tabular}{|c|c|c|c|c|c|c|}
\hline & 3,4 & 0,145 & 0,097 & 0,67 & 1,13 & \\
\hline & 6,2 & 0,267 & 0,167 & 0,63 & 2,09 & \\
\hline & 5,1 & 0,218 & 0,138 & 0,64 & 1,71 & \\
\hline & 3,1 & 0,133 & 0,097 & 0,78 & 1,04 & \\
\hline & 5,4 & 0,232 & 0,149 & 0,64 & 1,82 & \\
\hline & 3,0 & 0,131 & 0,095 & 0,75 & 1,03 & \\
\hline & 4,7 & 0,203 & 0,143 & 0,71 & 1,59 & \\
\hline & 3,2 & 0,138 & 0,092 & 0,67 & 1,08 & \\
\hline & 6,1 & 0,163 & 0,116 & 0,86 & 2,06 & \\
\hline & 3,6 & 0,155 & 0,102 & 0,67 & 1,21 & \\
\hline & 6,3 & 0,272 & 0,188 & 0,69 & 2,13 & \\
\hline & 6,9 & 0,295 & 0,210 & 0,73 & 2,31 & \\
\hline Média \pm DP & $4,4 \pm 1,2$ & $0,184 \pm 0,05$ & $0,130 \pm 0,04$ & $0,71 \pm 0,05$ & $1,48 \pm 0,48$ & \\
\hline & 6,9 & 0,297 & 0,211 & 0,77 & 2,32 & 20,66 \\
\hline & 11,1 & 0,479 & 0,344 & 0,72 & 3,75 & 33,32 \\
\hline & 8,3 & 0,358 & 0,270 & 0,76 & 2,80 & 24,90 \\
\hline & 7,4 & 0,320 & 0,233 & 0,75 & 2,50 & 22,26 \\
\hline & 6,5 & 0,279 & 0,210 & 0,83 & 2,18 & 19,41 \\
\hline & 8,8 & 0,378 & 0,288 & 0,85 & 2,96 & 26,29 \\
\hline & 10,3 & 0,443 & 0,324 & 0,87 & 3,47 & 30,82 \\
\hline & 6,8 & 0,293 & 0,210 & 0,77 & 2,29 & 20,38 \\
\hline & 10,8 & 0,466 & 0,326 & 0,72 & 3,65 & 32,42 \\
\hline & 10,5 & 0,452 & 0,325 & 0,79 & 3,54 & 31,44 \\
\hline$\underline{0}$ & 11,2 & 0,482 & 0,332 & 0,71 & 3,77 & 33,53 \\
\hline$\underline{\bar{U}}$ & 10,4 & 0,448 & 0,348 & 0,80 & 3,51 & 31,16 \\
\hline U્ષ & 9,5 & 0,409 & 0,312 & 0,80 & 3,20 & 28,45 \\
\hline 岀 & 9,7 & 0,417 & 0,303 & 0,76 & 3,26 & 29,01 \\
\hline 崫 & 11,7 & 0,505 & 0,326 & 0,67 & 3,95 & 35,13 \\
\hline & 9,1 & 0,393 & 0,321 & 0,84 & 3,08 & 27,34 \\
\hline & 10,5 & 0,453 & 0,327 & 0,76 & 3,54 & 31,51 \\
\hline & 9,3 & 0,400 & 0,326 & 0,88 & 3,13 & 27,82 \\
\hline & 9,6 & 0,414 & 0,293 & 0,77 & 3,24 & 28,80 \\
\hline & 9,0 & 0,387 & 0,319 & 0,87 & 3,03 & 26,92 \\
\hline & 8,7 & 0,376 & 0,288 & 0,78 & 2,94 & 26,15 \\
\hline & 8,4 & 0,360 & 0,300 & 0,90 & 2,82 & 25,04 \\
\hline & 10,4 & 0,446 & 0,340 & 0,79 & 3,49 & 31,02 \\
\hline & 9,7 & 0,418 & 0,313 & 0,75 & 3,27 & 29,08 \\
\hline & 9,2 & 0,395 & 0,314 & 0,81 & 3,09 & 27,48 \\
\hline Média \pm DP & $\begin{array}{c}9,4 \pm 1,4 \\
115\end{array}$ & $\begin{array}{c}\mathbf{0 , 4 0 3} \pm \mathbf{0 , 0 6} \\
0494\end{array}$ & $\begin{array}{c}\mathbf{0 , 3 0 0} \pm \mathbf{0 , 0 4} \\
0,376\end{array}$ & $\mathbf{0 , 7 9} \pm \mathbf{0 , 0 6}$ & $\begin{array}{c}3,15 \pm 0,48 \\
387\end{array}$ & $28,01 \pm 4,23$ \\
\hline RECUPERA & 14,9 & 0,639 & 0,505 & 0,78 & 5,00 & \\
\hline ÇÃO & 10,6 & 0,454 & 0,383 & 0,85 & 3,55 & \\
\hline & 8,2 & 0,351 & 0,308 & 0,88 & 2,75 & \\
\hline & 12,8 & 0,550 & 0,482 & 0,90 & 4,30 & \\
\hline & 8,1 & 0,349 & 0,297 & 0,85 & 2,73 & \\
\hline & 7,5 & 0,322 & 0,240 & 0,75 & 2,52 & \\
\hline & 5,8 & 0,250 & 0,207 & 0,85 & 1,96 & \\
\hline & 4,1 & 0,175 & 0,144 & 0,82 & 1,37 & \\
\hline & 4,4 & 0,191 & 0,155 & 0,82 & 1,49 & \\
\hline & 3,0 & 0,130 & 0,107 & 0,82 & 1,02 & \\
\hline & 4,0 & 0,174 & 0,134 & 0,78 & 1,36 & \\
\hline & 3,4 & 0,148 & 0,115 & 0,77 & 1,16 & \\
\hline & 3,8 & 0,163 & 0,124 & 0,77 & 1,28 & \\
\hline
\end{tabular}




\begin{tabular}{cccccc} 
& 3,4 & 0,146 & 0,111 & 0,76 & 1,14 \\
& 4,3 & 0,186 & 0,142 & 0,76 & 1,46 \\
3,6 & 0,154 & 0,118 & 0,77 & 1,21 \\
3,6 & 0,155 & 0,119 & 0,77 & 1,21 \\
3,4 & 0,146 & 0,112 & 0,77 & 1,14 \\
& 4,3 & 0,185 & 0,140 & 0,76 & 1,45 \\
Média \pm DP & $\mathbf{4 , 2} \pm \mathbf{3 , 5 3}$ & $\mathbf{0 , 2 6 5} \pm \mathbf{0 , 1 5}$ & $\mathbf{0 , 2 1 3} \pm \mathbf{0 , 1 3}$ & $\mathbf{0 , 8 0} \pm \mathbf{0 , 0 4}$ & $\mathbf{2 , 0 7} \pm \mathbf{1 , 1 9}$ \\
\hline \hline
\end{tabular}

\begin{tabular}{|c|c|c|c|c|c|c|}
\hline Padrão & $\begin{array}{c}\mathrm{VO}_{2} \\
\mathrm{mlKg} / \mathrm{min}\end{array}$ & $\begin{array}{l}\mathrm{VO}_{2} \\
\mathrm{~L} / \mathrm{min}\end{array}$ & $\begin{array}{l}\mathrm{VCO}_{2} \\
\mathrm{~L} / \mathrm{min}\end{array}$ & QR & $\begin{array}{c}\text { Energia } \\
\text { Consumida } \\
\text { J/Kgs }\end{array}$ & $\begin{array}{c}\text { Gasto } \\
\text { Energético } \\
\text { J/Kgm }\end{array}$ \\
\hline \multirow{20}{*}{ 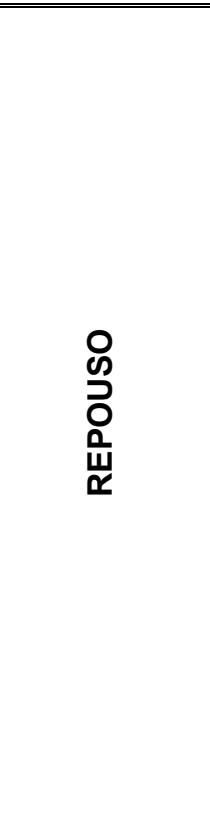 } & $\begin{array}{c}4,45 \\
\end{array}$ & $\overline{00,344}$ & 0 & $\begin{array}{c}0,68 \\
\end{array}$ & 1,5 & \\
\hline & 4,49 & 0,337 & 0,225 & 0,67 & 1,6 & \\
\hline & 3,75 & 0,281 & 0,185 & 0,66 & 1,3 & \\
\hline & 4,16 & 0,312 & 0,209 & 0,67 & 1,4 & \\
\hline & 4,19 & 0,314 & 0,211 & 0,67 & 1,4 & \\
\hline & 4,44 & 0,333 & 0,227 & 0,68 & 1,5 & \\
\hline & 3,87 & 0,290 & 0,201 & 0,69 & 1,3 & \\
\hline & 4,83 & 0,362 & 0,244 & 0,67 & 1,7 & \\
\hline & 4,64 & 0,348 & 0,233 & 0,67 & 1,6 & \\
\hline & 4,28 & 0,321 & 0,215 & 0,67 & 1,5 & \\
\hline & 3,95 & 0,296 & 0,203 & 0,69 & 1,4 & \\
\hline & 4,07 & 0,305 & 0,214 & 0,70 & 1,4 & \\
\hline & 4,92 & 0,369 & 0,250 & 0,68 & 1,7 & \\
\hline & 4,32 & 0,324 & 0,225 & 0,69 & 1,5 & \\
\hline & 4,53 & 0,340 & 0,232 & 0,68 & 1,6 & \\
\hline & 4,23 & 0,317 & 0,220 & 0,69 & 1,5 & \\
\hline & 4,41 & 0,331 & 0,232 & 0,70 & 1,5 & \\
\hline & 5,24 & 0,393 & 0,269 & 0,68 & 1,8 & \\
\hline & 4,83 & 0,362 & 0,253 & 0,70 & 1,7 & \\
\hline & 4,01 & 0,301 & 0,234 & 0,78 & 1,4 & \\
\hline \multirow{4}{*}{ Média \pm DP } & $4,38 \pm 0,38$ & $0,329 \pm 0,03$ & $0,226 \pm 0,02$ & $0,69 \pm 0,02$ & $1,5 \pm 0,13$ & \\
\hline & 11,60 & 0,870 & 0,493 & 0,57 & 4,0 & 10,00 \\
\hline & 8,95 & 0,671 & 0,390 & 0,58 & 3,1 & 7,7 \\
\hline & 8,55 & 0,641 & 0,410 & 0,64 & 3,0 & 7,4 \\
\hline \multirow{9}{*}{ 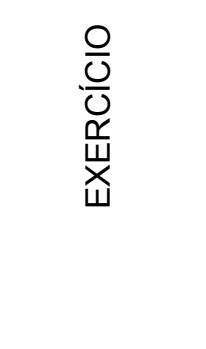 } & 9,49 & 0,712 & 0,447 & 0,63 & 3,3 & 8,2 \\
\hline & 10,28 & 0,771 & 0,408 & 0,53 & 3,6 & 8,9 \\
\hline & 10,51 & 0,788 & 0,412 & 0,52 & 3,6 & 9,1 \\
\hline & 12,51 & 0,938 & 0,526 & 0,56 & 4,3 & 10,8 \\
\hline & 9,88 & 0,741 & 0,406 & 0,55 & 3,4 & 8,5 \\
\hline & 10,40 & 0,780 & 0,473 & 0,51 & 3,6 & 9,0 \\
\hline & 9,91 & 0,743 & 0,427 & 0,57 & 3,4 & 8,6 \\
\hline & 8,72 & 0,654 & 0,378 & 0,58 & 3,0 & 7,5 \\
\hline & 9,03 & 0,677 & 0,397 & 0,59 & 3,1 & 7,8 \\
\hline Média \pm DP & $10,00 \pm 1,18$ & $0,749 \pm 0,09$ & $0,431 \pm 0,05$ & $0,58 \pm 0,03$ & $3,5 \pm 0,41$ & $8,6 \pm 1,02$ \\
\hline \multirow{3}{*}{ 岂岕 } & 14,03 & 1,052 & 0,678 & 0,64 & 4,8 & \\
\hline & 5,09 & 0,382 & 0,258 & 0,68 & 1,8 & \\
\hline & 4,49 & 0,337 & 0,237 & 0,70 & 1,6 & \\
\hline
\end{tabular}




$\begin{array}{lllll}4,93 & 0,370 & 0,249 & 0,67 & 1,7 \\ 4,01 & 0,301 & 0,211 & 0,70 & 1,4 \\ 4,49 & 0,337 & 0,232 & 0,69 & 1,6 \\ 4,52 & 0,339 & 0,239 & 0,71 & 1,6 \\ 4,40 & 0,330 & 0,232 & 0,70 & 1,5 \\ 4,71 & 0,353 & 0,257 & 0,73 & 1,6 \\ 4,36 & 0,327 & 0,234 & 0,72 & 1,5 \\ 5,08 & 0381 & 0,277 & 0,73 & 1,8 \\ 4,64 & 0348 & 0,262 & 0,75 & 1,6 \\ 3,99 & 0,299 & 0,208 & 0,70 & 1,4 \\ 4,11 & 0,308 & 0,207 & 0,67 & 1,4 \\ 3,93 & 0,295 & 0,205 & 0,69 & 1,4 \\ 4,79 & 0,359 & 0,249 & 0,69 & 1,7 \\ 4,63 & 0,347 & 0,237 & 0,68 & 1,6 \\ 3,99 & 0,299 & 0,206 & 0,69 & 1,4 \\ 4,76 & 0,357 & 0,255 & 0,71 & 1,6 \\ 4,03 & 0,302 & 0,217 & 0,72 & 1,4\end{array}$

$\begin{array}{llllll}\text { Média } \pm \text { DP } & 4,9 \pm 2,17 & 0,371 \pm 0,16 & 0,258 \pm 0,10 & 0,70 \pm 0,02 & 1,7 \pm 0,75\end{array}$ 
Apêndice 2 - Tabela do Quociente Respiratório

\begin{tabular}{|c|c|c|}
\hline \multirow[b]{2}{*}{ QUOCIENTE RESPIRATÓRIO } & \multicolumn{2}{|c|}{ NUTRIENTES } \\
\hline & LIPÍDIOS (\%) & CARBOIDRATO (\%) \\
\hline 0.70 & 100.0 & 0.0 \\
\hline 0.71 & 69.7 & 3.3 \\
\hline 0.72 & 93.3 & 6.7 \\
\hline 0.73 & 90.0 & 10.0 \\
\hline 0.74 & 86.7 & 13.3 \\
\hline 0.75 & 83.3 & 26.7 \\
\hline 0.76 & 80.0 & 20.0 \\
\hline 0.77 & 76.7 & 23.3 \\
\hline 0.78 & 73.3 & 26.7 \\
\hline 0.79 & 70.0 & 30.0 \\
\hline 0.80 & 66.7 & 33.3 \\
\hline 0.81 & 63.3 & 36.7 \\
\hline 0.82 & 60.0 & 40.0 \\
\hline 0.83 & 56.7 & 43.3 \\
\hline 0.84 & 53.3 & 46.7 \\
\hline 0.85 & 50.0 & 50.0 \\
\hline 0.86 & 46.7 & 53.3 \\
\hline 0.87 & 43.3 & 56.7 \\
\hline 0.88 & 40.0 & 60.0 \\
\hline 0.89 & 36.7 & 63.3 \\
\hline 0.90 & 33.3 & 66.7 \\
\hline 0.91 & 30.0 & 70.0 \\
\hline 0.92 & 26.7 & 73.3 \\
\hline 0.93 & 23.3 & 76.7 \\
\hline 0.94 & 20.0 & 80.0 \\
\hline 0.95 & 16.7 & 83.3 \\
\hline 0.96 & 13.3 & 86.7 \\
\hline 0.97 & 10.0 & 90.0 \\
\hline 0.98 & 6.7 & 93.3 \\
\hline 0.99 & 3.3 & 96.7 \\
\hline 1.00 & 0.0 & 100.0 \\
\hline
\end{tabular}


Apêndice 3 - Esquema Resumido da Incorporação do Ácido Pirúvico no Ciclo de Krebs

ANAEROBIOSE

Fluidos Celulares

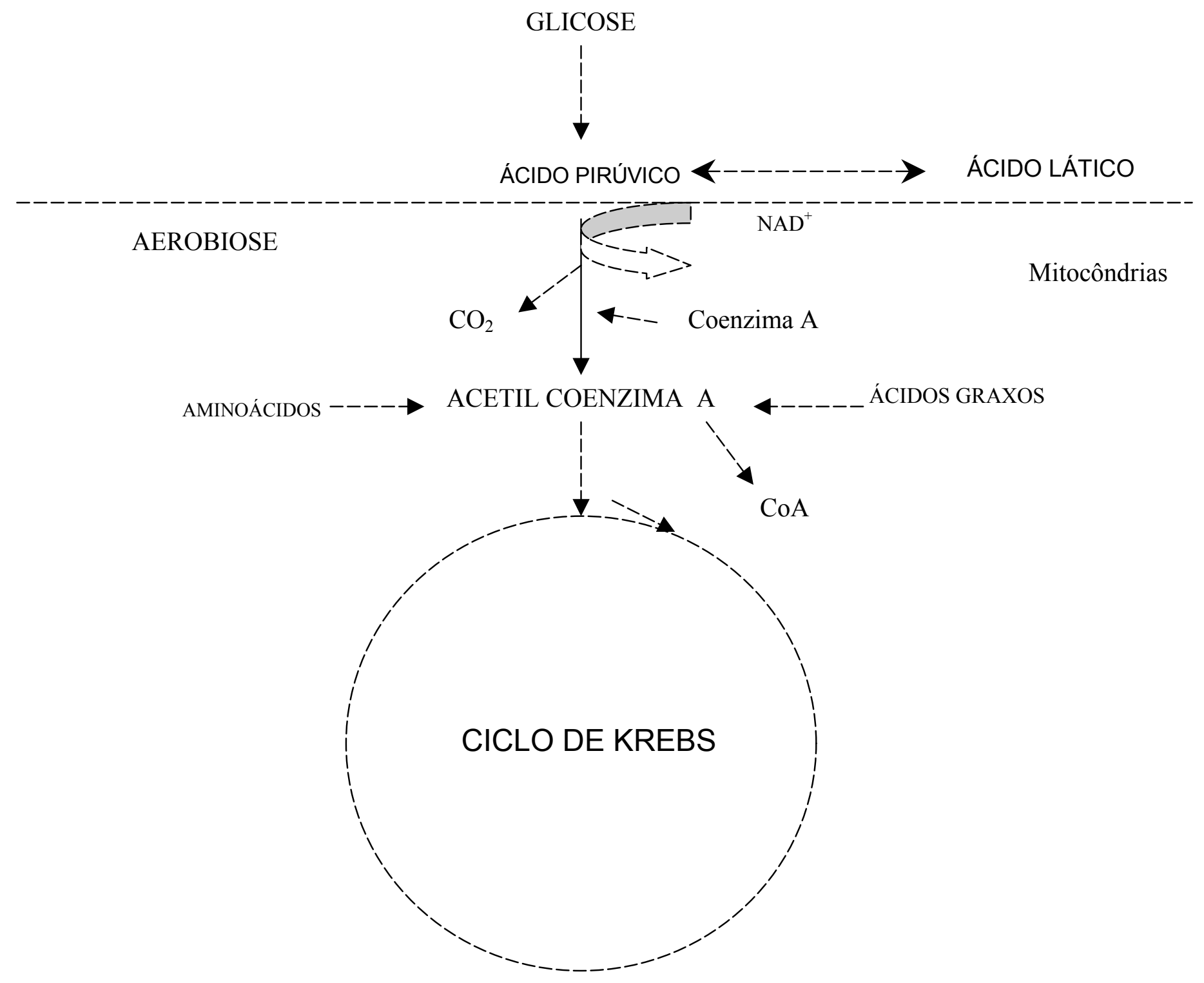

